WHC-EP- 0188

DE9 1001286

\title{
Corrosion Behavior of Copper-Base Materials in a Gamma-Irradiated Environment Final Report
}

\author{
W. H. Yunker \\ Date Published \\ September 1990
}

Prepared for the U.S. Department of Energy Office of Civilian Radioactive Waste Management

\section{(2) Mestinghouse Hantord Company Richland, Washington 99352}

Hanford Operations and Engineering Contractor for the U.S. Department of Energy under Contract DE-AC06-87RL10930

Proparad by Yucca Mountain Project (YMP) participants as part of the Civilian Radioactivo Wasto Managornent Program. The Yucca Mountain Project is managed by the Waste Management Projed OHlice of the U.S. Departmont of Energy, Novade Operations Offica. Yucca Mountain Propect work is sponsored by the DOE Office of Civilien Radionctivo Wasto Management. 


\section{ACKNOWLEDGEMENTS}

The assistance of Westinghouse Hanford Company Senior Technician D. Paine is gratefully acknowledged. Mr. Paine made major contributions in all phases of the work, from equipment construction to operation of the experiments to record keeping and data reduction. Design and construction of the corrosion cells was by D. L. Greenslade, also of Westinghouse Hanford Company. Program support and direction was by R. S. Glass and R. D. MCCright of Lawrence Liver. more National Laboratory. 


\title{
CORROSION BEHAVIOR OF COPPER-BASE MATERIALS
}

\section{IN A GAMMA-IRRADIATED ENVIRONMENT: FINAL REPORT}

\author{
Wayne H. Yunker
}

\begin{abstract}
Specimens of three copper-base materials were corrosion tested with gamma radiation exposure dose rates in the range of $1.9 \times 10^{3} \mathrm{k} / \mathrm{h}$ to $4.9 \times 10^{5} \mathrm{R} / \mathrm{h}$. Materials used were pure copper, $7 \%$ aluminum bronze and 30\% copper-nicke7. Exposures were performed in moist air at $95{ }^{\circ} \mathrm{C}$ and $150{ }^{\circ} \mathrm{C}$ and liquid Well $\mathrm{J}-13$ water at $95{ }^{\circ} \mathrm{C}$, for periods of up to 16 mo. Specimens were monitored for uniform weight loss, stress-induced corrosion and crevice corrosion. Specimen surfaces were examined visually at 10X magnification as well as by Auger Electron Spectroscopy, x-ray diffraction and metallography. Corrosion was not severe in any of the cases. In general, the pure copper was corroded most uniformly while the copper-nickel was the least reproducibly corroded.
\end{abstract}




\section{CONTENTS}

\subsection{SUMMARY}

page

2.0 INTRODUCTION

3.0 EXPERIMENTAL

3.1 ENVIRONMENT

3.2 CORROSION CELLS

3.2.1 Specimens

3.2.2 Support Cages

3.2.3 Vessels

3.3 SUPPORT EQUIPMENT

3.3.1 Gas System

3.3.2 Heaters and Controllers

18

3. 3.3

Data Systems

\subsection{PROCEDURES AND TECHNIQUES}

\subsubsection{Specimens}

3.5 QUALITY ASSURANCE

4.0 RESULTS

4.1 DATA BASE

4.2 VESSEL ENVIRONMENT

4.2.1 Air-Water Vapor at $150{ }^{\circ} \mathrm{C}$

4.2.2 Air-Water Vapor At $95{ }^{\circ} \mathrm{C}$

4.2 .3

Liquid Water at $95^{\circ} \mathrm{C}$

4.3 METAL SPECIMENS

4.3.1 Stress-Assisted Cracking

4.3.2 Crevice Corrosion

Prepitted Specimens

Interface Specimens

4.3.5 Metallographic Examinations

4.3.7 General Corrosion (Weight Loss) 


\section{CONTENTS (Cont'd)}

4.4 OXIDE LAYERS

Page

4.4.1 Visual

4.4.2 Metal-0xygen Ratios

4.4.3 X-ray Diffraction

4.4.4 Auger Electron Spectroscopy

5.0

DISCUSSION

5.1 GENERAL OBSERVATIONS

$5.2 \operatorname{CDA} 101 / 102$

73

5.3 CDA $613 / 614$

73

$5.4 \operatorname{CDA} 715$

74

6.0 REFERENCES

75

APPENDIX A

APPENDIX B 


\section{FIGURES}

Figure

$\underline{\text { Page }}$

1 Cobalt 60 Gamma Irradiation Facility in the 3730 Building at Westinghouse Hanford Company

2 Gamma Radiation Flux vs. Distance From the Bottom of the Irradiation Tubes

6 Three Specimen Cages Stacked as in a Corrosion Vessel

7 Schematic of Corrosion Vessel

8 Two Corrosion Vessels with the Stainless Steel

Guard Vessel Removed

$9 \quad$ Experiment Support Equipment

10 Schematic of Two Gas Manifold Systems

11 Gas Pressure Variation in Vessel T-1 $\left(95^{\circ} \mathrm{C}\right)$

During the Last 3-3/4 Months of the 7-Month Experiment

12 Surface Roughness After Electrochemical Prepitting of a CDA 102 Tear Drop Specimen and No Subsequent

Corrosion Exposure (400X)

13 Surface Pitting on Electrochemically Prepitted CDA 102 Tear Drop Specimen After 6-Month Exposure at $95{ }^{\circ} \mathrm{C}$ in the Liquid Water (J-13) Phase (400X)

14 Surface Pitting After Electrochemical Prepitting of a CDA 613 Tear Drop Specimen and No Subsequent Corrosion Exposure (400X)

15 Surface Pitting on Electrochemically Prepitted CDA 613 Tear Drop Specimen After 6-Month Exposure at $95{ }^{\circ} \mathrm{C}$ in the Liquid Water $(\mathrm{J}-13)$ Phase (400X) 


\section{FIGURES (Cont'd)}

Figure

Page

16 Surface Pitting After Electrochemical Prepitting of CDA 715 Tear Drop Specimens and Without Subsequent Corrosion Exposure (400X)

Surface Corrosion of Electrochemically Prepitted CDA 715 Tear Drop Specimen After 6-Month Exposure at $95{ }^{\circ} \mathrm{C}$ in the Gas Phase (50X)

18 Surface Pitting of Electrochemically Prepitted CDA 715

Tear Drop Specimen After 6-Month Exposure at $95{ }^{\circ} \mathrm{C}$ in the Gas Phase (400X)

Surface Roughening on Specimen 1 W032 Exposed for 9 Months in the Liquid-Gas Interface at $95^{\circ} \mathrm{C}$

The Front Surface of CDA 715 Specimen 3 WOOB at the

Liquid-Gas Interface Position (5x)

48

Section of Local Corrosion on Specimen 3W031 After 9-Month Exposure in the Liquid-Gas Interface at $95{ }^{\circ} \mathrm{C}(400 \mathrm{X})$

General Surface Roughening on Copper Specimen $11: 002$

Pits in Copper Specimen 1 W046 From 4-Month Exposure in the Gas Phase at $95{ }^{\circ} \mathrm{C}(400 \mathrm{X})$

Corrosion Surface of CDA 613 Specimen 2W013 From 13-Month

Gas Phase Exposure at $95{ }^{\circ} \mathrm{C}(50 \mathrm{X})$

Adherent Corrosion Product on CDA 613 Specimen 2 W032

After 7 -Month Exposure in Liquid Water at $95^{\circ} \mathrm{C}$ (200X)

Pit Formed on CDA 715 Specimen 3B001 During 13-month

Exposure in the Gas Phase at $95{ }^{\circ} \mathrm{C}$

Broad Pit and Surface Roughening of Specimen 3 W047

After 9-month Exposure in Liquid Water at $95{ }^{\circ} \mathrm{C}$ (200X)

Broad Surface Deformations Seen on Most Specimens With and Without Corrosion Exposures (200X)

29 Surface Crack Associated with Compression Deformation of Specimen That Occurred Prior to Corrosion

Experiments (400X) 


\section{FIGURES (Cont'd)}

\section{Fiqure}

Page

30 CDA $101 / 102$ Corrosion at $150{ }^{\circ} \mathrm{C}$ in the Gas Phase

31 CDA $101 / 102$ Corrosion at $95{ }^{\circ} \mathrm{C}$ in the Gas Phase

32 CDA $101 / 102$ Corrosion at $95{ }^{\circ} \mathrm{C}$ in the Liquid Phase

33 CDA $613 / 614$ Corrosion at $150^{\circ} \mathrm{C}$ in the Gas Phase

34 CDA 613/614 Corrosion at $95{ }^{\circ} \mathrm{C}$ in the Gas Phase

35 CDA $613 / 614$ Corrosion at $95{ }^{\circ} \mathrm{C}$ in the Liquid Phase

60

36 CDA 715 Corrosion at $150^{\circ} \mathrm{C}$ in the Gas Phase

37 CDA 715 Corrosion at $95{ }^{\circ} \mathrm{C}$ in the Gas Phase

38 CDA 715 Corrosion at $95^{\circ} \mathrm{C}$ in the Liquid Phase

39 Concentration (atom per-cent) Profile of the 0xide Layer on a CDA 613 Specimen After One Month in the Gas Phase at $150{ }^{\circ} \mathrm{C}$

40 Concentration (atom per-cent) Profile of the 0xide Layer on a CDA 715 Specimen After One Month in the Gas Phase at $95{ }^{\circ} \mathrm{C}$ 


\section{TABLES}

Table

Page

1 Well J-13 Water Composition 4

2 Nominal Composition of Corrosion Specimens 10

3 Composit:on of Synthetic Well J-13 Type Water 26

4 Ranges of Measured Corrosion and Pitting Potentials Used by LLNL for Preparation of Prepitted Specimens 27

$5 \quad$ Numbers of Exposed Specimens 32

6 Gas Composition in Vessel T-2 at $150^{\circ} \mathrm{C} \quad 33$

7 Gas Composition in Vessels During Corrosion Experiments 35

$8 \quad$ Water Compositions at $95^{\circ} \mathrm{C} \quad 36$

9 Crevice Specimen Corrosion: CDA 101/102 38

10 Crevice Specimen Corrosion: CDA 613/614 39

11 Crevice Specimen Corrosion: CDA 715

12 Percentage of Visually Observed Corrosion Features 56

13 Summary of Metal-oxygen Ratios in Corrosion Layers 64

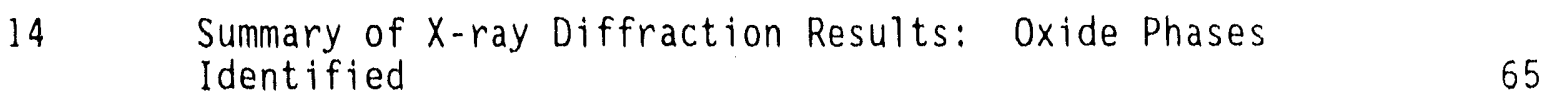

15 Summary of Corrosion Behaviors 71 


\section{CORROSION BEHAVIOR OF COPPER-BASE MATERIALS}

IN A GAMMA-IRRADIATED ENVIRONMENT: FINAL REPORT

\section{$1.0 \quad$ SUMMARY}

Over 400 spectimens, made from three copper-base materials, were exposed to three corrosion environments in a gamma radiation field. The envirorments approximated those expected during the early, mid, and late periods of storage of nuclear waste in the tuff formation inside of Yucca Mountain near the Nevada Test site (NTS). The work was performed in support of the Nevada Nuclear Waste Storage Investigations (NNWSI) Project under the direction of the Lawrence Livermore National Laboratory ( $L L N L)$. The three materials used were pure copper, 7 wt\% aluminum copper alloy, and 30 wt\% copper-nickel alloy. The object of the tests was to observe the corrosion behaviors of these materials under a variety of conditions and specimen configurations and in a radiation field that was at least 10 times stronger than expected under storage conditions in order to enhance any radiation effects. Specimen types used were weight loss, crevice, tear drop, and electrochemically prepitted. Environments consisted of moist air at $150{ }^{\circ} \mathrm{C}$, air that was nearly saturated with water vapor at $95{ }^{\circ} \mathrm{C}$, 1 iquid Well $\mathrm{J}-13$ water at $95{ }^{\circ} \mathrm{C}$, and the 1iquid-gas interface at $95^{\circ} \mathrm{C}$. A data base was created that specifies all conditions and observations for each specimen. Analyses were also made of the yas and liquid phase compositions. Exposure times rarged from 1 mo to 16 mo and gamma exposure dose rates from $1.9 \times 10^{3} \mathrm{R} / \mathrm{h}$ to $4.9 \times 10^{5} \mathrm{R} / \mathrm{h}$.

Corrosion damage was relatively mild during these time intervals. No evidence of stress-induced corrosion was found. Underfilm corrosion features were seen with the aluminum bronze and the copper-nickel alloy. The defects in the electrochemically prepitted specimens tended to disappear with general corrosion, rather than grow. In general, the most severe corrosion occurred on specimens in the gas phase at $95^{\circ} \mathrm{C}$ t'lat was very nearly saturated with water vapor. Metallographic examination showed some pit.ing of the aluminum bronze and the co:oer-nickel alloy. Surface examination of the pure copper specimens 
showed isolated pitting only. General corrosion rates varied from 0.01 $\mathrm{mil} / \mathrm{yr}$ to $0.15 \mathrm{mtl} / \mathrm{yr}$ at $10,000 \mathrm{~h}$ exposure. Both 1 inear and parabolic corrosion rates were seen. $X$-ray diffraction of the oxide formed on pure copper showed both $\mathrm{CuO}$ and $\mathrm{Cu}_{2} \mathrm{O}$. The compound $\left(\mathrm{Cu}_{0.2} \mathrm{Ni}_{0.8}\right) \mathrm{O}$ was identiffed on one nickel alloy specimen. Auger electron spectroscopy of several very thin corrosion films showed oxide with layers having different compositions. There was no excessive corrosion at the gas-liquid interface. However, where isolated drops of water may have formed during part of a test, more severe local corrosion appeared. The corroston of the copper-nicke? alloy was the most severe in appearance and the least reproducible. 
The U.S. Department of Energy (DOE) is evaluating the feastbility of using copper-base materials in the construction of containers for high-level radioactive waste for permanent, geologic disposal. The disposal site being considered is at Yucca Mountain, adjacent to the NTS. For this evaluation, the corrosion behaviors of several candidate materials need to be determined in chemical, physical, and radiological environments similar to those in the proposed repository site. The experiments described here were conducted during fiscal years (FY) 1985 and 1986 at Westinghouse Hanford Company (Westinghouse Hanford) located in Richland, Washington. They are part of the NNWS I Project under the direction of LLNL.

The primary objective of this work is to measure the corrosion rates and behaviors of selected copper-base materials in ganma radiation fieldi under conditions that are similar to those expected in the proposed repository. These experiments were designed to produce as much quantitative and qualitative corrosion data as possible, in a short time. Resources were focused on exploratory experiments that produced severe corrosion rather than on tests that used large numbers of specimens (for statistical purposes) or on parallel experiments without gamma radiation.

The environmental conditions expected for nuclear waste containers buried in the proposed repository have been described. (1) Briefly, the site is in a layer of tuff rock (a welded, devitrified volcanic as!) permeated by air, water vapor, and some condensed water. The reference horizon at the proposed site is about $200 \mathrm{~m}$ above the static water table. Water used for these experiments is from We11 J-13 near Yucca Mountain on the NTS. The composition of this water is presented in Tab7e 1. The radiation doses expected initially at the burial container surfaces range from about $5 \times 10^{3} \mathrm{rd} / \mathrm{h}$ for defense high-level waste to about $2 \times 10^{4} \mathrm{rd} / \mathrm{h}$ for commercial spent fuel. For the early years of burial, the temperatures at the surfaces of mariy of the packages are expected to exceed the boiling point of water $\left(95^{\circ} \mathrm{C}\right)$ at the 


\section{TABLE 1}

WELL J-13 WATER COMPOSITION*

Impurity

\section{Silicon}

Sodium

Calcium

Potassium

Magnesium

Lithium

Strontium

Iron

Aluminum

Bicarbonate

Sulfate

Chloride

Nitrate

Fluoride
Concentration (mg/1)

27.0

43.9

12.5

5.1

1.9

0.042

0.035

0.006

0.012

125.0

18.7

6.9

9.6

2.2

\footnotetext{
* Reference groundwater composition for tuff repositories (based on composition of Jackass Flats Well J-13 at the Nevada Test Site). The $\mathrm{pH}$ is slightly alkaline $(7.6)$.

Source: J. Delaney, "Reaction of Topopah Spring Tuff with J-13 Water: A Geochemical Modeling Approach Using the EQ3/6 Reaction Path Code," UCRL-53631, Lawrence Livermore National Laboratory, Livermore, California, March 1985.
} 
elevation of the reference horizon. The radiation field and temperature will decrease with time. When the temperature of the waste package reaches $95{ }^{\circ} \mathrm{C}$, the radiation dose rates in many of the packages will have decreased to about $2 \times 10^{2} \mathrm{rd} / \mathrm{h}$.

The interaction of gamma radiation with aqueous environments produces a host of transient radicals, ions, and stab?e molecular species. These have been thoroughly described in Reference 2. Radiolysis of air-saturated We11 J-13 water is expected to result in an oxidizing environment with $\mathrm{O}_{2}$ (from air) and $\mathrm{H}_{2} \mathrm{O}_{2}$ as the dominant species. Much smaller concentrations of $\mathrm{O}_{2}{ }^{-}, \mathrm{HO}_{2}, \cdot \mathrm{OH}$, $\mathrm{H}_{2}, \mathrm{H} \cdot$, and $\mathrm{e}_{\mathrm{aq}}$ - are also generated. In the moist air phase, nitric acid and various oxides of nitrogen are formed and can dissolve in any liquid vater phase that is present. These radiation-induced changes in the chemical environment can be expected to alter the normal rates or mecharisms of corrosion.

Early results and a description of this work have been published. $(3,4)$ Most of that information has been repeated here to provide a more complete view of the program results. The few details not repeated are referenced: in the text. Some of the preliminary interpretations previously offered have been revised in the light of this more complate data set. 
For these experiments, gamma radiation fields in the range of $1.9 \times 10^{3}$ to $4.9 \times 10^{5} \mathrm{R} / \mathrm{h}$ were used. This was supplied by a ${ }^{60} \mathrm{Co}$ gamma radiation source (Figure 1). The flux calibration values are shown in Figure 2 . These values had been obtained using an ion chamber and thermoluminescent dosimeters and are traceable to a National Bureau of Standards (NBS) certified source. No additional calibrations were made for these tests. The corrosion specimens were located in the lowest $30 \mathrm{in.} \mathrm{of} \mathrm{each} \mathrm{tube.} \mathrm{The} \mathrm{other} \mathrm{environmental}$ conditions used were: 1) an air-water vapor mixture at $150{ }^{\circ} \mathrm{C}$; 2) a watervapor-saturated air phase at $95^{\circ} \mathrm{C}$, and 3) liquid We $11 \mathrm{~J}-13$ water at $95{ }^{\circ} \mathrm{C}$. The two gas phases had similar dew points. Condition 1 represents early life repository conditions and conditions 2 and 3 represent the conditions after several hundred years.

\subsection{CORROSION CELLS}

\subsubsection{Specimens}

The compositions of the three materials selected for study are shown in Table 2. Over 400 weight loss, crevice, and tear drop (stressed) specimens were exposed for periods of from 1 mo to $16 \mathrm{mo}$. The specimen configurations are shown in Figure 3 . The mating surfaces of the crevice specimens were polished with 600 -grit abrasive to within $\pm 0.05 \mathrm{~mm}(0.002 \mathrm{in}$.) of flatness. The tear drop specimens were prepared by the single stressing method $(5)$ and fusion-welded with a tungsten inert gas (TIG) electrode.

\subsubsection{Support Cages}

All specimens were mounted on high-purity aluminum-oxide spacers in specimen support cages as shown in Figures 4, 5, and 6 . The cages were $127 \mathrm{~mm}(5 \mathrm{in}$.) high and just fit into the $95-\mathrm{mm}(33 / 4-\mathrm{in}$.$) diameter space of a containment$ 


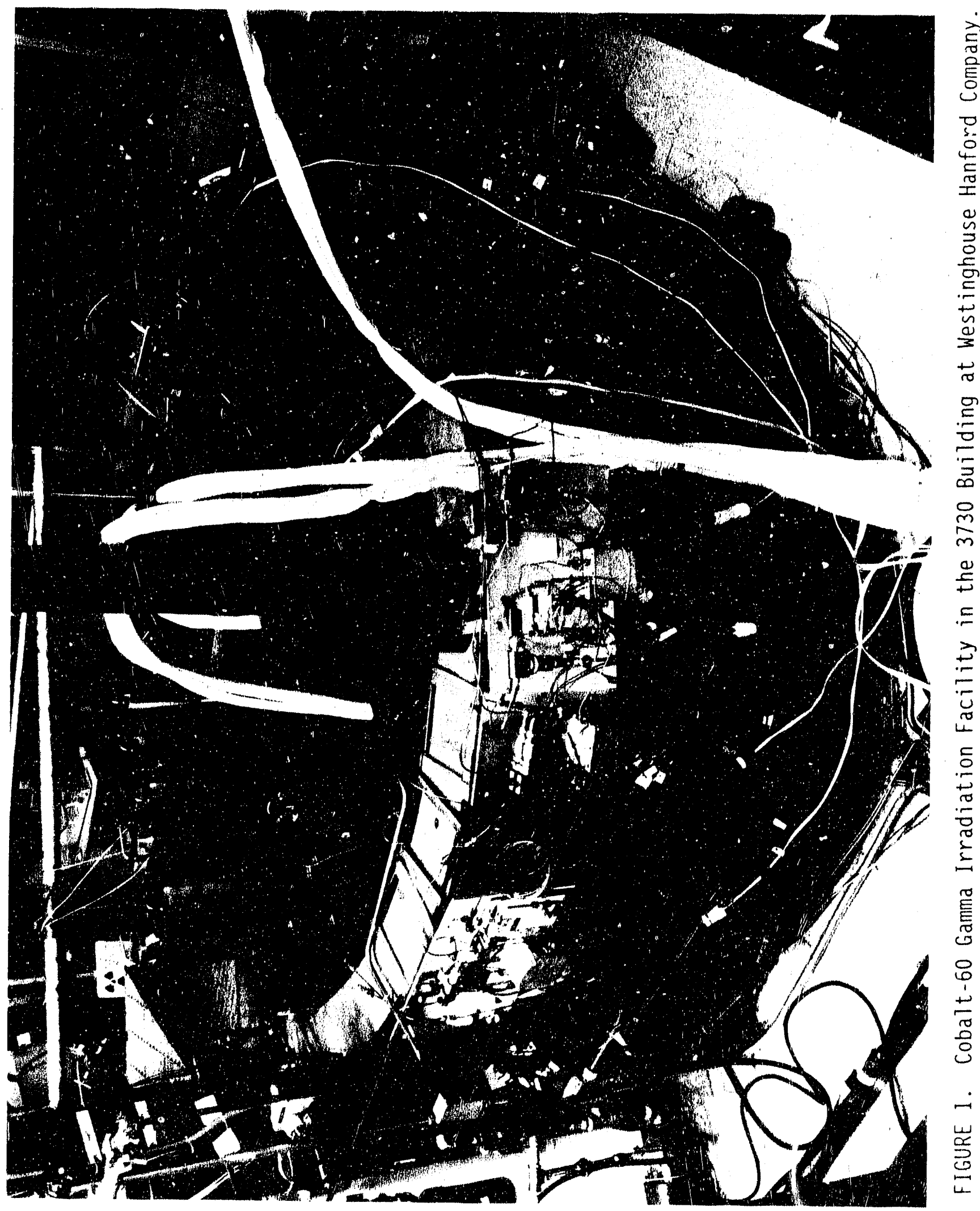




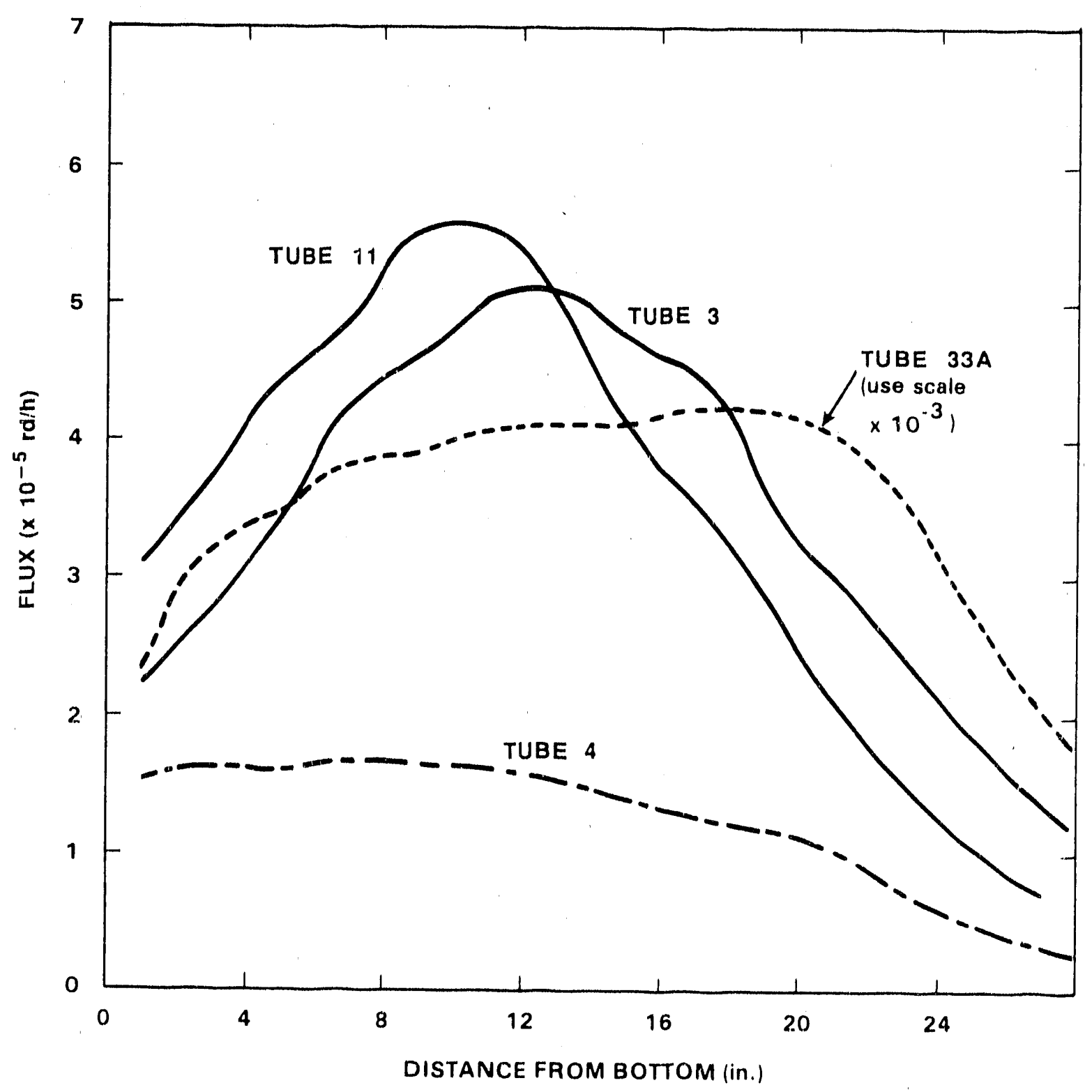

$38806 \cdot 136.1$

FIGURE 2. Gamma Irradiation Flux versus Distance from the Bottom of the Irradiation Tubes. 
TABLE 2

NOMINAL COMPOSITION OF CORROSION SPECIMENS

Element

A Tuminum

Cadinium

Carbon

Cobalt

Copper

Iron

Lead

Manganese

Mercury

Nickel

Phosphorus

Sulfur

Tin

Zinc

\begin{tabular}{l} 
Alloy Composition (wt\%) \\
\hline CDA* $101 / 102^{\text {CDA 613/614 }}$ CDA 715
\end{tabular}

6.75

$0.001 \max$

0.01

90.82

69.18

2.46

0.53

$0.001 \max$

0.01

0.01

0.16

0.51

$0.0001 \max$

0.05

29.6

$0.0003 \max$

$0.0018 \max$

0.002

0.01

$0.2 * * \star$

0.01

0.07

*Copper Development Association (CDA) identification number. $\star \star$ Equals 99.95 for CDA 102.

$\star \star \star$ Only in CDA 613 . 
WHC-EP-0188
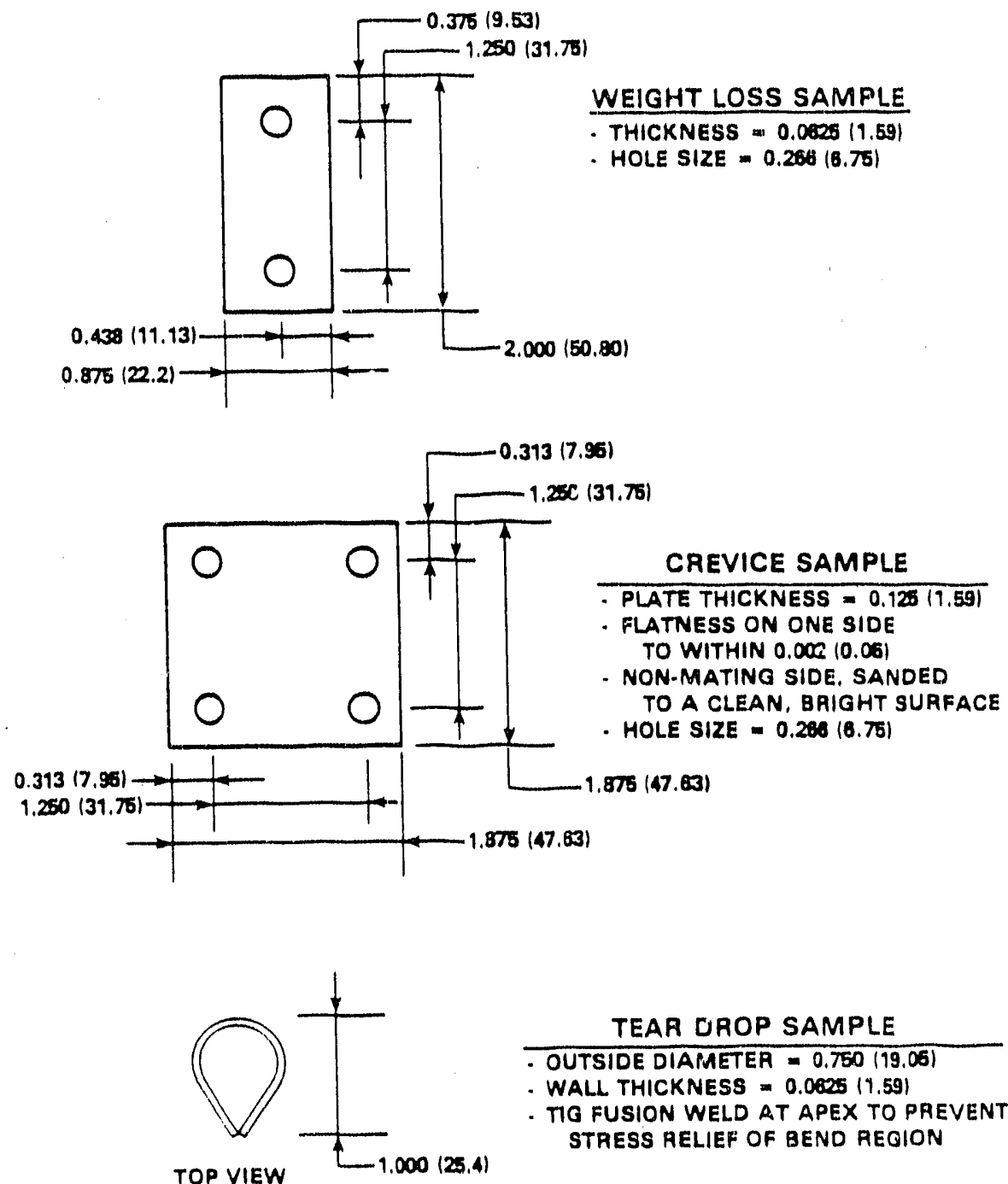

TEAR DROP SAMPLE

- OUTSIDE DIAMETEA $=0.750(19.06)$

- WALL THICKNESS $=0.0025(14.59)$

- TIG FUSION WELD AT APEX TO PAEVENT STRESS RELIEF OF BEND REQION

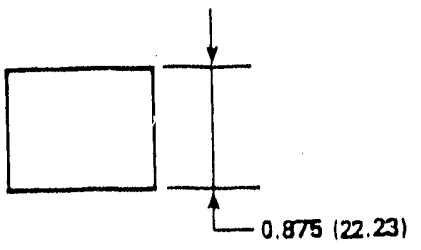

SIDE VIEW

HEDL 17006

FIGURE 3, Sketches of the Weight Loss, Crevice, and Tear Drop Corrosion Specimens. 
WHC-EP-0188

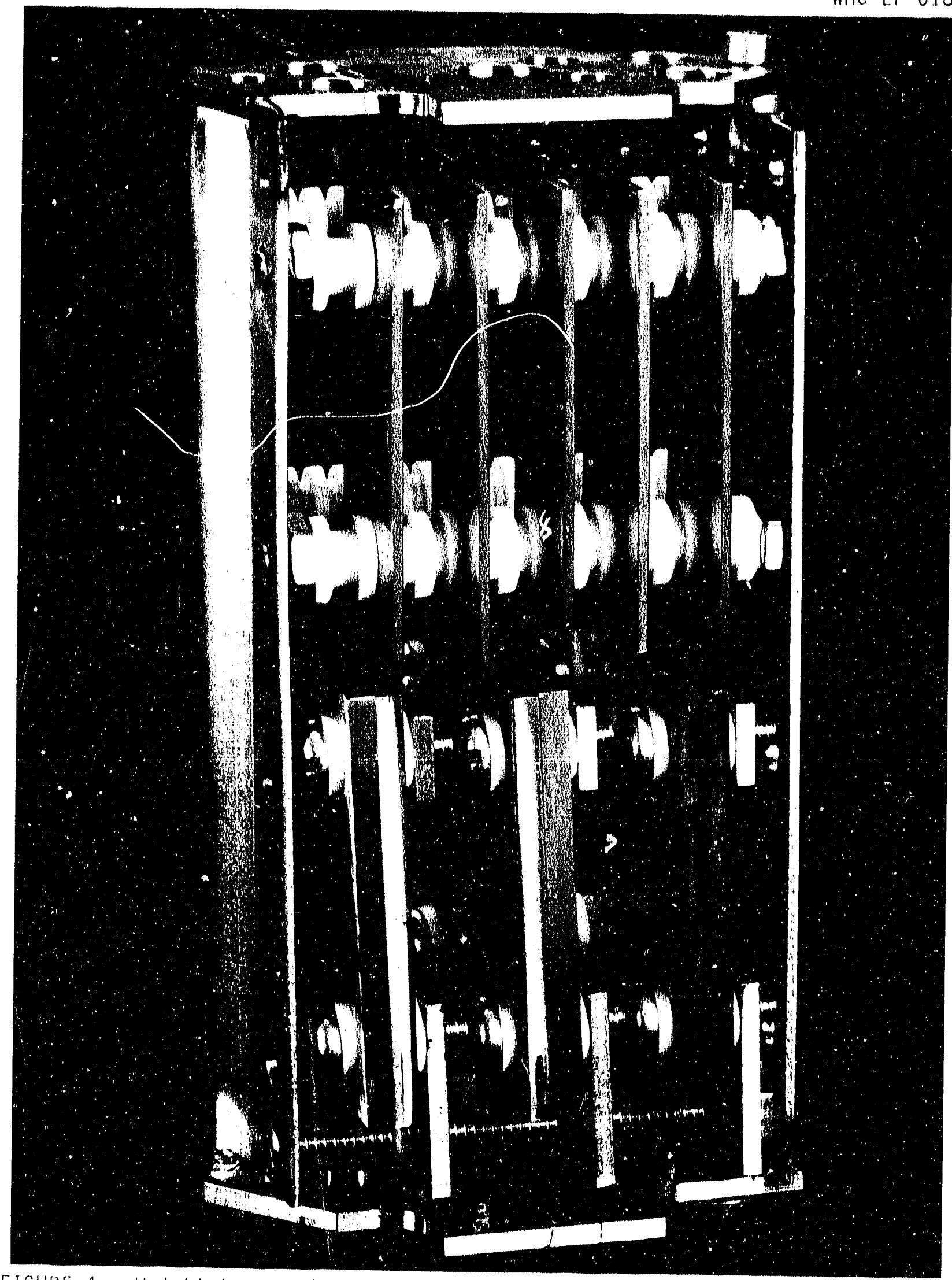

FIGURE 4. Weight Loss and Crevice Specimens Assembled in a Support Cage. (Spacers are made of high-purity a? uminum oxide.) 


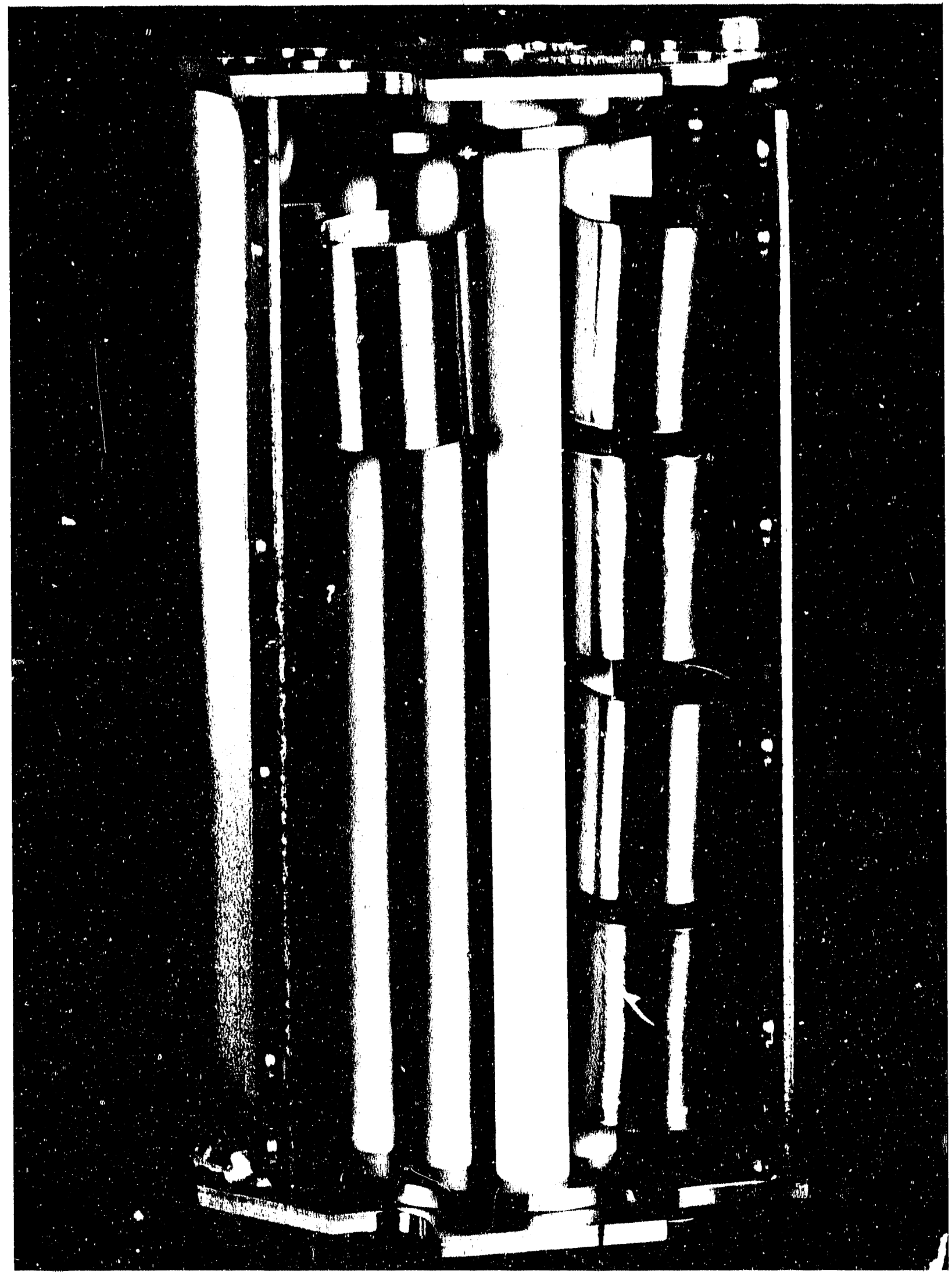

FIGURE 5. Tear Drop Specimens Mounted in a Support Cage. (Spacers are made of high-purity aluminum oxide.) 
vessel (see below). All metal parts were made of the same alloy as the enclosure vessel. The six cages stacked into a vessel could be placed th any vertical order to provide flexibility in the exposures given to the specimens. The cages had a standard design and colid hold any of the three types of specimens. The cage capactties were: 16 tear drop specimens, 6 crevice spectmens, 50 wetght loss specimens, or 3 srevice with 28 weight loss spectillens.

As the cages were lowered into a vessel, a keytng arrangement aligned and held each cage in posttion in the vessel to ensure that the specimens were not in contact with the thermowell tube and gas ventilation tube. Because the operation of transferring a vesse 1 into and out of the gamma irradiation tubes requitred considerable handling and movement of the vessel, all specimens vere physically restrained in their mountings to prevent any metal-to-metal contact.

\section{$3.2 .3 \quad$ Vessels}

Environmental control for the corrosion specimens was maintained in the sealed pressure vessels that were lowered into the exposure tubes of the cobalt-60 Camma Irradiation Facility. (6) Permanent mounting of the stainless steel exposure tubes ensured that the flux calibrations were reproducible. The stainless steel tubes contained air at about $24^{\circ} \mathrm{C}$.

A schematic of the vessels is shown in Figure 7 and a photograph is shown in Figure 8. Metals used were titaniun and Mone ${ }^{*}$ 400. The titanium vessels were fabricated with full-penetration electron beam and TIG welds to eliminate internal crevices. The outer protective containers for the vessels and their electrical heaters were made of 304 stainless steel. The two $3.2 \mathrm{~mm}\left(1 / 8-\mathrm{in.}_{\text {.) }}\right.$ outside diameter gas lines, made of Incone ${ }^{* *} 600$, connected the vessels to

*Mone is a trademark of Huntington Nlloy Products, Inc., International Nickel Company, Inc.

** Inconel is a trademark of Huntington Alloy Products, Inc., International Nickel Company, Inc. 


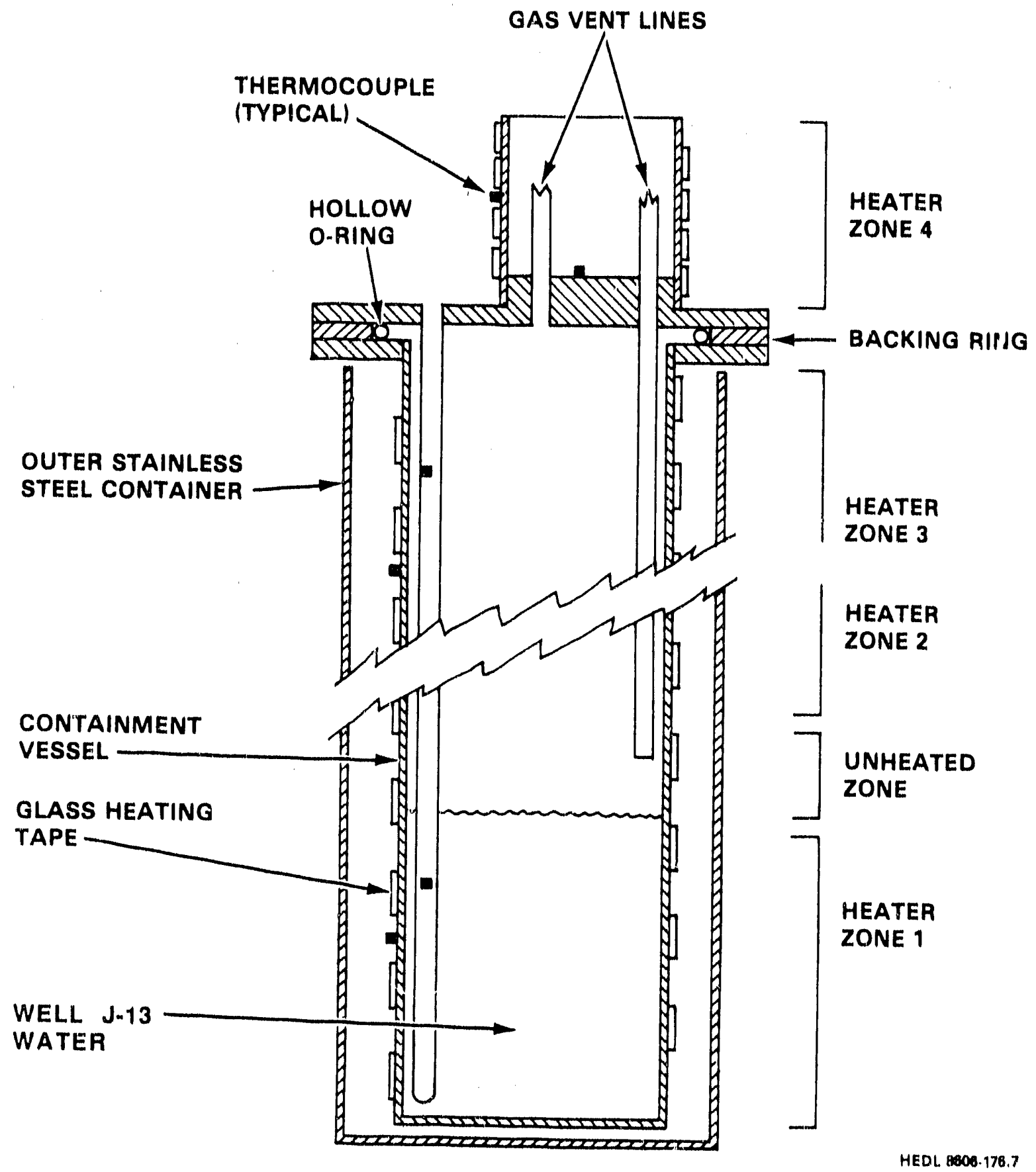

FIGURE 7. Schematic of a Corrosion Vessel. 


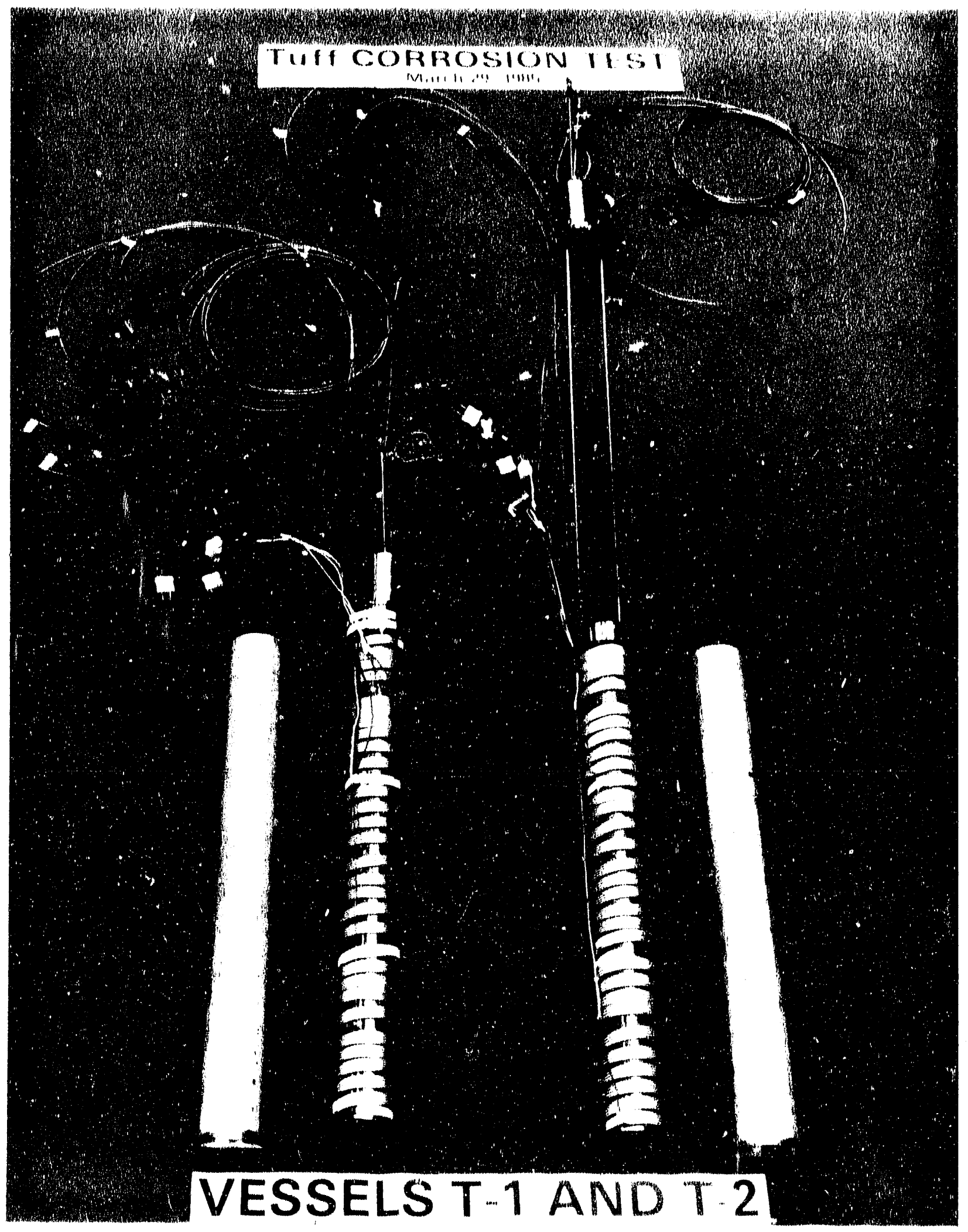

FICiURE 8. Two Corrosion vessels with the Stainless steel cuard Vessel Removed. (The lid of the right-hand vessel is also removed.) 
the pneumatic control panels on the operating floor of the laboratory. The vessels were sealed by hollow metal 0 rings made of 321 stainless steel and plated with a $0.05-\mathrm{mm}(2-\mathrm{m}+1)$ thick layer of nickel.

To prevent refluxing of water on the underside of the vessel lid anci in the gas line connections just above the ifd, heat was supplied to the top of the vessel by a glass-insulated heating tape wrapped around a brass cylinder. The 127-mm (5-in.) high cylinder formed a heated enclosure for the gas line connections and conducted heat to the vessel 11d. A thermocouple mounted on the upper surface of the lid was used to determtne the set point for the heater controller.

For vessels containing a liquid water phase, particular care was needed to prevent condensation of liquid on the surfaces of specimens that were mounter in the gas phase of the vessel. Such condensation can have a marked effect on the observed corrosion behavior. The tall, narrow gas chamber in these vessels normally promotes the formation of a vertical temperature gradient and stagnation of the gas in this space. The design and operation techniques used in the experiment to prevent this were: 1) a $64-\mathrm{mm}$ (2-1/2 in.) gap between the top of the water, the water heater zone, and the lowest specimens in the gas space, the lower end of the gas phase heaier, and 2) an independent, twozone heating of the gas space. By careful adjustment of the three heater controllers, thermal convection was created in the gas space to mix the gas, maintain a more nearly uniform temperature distribution, and maintain a gas temperature slightly greater $\left(3^{\circ} \mathrm{C}\right.$-estimated) than the dew point.

\section{$3.3 \quad$ SUPPORT EQUIPMENT}

The experiment support equipment was mounted on three racks as shown in Figure 9.

\subsubsection{Gas System}

Gas circulation from the pneunatic control panel and through a vessel was ensured since one gas vent was on the vessel lid and the other was located 


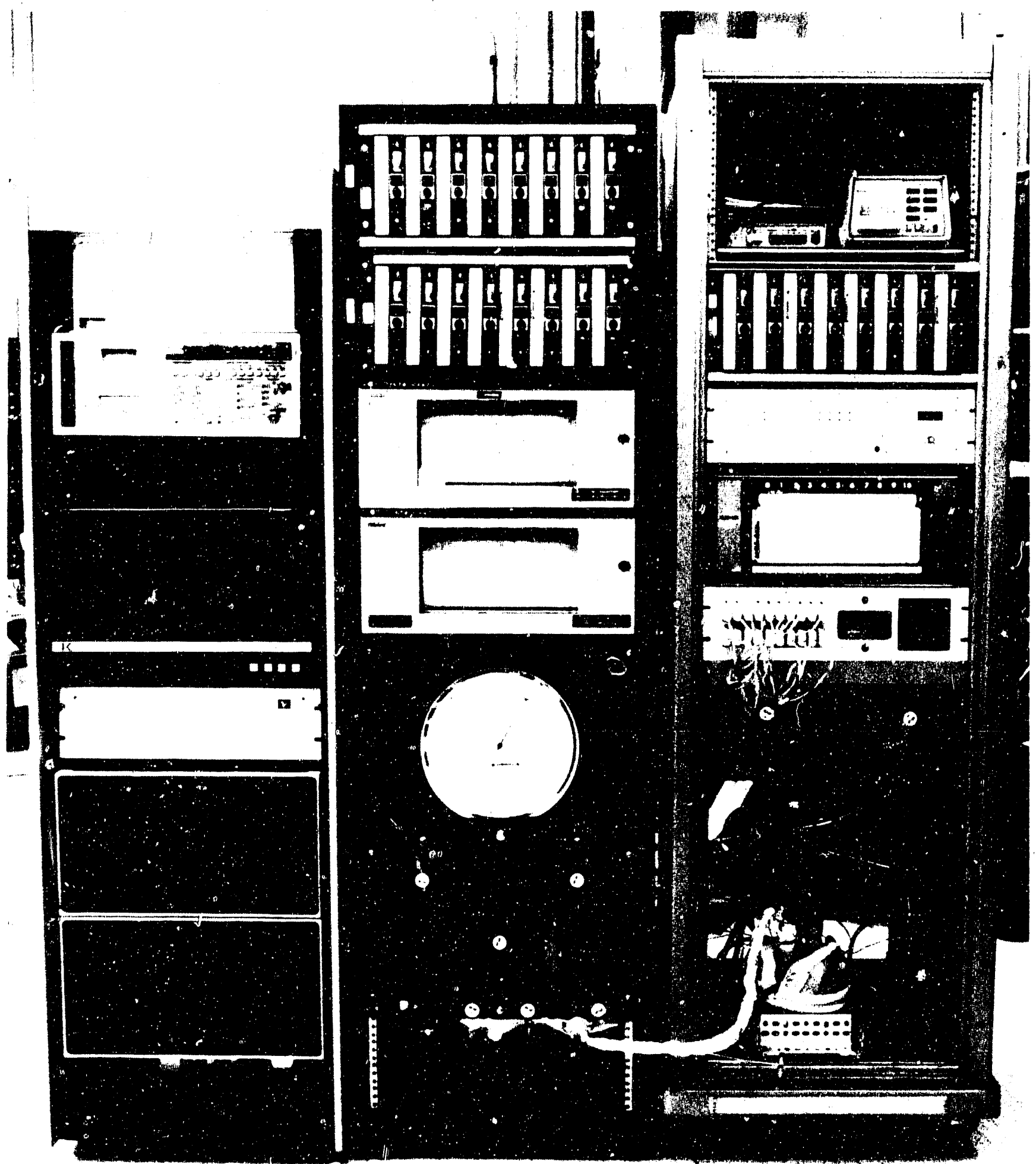

FICUE 9. Experiment Support Equipment. (The data logger is in the eft-hand cabinet. Tre other cabinets contain the temperaturt: controllers, recorders, and gas manifolds.) 
about $25 \mathrm{~mm}$ ( $1 \mathrm{in}$. ) above the water level, or bottom of the vessel. The two 3.2-mm (1/8-in.) diameter gas lines from each vessel were attached to separate gas control manifolds. A schematic of two manifolds is shown in Figure 10. This arrangement allowed for gas sampling, purging of the gas space and calibration of the pressure transducers under operating conditions. Each vessel was protected from overpressure with a Nupro* series CPA adjustable pressure relief valve.

\subsubsection{Heaters and Controllers}

All six heaters on each vessel installation were individually controlled by Research, Inc., Model 639B three-function controllers ${ }^{\star *}$. Control thermocouples were banded to the outside of the vessel, or gas lines, between wraps of the heating tape. Thu controller set points were adjusted to produce the desired temperature values on the immersion thermocouples inside of the vessel. The irimersion thermocouples were spring loaded against the inside walls of their immersion tube to assure minimum temperature error. The calibrations of the immersion thermocouples were varified before an experiment by operation of the vessel when it was filied with water at the normal boiling point. The $3.2-\mathrm{mm}(1 / 8-\mathrm{in}$.$) tubes, 7.6$ to $12.2 \mathrm{~m}(25$ to $40 \mathrm{ft})$ in length, were trace heated with metal-sheaihed resistance heating cables. All parts of a gas manifold that were directly cormected to the vessel were trace heated with glass-covered resistance heating tape. The manifolds and gas lines were maintained at about $115^{\circ} \mathrm{C}$ to prevent moisture condensation. The extra thermocouples installed on the equipment to check the trace heating were monitored on a multistation thermocouple readout panel.

*Nupro series CPA adjustable pressure relief valve is a trademark of the Nupro Company, Willoughby, $\mathrm{OH}$.

${ }^{*}$ Model $639 \mathrm{~B}$ three-function controller is a trademark of Research, Inc. 


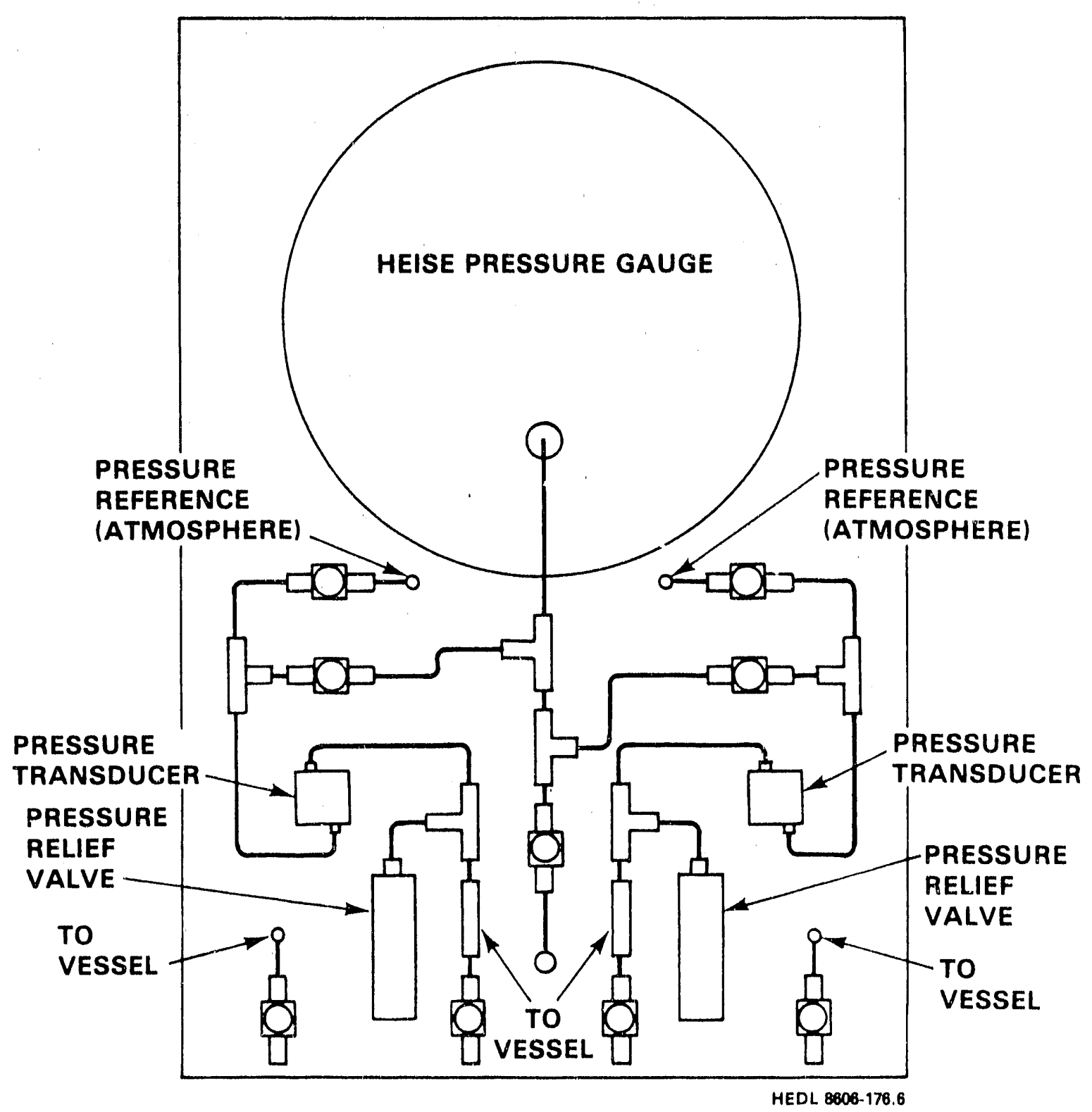

FIGURE 10. Schematic of Two Gas Manifold Systems. 


\subsubsection{Data Systems}

System condition values were measured hourly by a Fluke Model $2240 \mathrm{~A}$ data loggera and recorded on nine-track magnetic tape by a Kennedy Mode 1600 recorderb. Periodically, the data tapes were read by a Kennedy Model 9832 tape deck ${ }^{c}$ and the data transmitted to a Sperryd 1100/40 computer for processing. Details of the data channels and output records are given in Reference 3. To provide backup records for the vessel temperatures and to detect temperature transients that might occur between recordings by the data logger, the midlevel immersion thermocouple voltage from each vessel was recorded on an Esterline Model Ll102S strip chart recordere. The pressure in each vessel was measured with a Validyne Model CD280 Multichannel Carrier Demodulatorf with Model DP-7 and DP-15 variable reluctance, differential pressure transducers that used the air atmosphere as a reference. Calibration of these units was made under operating conditions with a calibrated, $690 \mathrm{kPa}$ $\left(100-1 \mathrm{~b} / \mathrm{in}^{2}\right)$ Heiseg gauge, readable to less than $0.69 \mathrm{kPa}\left(0.1 \mathrm{lb} / \mathrm{in}^{2}\right)$. Finally, a telephone callout system was installed that would automatically call one of several key personnel if any abnormal value of temperature or pressure occurred in any vessel or if electrical power was interrupted.

afluke Model $2240 \mathrm{~A}$ data logger is a trademark of John Fluke Manufacturing Company, Inc.

bKennedy Model 1600 recorder is a trademark of an Allegheny International corporation

CKennedy Model 9832 tape deck is a trademark of an Allegheny International Corporation

dSperry is a trademark of UNISYS

Esterline Model 111025 strip chart recorder is a trademark of Scientific Columbus, Inc.

fValidyne Model CD280 Multichannel Carrier Demodulator is a trademark of Validyne Engineering Corporation

gheise gauge is a trademark of Dresser Industries, Newtown, CT. 


\subsubsection{Specimens}

\subsubsection{General Treatments}

Each new specimen was engraved with a unique serial number that identifies origin and composition throughout all phases of exposure and examination. A record was kept of the specific location of each specimen in each cage, vessel, and experiment. The serial number code is XYZZZ where:

$$
\begin{aligned}
X= & \text { Alloy } \\
& 1=\text { CDA } 101 / 102-\text { pure copper } \\
& 2=\text { CDA } 613 / 614 \text { - aluminum bronze } \\
& 3=\text { CDA } 715-30 \% \text { nickel-copper } \\
Y= & \text { Specimen type } \\
& W=\text { Weight loss } \\
& B=\text { Bend (tear drop) } \\
& C=\text { Crevice }
\end{aligned}
$$

$z Z z=$ Serial number

Specimens were prepared for use by ultrasonic cleaning in $x y l e n e$, then hand polished with 600-grit silicon carbide paper and rinsed several times in absolute ethyl alcohol; one rinse was in the ultrasonic cleaner. All specimen cages, hardware, and vessels were cleaned in a similar manner. The ceramic hardware was etched in $30 \%$ nitric acid at approximate $1 y=0^{\circ} \mathrm{C}$, rinsed in demineralized water several times, and baked in a vacuum oven overnight at approximately $200{ }^{\circ} \mathrm{C}$. When specimens were loaded into their respective cages, the spatial arrangement of each specimen type assured that adjacent specimens were of different alloys.

Specimen cages removed from an experiment were isolated in closed containers and taken to the laboratory for disassembly and specimen replacement. New specimens were mounted with clean ceramic spacers. To minimize bias, speci- 
mens of each type and alloy were examined in as large a group as posstble and without regard for exposure history.

Oxide fllms were removed according to ASTM G1-81:(7) 1 to $3 \mathrm{~min}$ in a deaerated, hydrochloric acid solution (1:1) at room temperature. Separate solutions were used for each alloy. After the films were removed, the specimens were rinsed in demineralized water, rubbed hard by hand with a lint-free cotton cloth, rinsed again in absolute ethyl alcohol, and air dried.

\subsubsection{Crevice Specimens}

Crevice specimen pairs were not washed or rinsed after removal from the vessel. The pairs were kept tightly bolted together until ready for examination. After the pairs were opened, a careful, visual examination was made of all inner surfaces, using a lox magnifier. A color photograph was made of one inside and one outside surface of each specimen. Specimens were cut by a hand-operated hacksaw for analysis and examination.

\subsubsection{Tear Drop Specimens}

After the oxide films were removed, each specimen was given a careful, visual examination with the aid of a lox magnifier. Color photographs werc made (up to $10 x$ magnification) of any features of particular interest. The specimens were examined for microcracks by fluorescent dye penetrant per ASME code. ( 8 ) The specimens were then cut with a hand-operated hacksaw for analys is and examination.

\subsubsection{Weight-Loss Specimens}

Specimens were lightly rinsed with demineralized water and dried overnight in air. Weighings were made before the corrosion exposure (after final cleaning and polishing), before removal of the oxide film (after rinsing and drying), after the oxide film was removed, and after a second acid treatment of equal length to the first treatment (to correct for the metal loss by the acid). A color photograph was made of one side of each specimen before oxide removal. 
After the oxide film was removed, a close visual inspection was made of all surfaces, using a 10X magnifier. Color photographs were taken following the same procedure used on the tear drop specimens.

In each $95^{\circ} \mathrm{C}$ experiment, one set of weight-loss specimens was mounted so that half of the metal was in Well J-13 water .nd the other half was in the gas phase. Twenty-seven specimens were exposed at approximately $4 \times 10^{5} \mathrm{R} / \mathrm{h}$ for 1,3 , and 9 mo. Nine others were exposed at approximately $4 \times 10^{3} \mathrm{R} / \mathrm{h}$ for $31 / 2$ mo. After their exposures to the corrosion environments, the specimens were cut in half lengthwise with a hand-powered hacksaw. The oxide film was removed from one piece and the metal surface examined visually using a $10 \mathrm{X}$ magnifier. Some of the pieces were sectioned and polished for metallographic examination.

\subsubsection{Electrochemically Prepitted Specimens}

A set of weight loss and tear drop specimens of each of the three materials was electrochemically prepitted at LLNL and then placed in the gamma corrosion experiments at Westinghouse Hanford Company. The prepitting was performed in a synthetic Well J-13 type water solution prepared as shown in Table 3 . The pitting was accomplished by raising the electrochemical potential of a specimen by steps to several hundred millivolts above the measured corrosion potential. The ranges of process times and voltages used are summarized in Table 4. These specimens were not included in the Westinghouse Hanford marking system described above or included in the data base in the Appendix. The variations in the pitting conditions used produced a variety of pitting structures and was consistent with the program objectives, i.e., to determine the corrosion effects on a variety of specimens. At Westinghouse Hanford, the specimens were mounted in the all-titanium vessel T-3 and exposed to conditions similar to those that existed in vessel T-1 (i.e. $95{ }^{\circ} \mathrm{C}$, liquid and gas phases). The oxide film removal process mentioned above was modified for these specimens. The hydrochloric acid etch was a 30-s exposure in a highenergy ultrasonic bath. This was followed by a 30 -s rinse in the ultrasonic bath, followed by the normal rinse sequence. After the oxide films were 
TABLE 3

COMPOSITION OF SYNTHETIC, WELL J-13 TYPE WATER

(Used only for electrochemical prepitting)

$\begin{array}{lc}\text { Chemical } & \text { Quantity* } \\ \text { Sodium bicarbonate } & 17.0 \\ \text { Potassium nitrate } & 1.5 \\ \text { Sodium chloride } & 1.2 \\ \text { Potassium sulfate } & 3.36 \\ \text { Sodium fluoride } & 0.508 \\ & \\ \text { pH range: } & 8.17 \text { to } 3.64 \\ & \\ \text { * grams/liter of solution (molal) }\end{array}$

removed and visual observations were made, the cear drop specimens that had received the 6-mo exposures were sectioned, poitshed, and given metallographic examinations.

\subsubsection{Metallographic Examinations}

Metallographic sectioning and examinations were made to determine whether the surface corrosion features were related to any breakdown of the structure of the underlying metal. The metallography also complements the other types of examinations performed. This sampling provided a litmited view only of possible metal structures and should not be considered a comprehensive examination of the specimens.

The 37 specimens selected for examination included examples from each subgroup of alloy and environmental condition. Specimens were mounted, sectioned, and polished using standard metallographic techniques. After the specimens were carefully examined, unusual features were photographed (magnification range $5 x$ to 400X). The specimen surfaces were then etched with a mixture of about. 


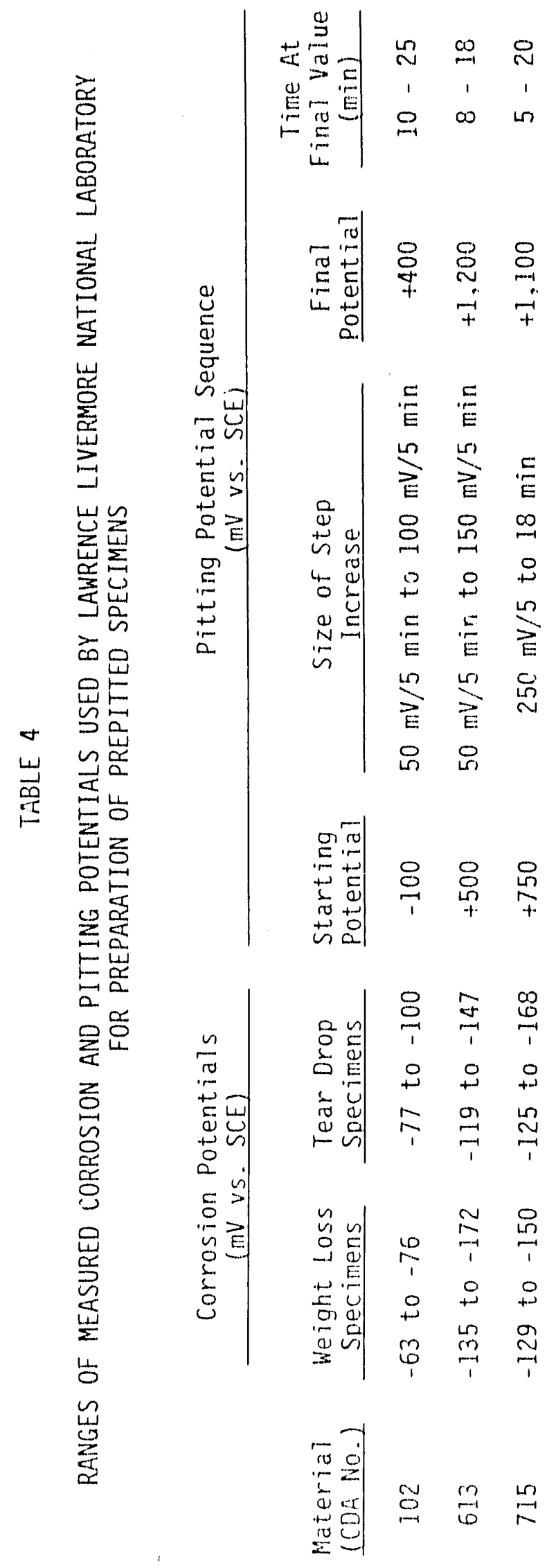


19 vol\% concentrated nitrte acte and concentrated formic: acte to rovoal the gratn structures. After the spectmens were reexamtned, addittonal photographs were made, as approprtate.

\subsubsection{Visulal Examinations}

Al1 specimen surfaces were carefulty examined under good lighting, using a 10x magnffer. Descriptions of spectmen condtions and special features were recorded. A sertes of two-letter codes or descriptors was devised to condense thits information into a usable form so that comparisons, groupings, and correlations could be made using the data base. A detalled description of the list is in Appendix A along with the data base. The descriptors are somewhat suggestive of thetr meaning, so that they can be strung together to make descriptive phrases, For example, "FWDKSPPT" reads "a few dark spots and pits."

While every effort was made to make the descriptors as explicit as posstble, the system is qualitative, and there are overlaps in the definttions. Hcivever, the value of being able to eastly analyze and compare spectmen conditions with other expertmental values in the data base was felt to outweigh the brief inconventence of learning the codes. In particular, the notation of "pits" was used in cases where it was not clear whether the features were pits (with recognizable depth) or spots. Thus this entry is on the conservative side.

\section{4 .1 .8 Air Water-Vapor at $150^{\circ} \mathrm{C}$}

To costablish the vessel T-2 atmospheric composition at the beginning of an experiment, the vessel was placed into the gamma fleld and all systems were brought to the operating temperatures. Compressed breathing atr was humidifted by sparging at $0.5 \mathrm{~L} / \mathrm{min}$ through water at $75^{\circ} \mathrm{C}$ to $80^{\circ} \mathrm{C}$, and then through a heated delfvery system to the vessel. After three to five vessel volumes of gas had passed through the system, the vessel exit valve was closed, the system was pressurized to 1 to $216^{f} / \mathrm{in}^{2}$ (gage), and the gas system was sealed. The small pressurtzation was used to detect leaks that 
mteght develop th the system during the expertment. The gas was not changed during the 1-mo and 3-mo expertments, Durtng the 6-mo exposure pertod, the vessel was repurged every 7 to 10 d (as above) wtth one vessel volume of humidlffed alr.

\section{4 .1 .9 Water-Saturated Air and Water at $95^{\circ} \mathrm{C}$}

The spectmen cages to be located in water were lodded into vessel T-1, T-3, or T-4. We11 J-13 water was added to a predetermined level that would be across the middle of the interface specimens during the expertment. The remainder of the cages were loaded and the vessel was then sealed and lowered int the gamma tube. All heaters, except the water heater, were then energlzed and brought to their operating temperatures.

After the metal spectmens had a chance to reach the system temperature (usually overnight), the water temperature was carefully increased without allowing it to reach the temperature of the gas space. Temperalure values used for this were based on an estimated overall measuroment uncertainty of $+1 \mathrm{C}^{\circ}$. When the vessel was depressurlzed or gas samples were taken during an experiment, the water temperature was first cooled to about $30^{\circ} \mathrm{C}$ to prevent a violent expanston of the water (from the pressure release) that would splash onto the specimens mounted in the gas phase.

As soon as a vessel was opened for spectmen exchange, the gas phase cages were quickly removed and a pH meter alectrode was lowered into the vessel. Sevoral readings of the pH were made with reference to standard buffer solutions. Several samples of the water were then removed from the vessel pool with pipettes. Finally, the cages under water were removed, and the rematider of the water was poured tnto storage containers. The vessel was then swabbed several times with clean, lint-free cotton cloths and rinsed with detonized water several times, drained, and alr-dried. Fresh Well d-13 water was used when the vessel was reloaded.

The seal surfaces for the o ring were hand polished with 600-yrit stiticon carbide paper before each experiment. The seal of a loaded vossel was glven a 
fthat leak check by pressurtzing the vessel to 340 to $550 \mathrm{kPa}\left[50-80 \mathrm{1b} / \mathrm{fm}{ }^{2}\right.$ (gage) ), depending on the setting of the pressure reltef valve, and by covertng all the seal flange areas with a commerctal bubble-forming liquid.

\subsection{QUALITY ASSURANCE}

The level of qualtty assurance for this work is level three as defined in Reference 9. The bastc elements of this level inciude traceability of specimens from the foundry heat number to the experimental conditions and the final analyses of each spectmen, callbrations of all primary measurement instruments to the NBS references, written laboratory procedures, and complete, indexed, laboratory records. 


\section{$4.0 \quad$ RESULTS}

\subsection{DATA BASE}

Al1 information regarding the spectimens and thetr examinations was entered into a Symphony data base on an IBM Personal Computer (PC), for ease of data veriftcation and analysis. The data base listing ts shown in Appendix $A$ along with an explanation of the codes and formats used. Elsewhere in this report, a shorthand notation is used for the exposure conditions for spectmens:

\section{$M M M / P / N$}

where:

$$
\begin{aligned}
M M M & =\text { Nominal temperature } i n{ }^{\circ} \mathrm{C} \\
P & =\text { Phase }(G=\text { gas } \quad L=1 \text { tquid }) \\
N & =\text { Number of mo of exposure. }
\end{aligned}
$$

Table 5 summartzes the numbers of each type and alloy of the specimens that were processed.

\subsection{VESSEL ENVIRONMENT}

Since gamma irradiation alters the chemical composition of an air-water environment, measurements of the changes that occurred under these experimental conditions are essential for the characterization of the observed corrosion and the development of an understanding of the corrosion processes. In situ measurements of many of the expected species (2) were beyond the scope of these experiments. Values recorded were 1) vessel pressure versus time, measured hourly, 2) water and gas temperature, measured hourly, 3) gas compositton, measured every few weeks, when excess vessel pressure was released loperating maximum was $340 \mathrm{kPa}\left(501 \mathrm{bf}^{\mathrm{f}} / \mathrm{in}^{2}\right.$ (gage)], and 4) 1 lquid water composition, measured each time an experiment was interrupted for the exchange of corroston spectmens. 
TABLE 5

NUMBERS OF EXPOSED SPECIMENS

Alloy

Spectmen Type

\begin{tabular}{|c|c|c|c|c|c|c|c|}
\hline & \multirow[b]{2}{*}{$\begin{array}{l}\text { Weight } \\
\text { Loss }\end{array}$} & \multirow[b]{2}{*}{$\begin{array}{l}\text { Inter- } \\
\text { face }\end{array}$} & \multirow[b]{2}{*}{$\begin{array}{l}\text { Tear } \\
\text { Drop } \\
\end{array}$} & \multirow[b]{2}{*}{ Crevice } & \multicolumn{2}{|c|}{ Prepltted } & \multirow[b]{2}{*}{ Totals } \\
\hline & & & & & $\begin{array}{c}\text { Weight } \\
\text { Loss }\end{array}$ & $\begin{array}{l}\text { Tear } \\
\text { Drop }\end{array}$ & \\
\hline Copper & 56 & 6 & 41 & 30 & 6 & 4 & 143 \\
\hline Al-Bronze & 56 & 6 & 39 & 30 & 6 & 4 & 141 \\
\hline $\mathrm{Ni}-\mathrm{Cu}$ & 56 & 6 & 40 & $\underline{30}$ & $\underline{6}$ & 4 & 142 \\
\hline TOTALS & 168 & 18 & 120 & 90 & 18 & 12 & 426 \\
\hline
\end{tabular}

lsymphony, V1.1 is a trademark of Lotus Development Corporation.

\subsubsection{Air-Water Vapor at $150^{\circ} \mathrm{C}$}

There was no noticeable change in the gas pressure in vessel T-2 during the experiment beyond the daily fluctuations in the barometric (reference) pressure. To make reliable measurements of changes in the amount of gas versus time would have required more extensive instrumentation and thermostating of the system. Mass spectrometric analyses of the gas samples are shown in Table 6. After the first 1-mo and 3-mo experiments were completed, the gas was replenished every 7 to $10 \mathrm{~d}$. (Note that water vapor was not determined by the sampling and analysis methods used.)

\subsubsection{Air-Water Vapor At $95{ }^{\circ} \mathrm{C}$}

Examples of the rates and amount of pressure buildup in vessel T-1 are shown in Figure 11 for the titanium vessel used in the second part of a 7-mo experiment. The composition of the gas in the vessel was measured with a mass spectrometer. Samples were drawn into evacuated stainless steel bulbs after the connecting lines and manifold were purged with gas from the vesse1. As mentioned above, the water vapor content cannot he reliably measured by this method. However, liquid water was always present in the vessel, hence its 
TABLE 6

GAS COMPOSITION IN VESSEL T-2 AT $150^{\circ} \mathrm{C}$

Gas Composition (vol \%)

After Last 15 Days After

4.5 Mo* Previous Purge/

After 3-Month of 6-Mo Replenishment

Gas

Air

Experiment

Experiment

of Vessel

Argon

0.95

0.79

0.04

0.08

Carbon dioxide

0.05

0.53

0.00

0.07

Carbon monoxide

$<0.1$

$<0.1$

$<0.1$

$<0.1$

Hydrogen

$<0.01$

$<0.01$

$<0.01$

$<0.01$

Methane

$<0.01$

$<0.01$

$<0.01$

$<0.01$

Nitrogen

78.0

80.1

80.2

80.1

oxygen

21.0

18.6

19.7

19.7

Water vapor

(not measured)

*Eight days after previous gas replenishment

NOTE: Analytical sensitivity for $\mathrm{N}_{2} \mathrm{O}, \mathrm{NO}_{2}$, and $\mathrm{NO}$ was 0.02 vol\% Ammonia $\left(\mathrm{NH}_{3}\right)$ was not present with water vapor.

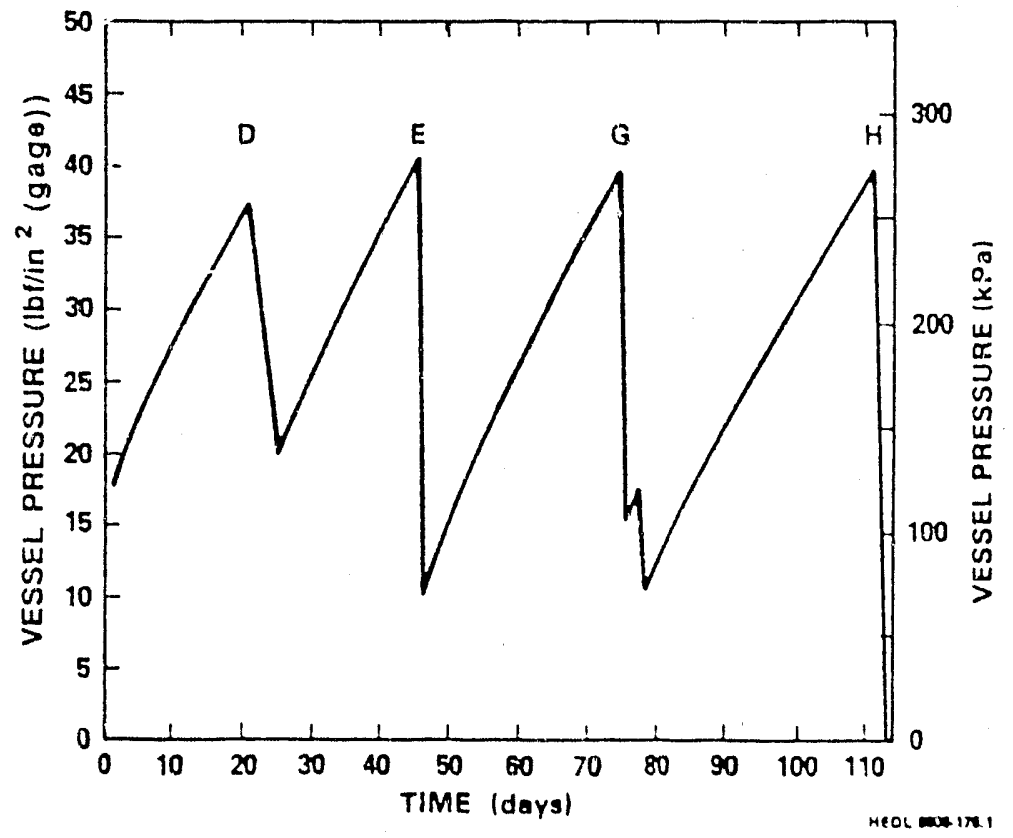

FIGURE 11. Gas Pressure Variation in Vessel T-1 $\left(95^{\circ} \mathrm{C}\right)$ During the Last $3-3 / 4$ Mo of the 7-Mo Experiment. The average rate of pressure increase is $\left(1.01 \mathrm{~b}^{f} / \mathrm{in}^{2} / \mathrm{d}\right) 6.9 \mathrm{kPa} / \mathrm{d}$. 
partial pressure was calculated from its temperature. The partial pressure of each gas in the vessel was calculated from the gas pressure and water temperature at the time of sampling and the measured composition of the sample. Results are shown in Table 7.

\subsubsection{Liquid Water at $95^{\circ} \mathrm{C}$}

Table 8 shows the chemical composition of the water solutions relative to the Well $\mathrm{J}-13$. Note that the $30-\mathrm{d}$ and $95-\mathrm{d}$ values were from a Monel 400 vessel while the others were from titanium vessels. Cation analyses were made by an inductively coupled plasma (ICP) emission spectrometer and the anion analyses by anion chromatography. Samples were filtered before being analyzed. The analyses of some precipitates found in the early experiments have been discussed. (3)

\subsection{METAL SPECIMENS}

\subsubsection{Stress-Assisted Cracking}

The dye penetrant examination performed on the 121 corroded tear drop specimens and on three archive specimens revealed no evidence of surface cracking. Twenty of these specimens, regular and prepitted, were then cross sectioned, polished, and metallographically examined. No evidence of subsurface corrosion or cracking was seen. Details of these examinations are discussed below.

\subsubsection{Crevice Corrosion}

Ten specimens of each alloy were exposed to each of the three corrosion environments. The results of the visual observations of the local corrosion features seen on the crevice specimens are listed in the data base (Appendix A). These are also summarized in Tables 9 through 11 . The width of the crevice corrosion penetration zone around the outer edge of the specimens is designated by the code "nM", where $n$ is the corrosion zone width in milli 


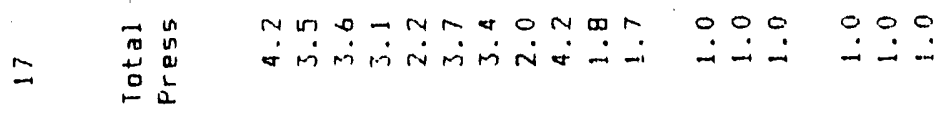

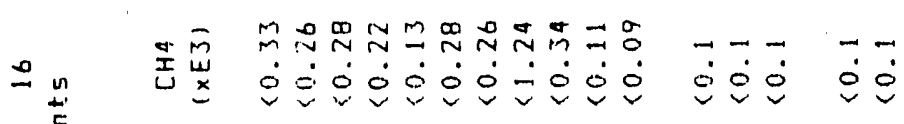

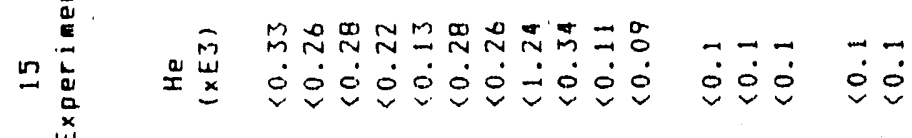

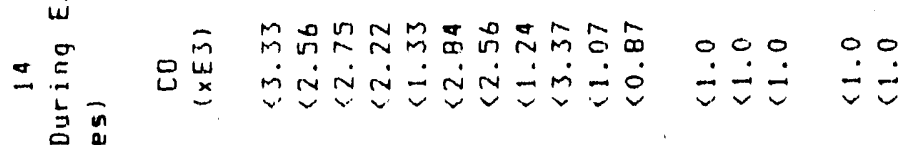

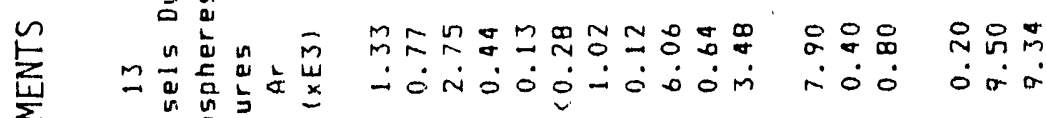

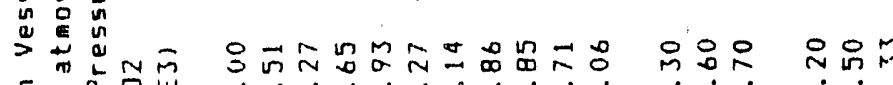

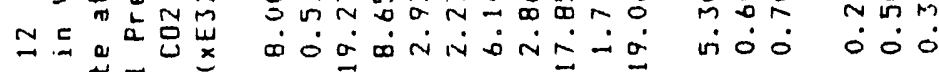

品落芯

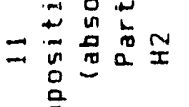

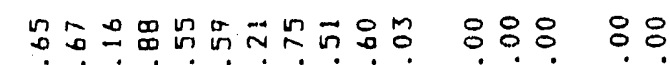

0 总

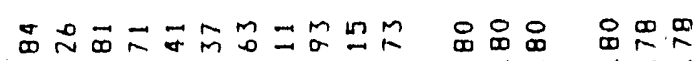

:

$=\underset{\substack{n \\ 0 \\ 0}}{N} \quad N$

वंல்:

$\therefore \dot{0} \div 0 \dot{0}$

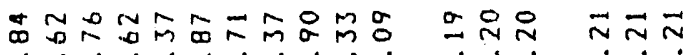

山 Э

N $\quad$

00000000

\begin{tabular}{ll}
0 & $\stackrel{N}{N} \bar{N}$ \\
\hdashline 00 & 000
\end{tabular}

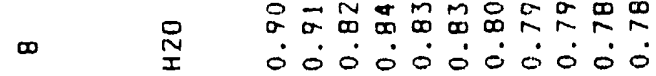

产

岕

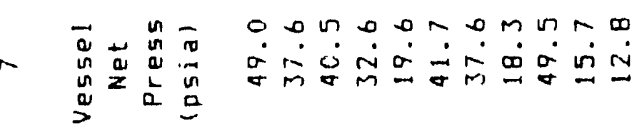

$z$

z

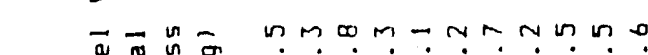

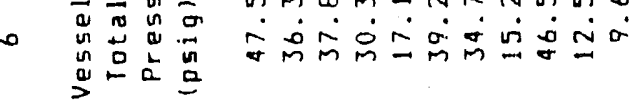

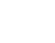

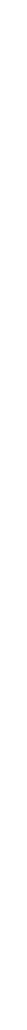




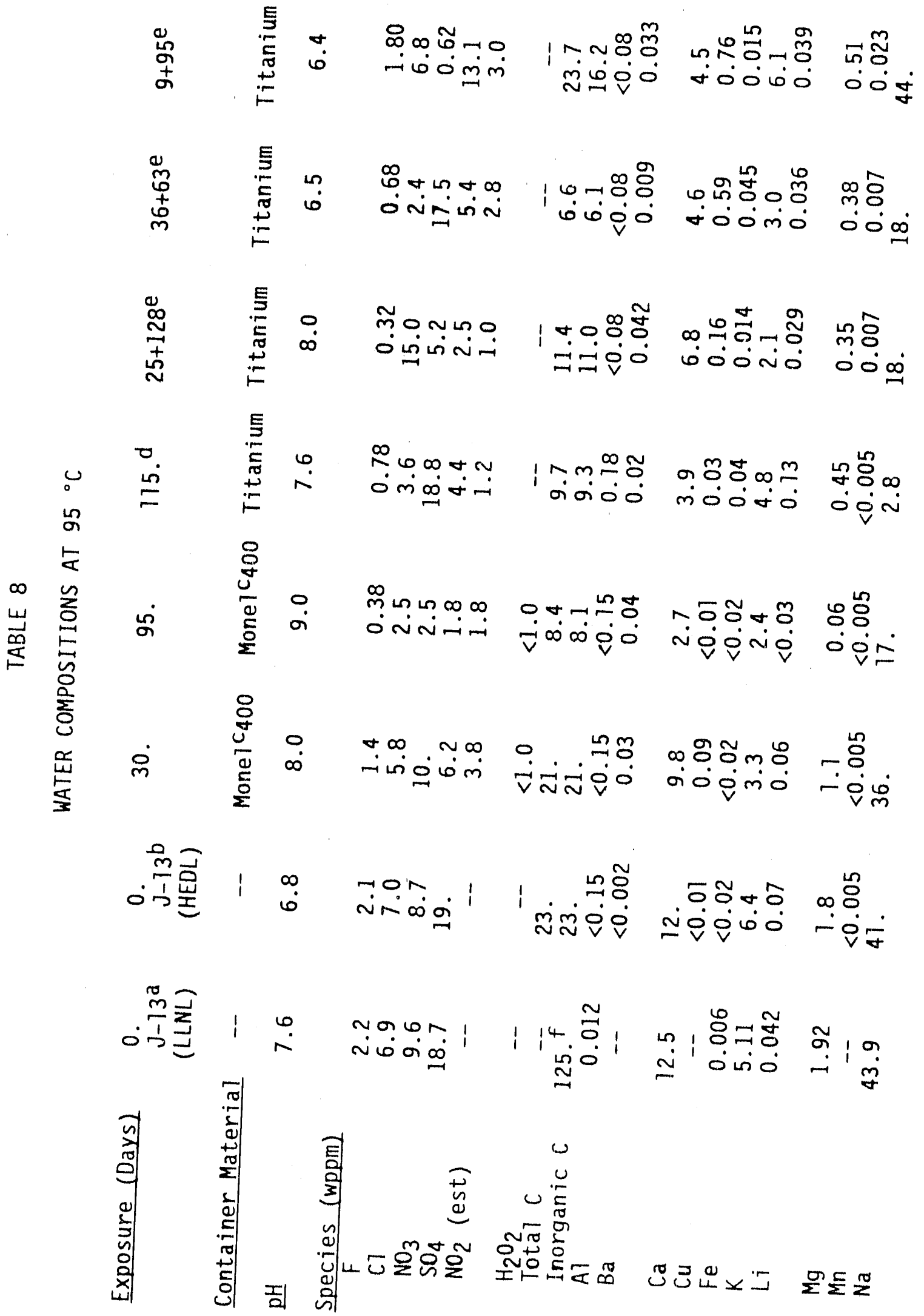




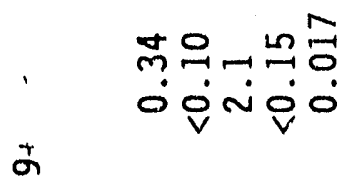

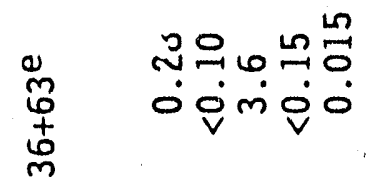

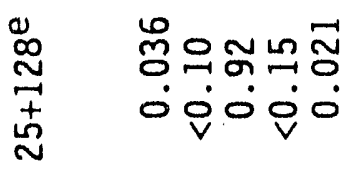

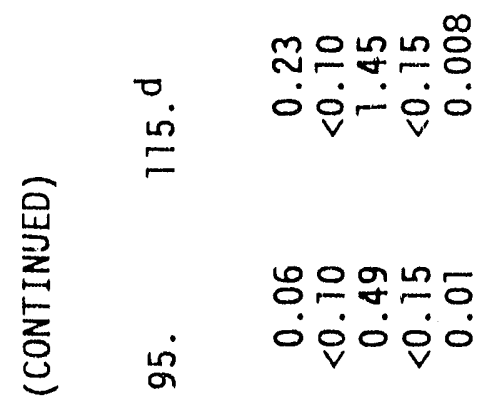

$\underset{⿱ ㇒}{\infty}$

$$
\begin{array}{ll}
0 & + \\
\sim & \sim
\end{array}
$$$$
\because \underset{\sim}{\because}
$$

$\stackrel{n}{-1}$

$\stackrel{m}{m} \dot{-}$

$\stackrel{\infty}{\infty}$ on

$\stackrel{m}{\sim}$

$\stackrel{\sim}{\sim}$

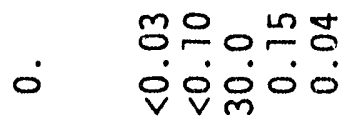

$\begin{array}{llll}0 & 1 & 0 & 0 \\ & \pi & 0\end{array}$

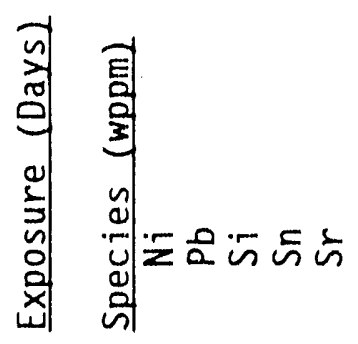

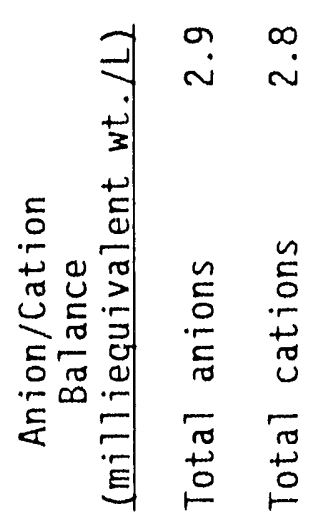

号

$\underset{j}{\stackrel{0}{a}} \stackrel{0}{a}$

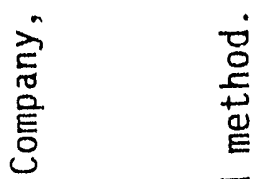

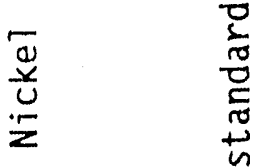

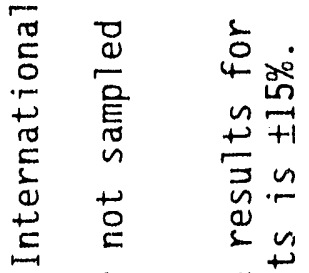

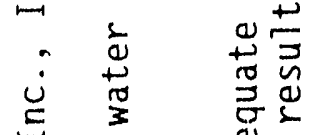

in

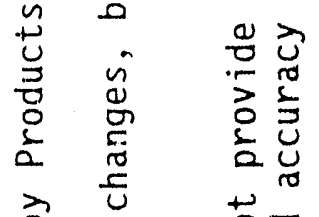

خे

崩 匹

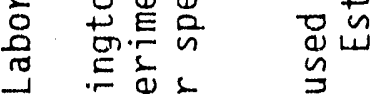

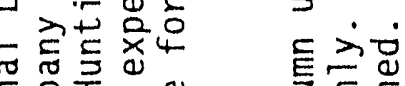

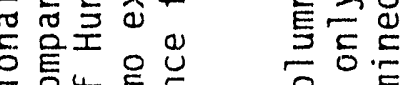

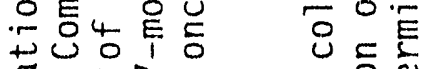

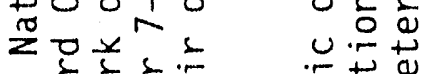

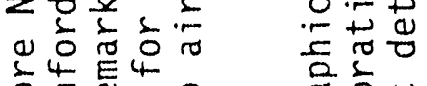

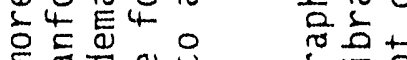
总牙它 Q) I

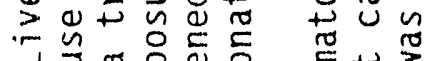

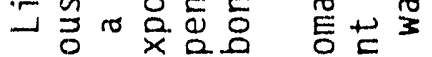

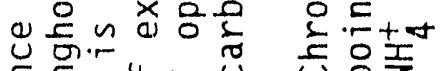

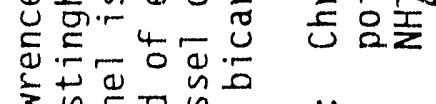

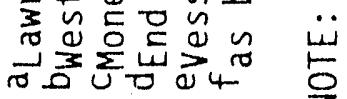




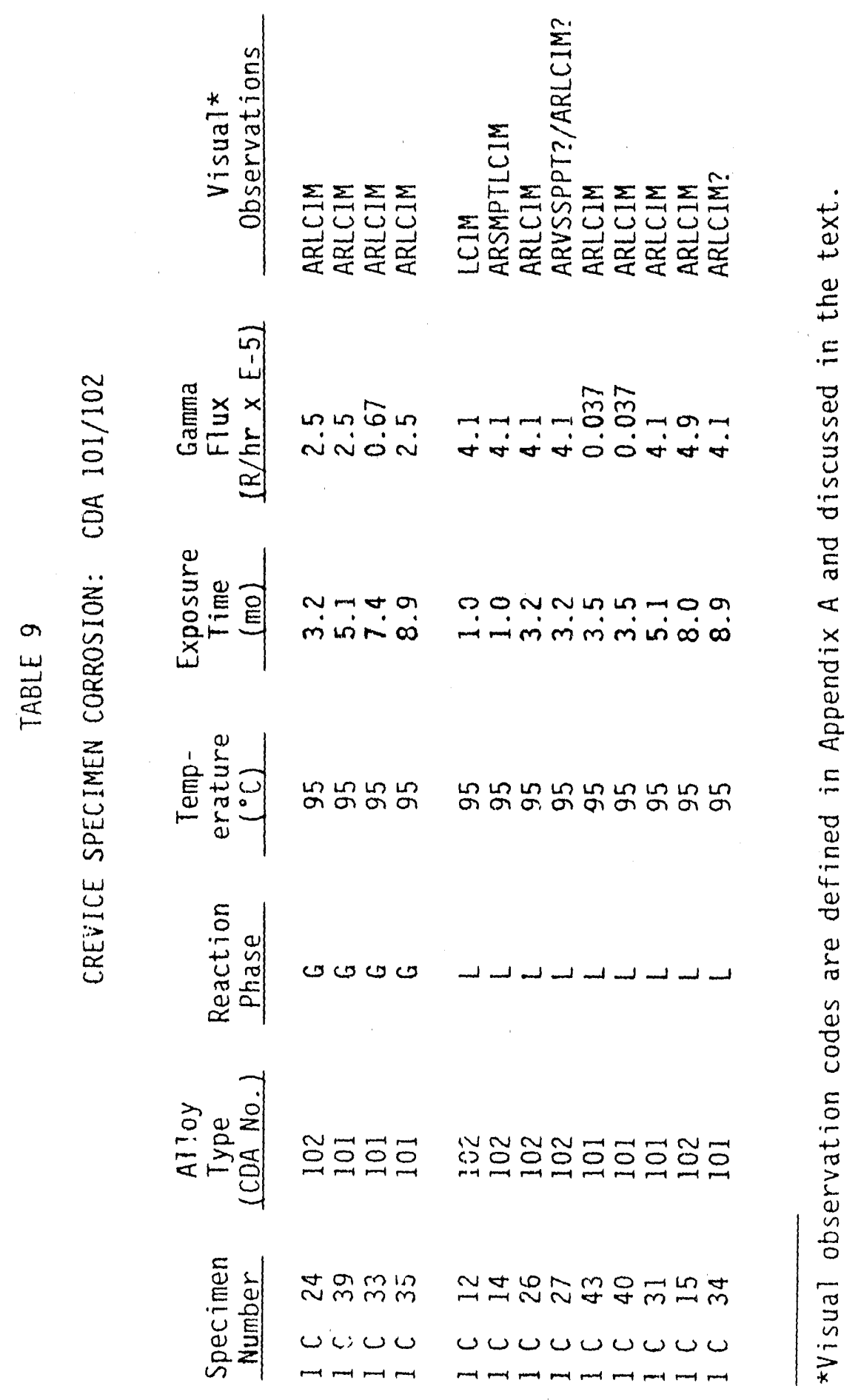


WHC-EP-0188
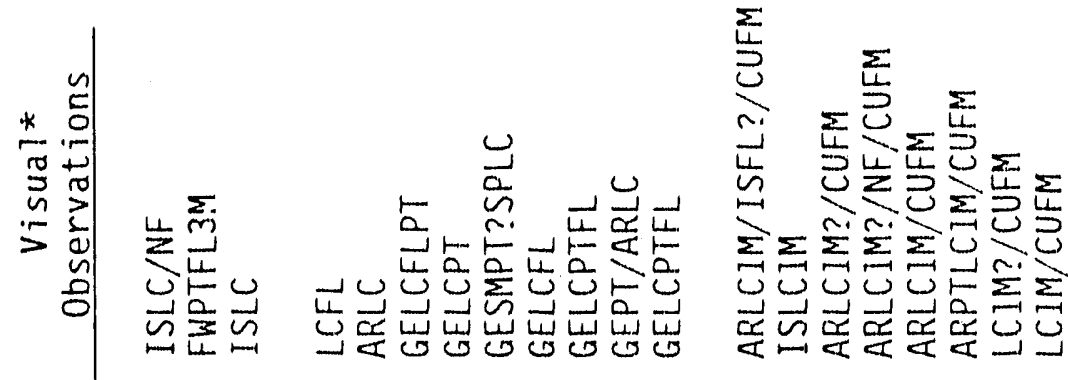

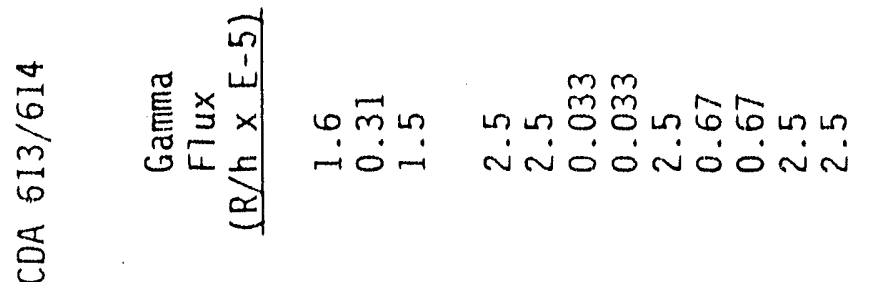

-

r

ñ

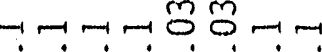

संषंषंठं

2

$\fallingdotseq$

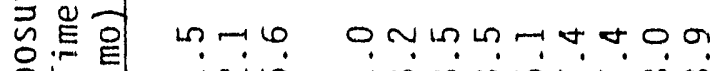
这

-ivin تiminisitió

o on nunto

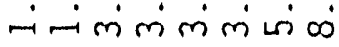

을

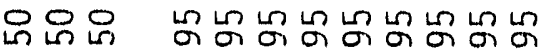

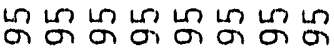

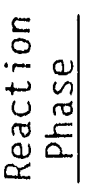

$\operatorname{sen}$

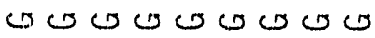

\lrcorner$-\lrcorner-\lrcorner-\lrcorner-$

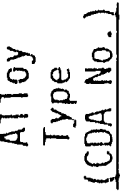

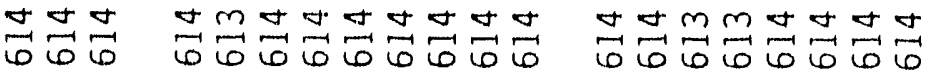

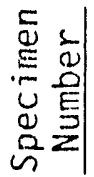

nᄄm

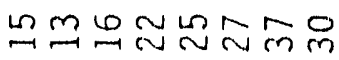

$\omega \omega \omega$

$\omega \cup \cup \cup \cup \omega \cup \cup \omega$

UU山U山ய山U

NNN

$\sim \sim N N \sim N N N N$

$\sim N \sim \sim N N N$

总

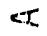

$\sqrt[x]{0}$

茪

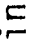

足

$\frac{1}{2}$

岁

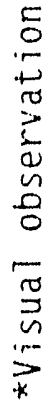




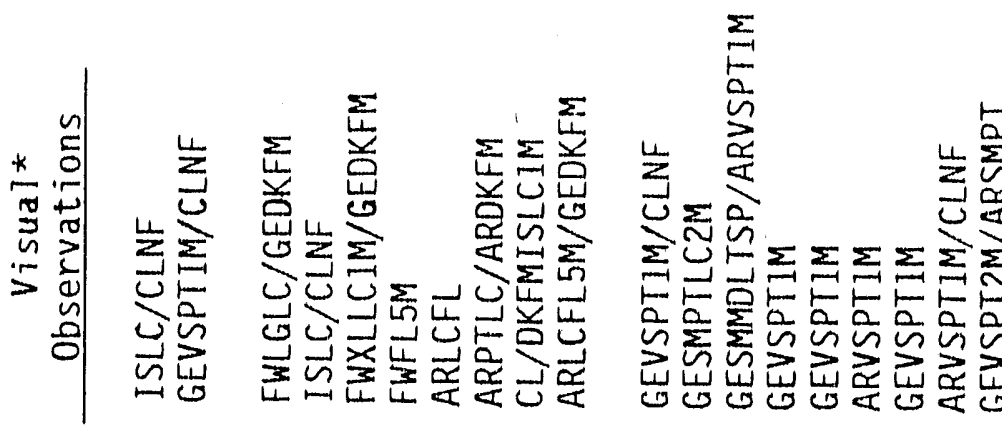

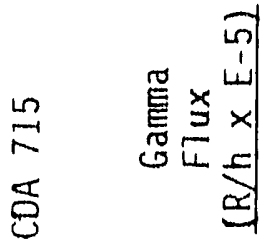

以 +i nónioin

กิ๊

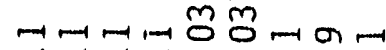

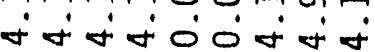

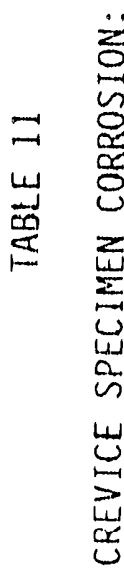

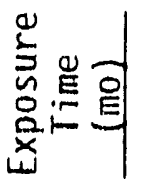

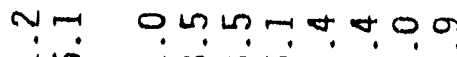

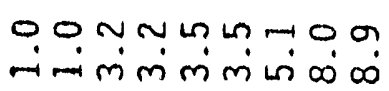

点站

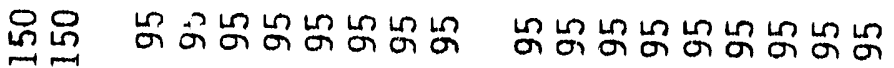
-mmint

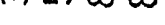

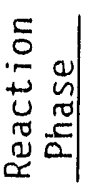

ज曰

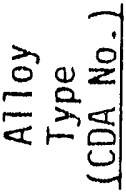

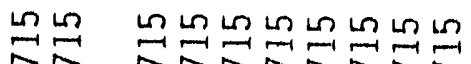

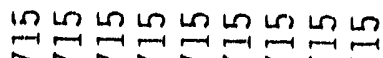

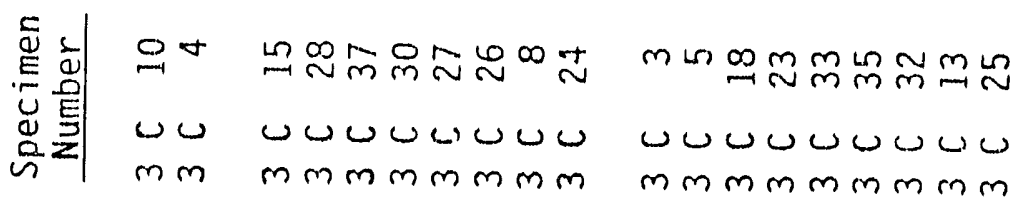


meters. Some spectmens also showed corrosion of the chosely maled surfaces at locations inward from the edges of the spectmens.

Crevice corroston was seen only around the outer edges on the CDA 101/102 spectmens and only on those exposed at $95^{\circ} \mathrm{C}$. Thitceen of the thirty speci. mens were thus affected.

Only 1 of the 12 corroded gas phase spectmens of CDA $613 / 614$ showed crevice corrosion around the outside edges; it had been exposed at $150^{\circ} \mathrm{C}$. Elght of the liquid phase spectmens showed stmilar attack. The local corrosion found on the other gas phase specimens was in the midsurface regions of the mated surfaces, away from the edges. Included in these features were the fillform. 1tke corrosion patterns that are also seen under the oxtde films on the weight loss and tear drop specimens.

Ten of the nickel alloy (CDA 715) specimens showed local corrosion. Half of the $95 / G$ specimens had 100 al corrosion in the inner areas away from the edges of the paired plates. All of the local corroston of the liquid phase specimens was in the crevice near their outer edges of the spectmens.

In summary, crevice corrosion at the edge of the specimens occurred only on the CDA 101/102 specimens exposed in the gas phase, not on those from the 1iquid phase. The results from the aluminum bronze CDA 613/614 specimens were just the reverse. The CDA 715 nickel alloy showed crevice corrosion on both 1 iquid and gas phase specimens but more regularly on those from the liquid phase. In the regions between the plates, but well away from the specimen edges, no local corrosion features were seen on pure copper. Some features were seen on the nickel alloy specimens, and local corrosion features were common in this region on the aluminum bronze specimens. 


\section{3 .3 Prepltted specimens}

Three sels of prepttted specimens wero visually examtnad:

- Those in an as recetved condition from LLNL.

- Those that recelved 3 -mo exposure

- Those that recelved a 6 -mo exposure.

In general, the pits found were rather broad, having a ratto of ptt clepth to pit width value (aspect) of one or less. The distribution, density, and size of the plts varied constderably across the surfaces of the spectmens; this likely is due to the vartations in electrochemical conditions used in thetr preparallon.

The exposure of the specimens to the irradiation corrosion environment in the Westinghouse Hanford Company gamma pit seemed to result generally in larger (broader) pits and fewer simall pits. Thts suggests that the pltting initiation process did not continue under the irradtation corrosion environment. Under these conditions, the smalier pits would disappear as the metal near the plts was consumed. A dense population of larger pits would combine, but would eventually disappear by the general corrosion process. The metallographic examinations described above showed no evidence of intergranular penetration or corrosion and there was no evidence of stressassisted cracking. The only cracks that were seen were related to mechanlcal deformations of the metal surface that apparently occurred before the corrosion experiments (l.e., in the manufacture of the specimens). There were dif. ferences in the behaviors of the different alloys, however.

On the CDA 101/102 specimens the pits were qutte broad. Some of the larger pits (about $20 \mu \mathrm{m}-300 \mu \mathrm{m}$ deep) showed roughness on their surfaces that was about $1 / 10$ the scale of the pit size. This small-scale roughness may have been smoothed somewhat by the corrosion, but not substantially. The unpitted 
surfaces wero relattvoly smooth. Examplos of these spectmons aro shown to Flgures 12 and $13(8 \% 5200$ and $8 \% 3200)$.

Some of the pits in the aluminum bronze (CDA 613/614) surfaces had a higher than avarage aspect, $0.9,3-5$ (dopth/wldth) and up to about 25 flim in dopth. In general, the unptted surfacos did not have the roughness found on the CDA 715 spectmen. Stgniftcant differences wero soen botwoen the three types of spectmens: as received, 3-mo, and 6-mo exposures. Examples are shown in Figures 14 and 15 (87521E and $87330 E$ ).

On the nickel alloy spectmens (CDA 715), the ortglnat ptts (as recelved) and those rematning after corrosion th the gas phase were qutte rough and trregular. See Ftgures 16, 17, and 18 (875220, 87328C, and 87328F). Under. culting of the spectmen surfaces was common. However, pitted and unptted surfaces on liquid phase spectmens were constderably smoother. plt depths ranged up to $50 \mathrm{\mu m}$. Other depresstons, found up to 180 km deep, likely wero related to other mechanisins (e.g., mechanical damage to the metal or electrode clamps).

\subsubsection{Interface Spectmens}

The location of the waterlthe was easlly recogntzable on these spectmens, both with and without the oxide layers. In most cases, there was only a faint The across the bare metal surface, showing that there was very little difference in the general corroston in this reglon. Local corrosion was quile evtdent on the spectmens that received the most exposure (9 mo).

On pure copper, CDA 101/102, isolated areas of dark spots and pits were found Just above and below the interface regton. The section in figure 19 (87302A) shows these pits to be about 5 jun deep. This is comparable with corroston seen on some of the $95 / G$ phase spectmens. Also, it illustrates that some of the dark oxide deposits not removed by the HCl solution can actually cover pits or other forms of local corrosion. The corrosion of the CDA 613/614 spectmens was about the same as for the CDA 101/102 specimens. Ptts found were comparable, but there was more coloration of the matal surface under the 


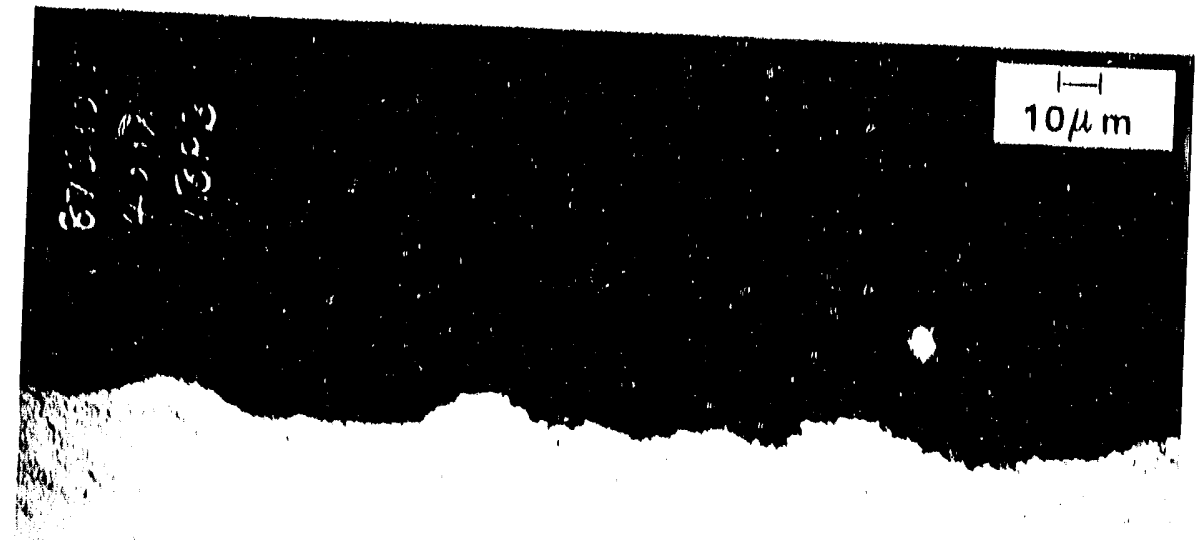

FIGURE 12. Surface Roughness After Electrochentcal prepltting of a CDA 102 Tear Drop Spectmen and No Subsequent Corroston Exposure
(400x). Photo No. 875 ?.0C.

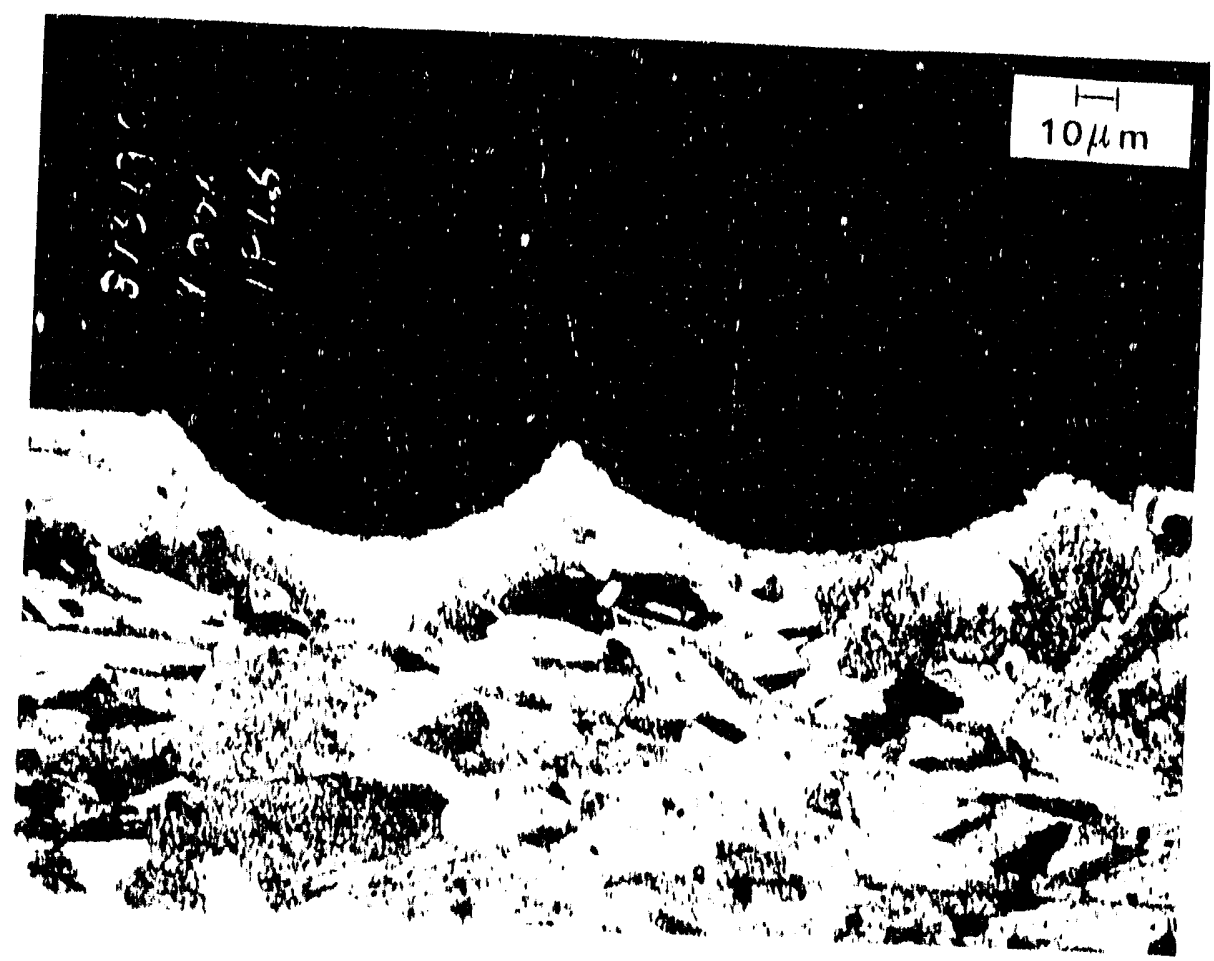

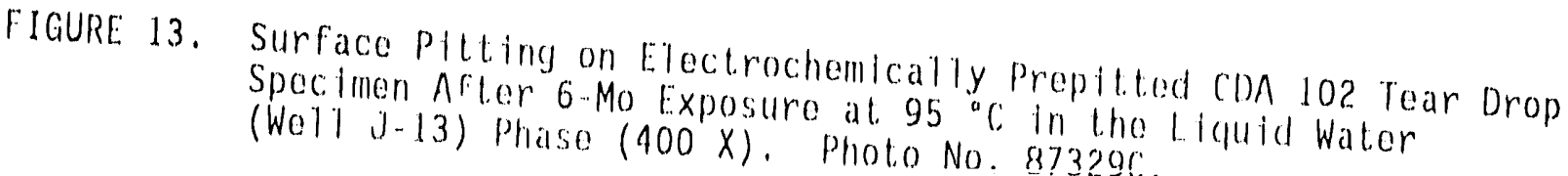




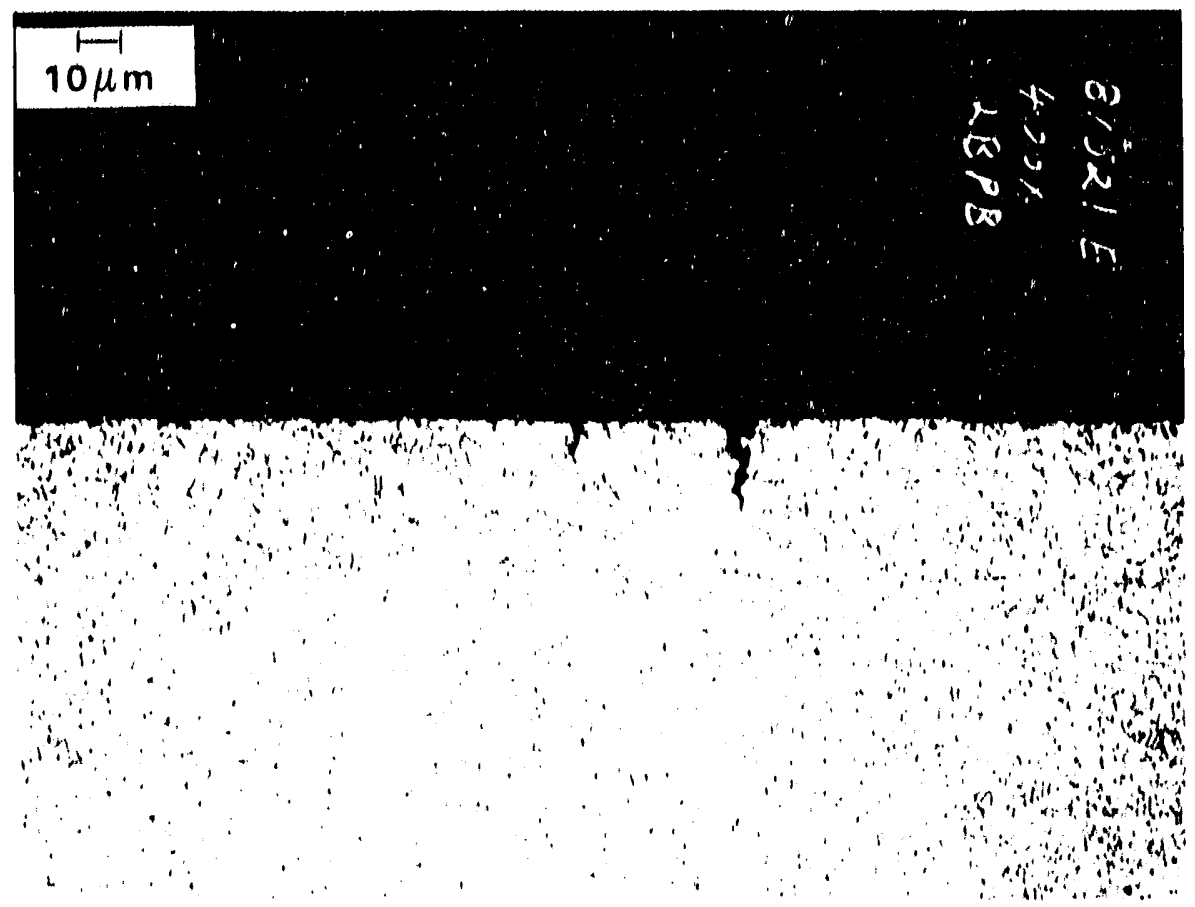

FIGURE 14. Surface Pitting After Electrochemical Prepitting of a CDA 613 Tear Drop Spectimens and No Subsequent Corrosion Exposure (400X). Photo No. 87521E.

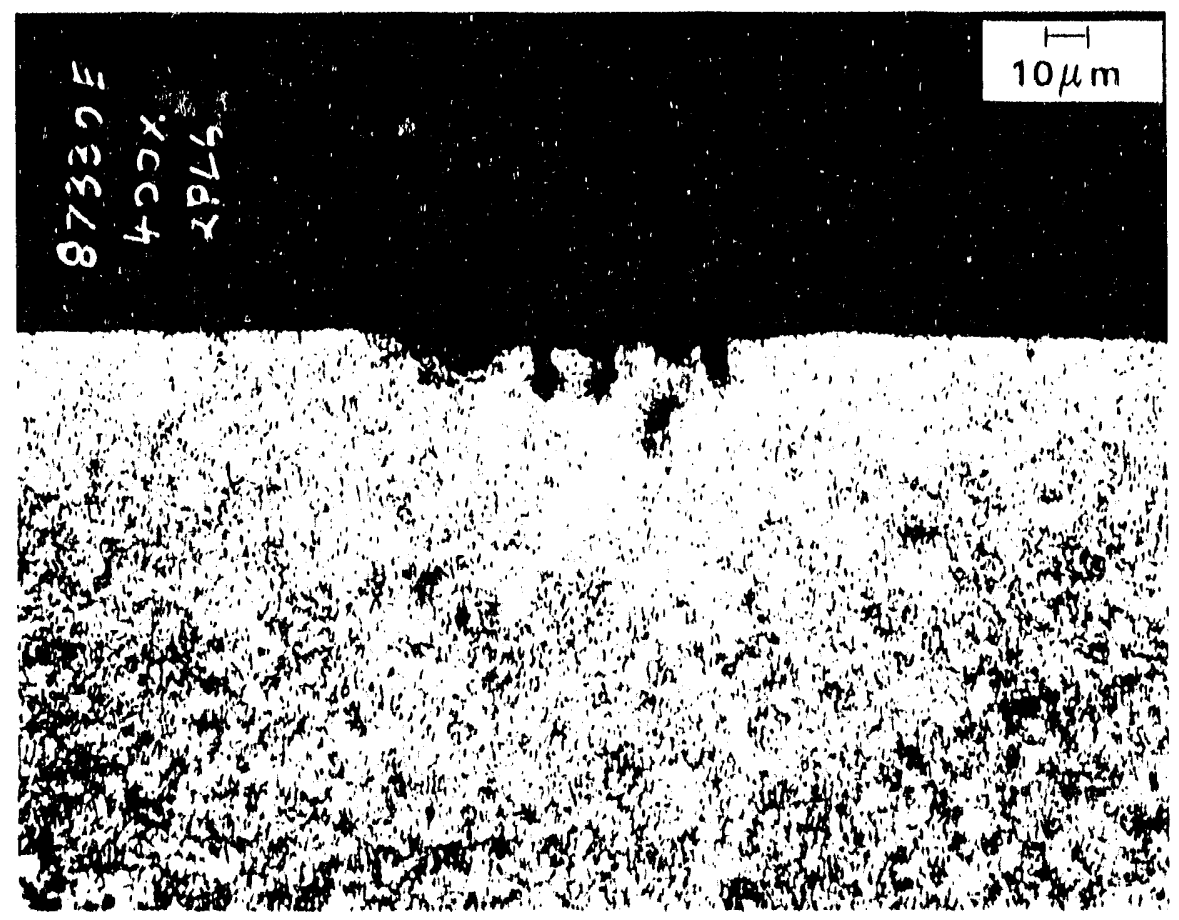

FIGURE 15. Surface Pitting on Electrochemically Prepitted CDA 613 Tear Drop Specimen After 6-Mo Exposure at $95^{\circ} \mathrm{C}$ in the Liquid Water (We11 J.13) Phase (400X). Photo No. 87330E. 


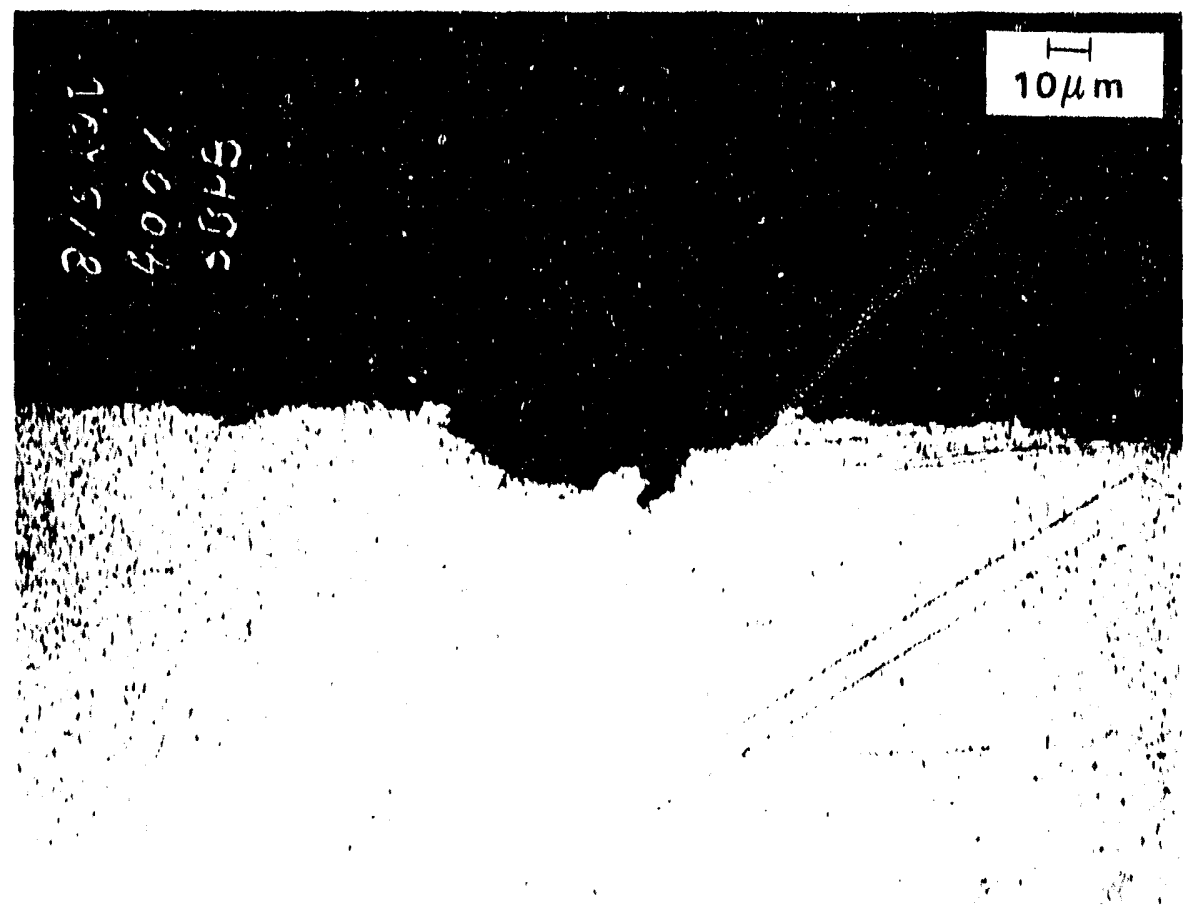

FIGURE 16. Surface Pitting After Elactrochemical Prepitting of CDA 715 Tear Drop Specimens and Without Subsequent Corrosion Exposure (400X). Photo No. 875220.

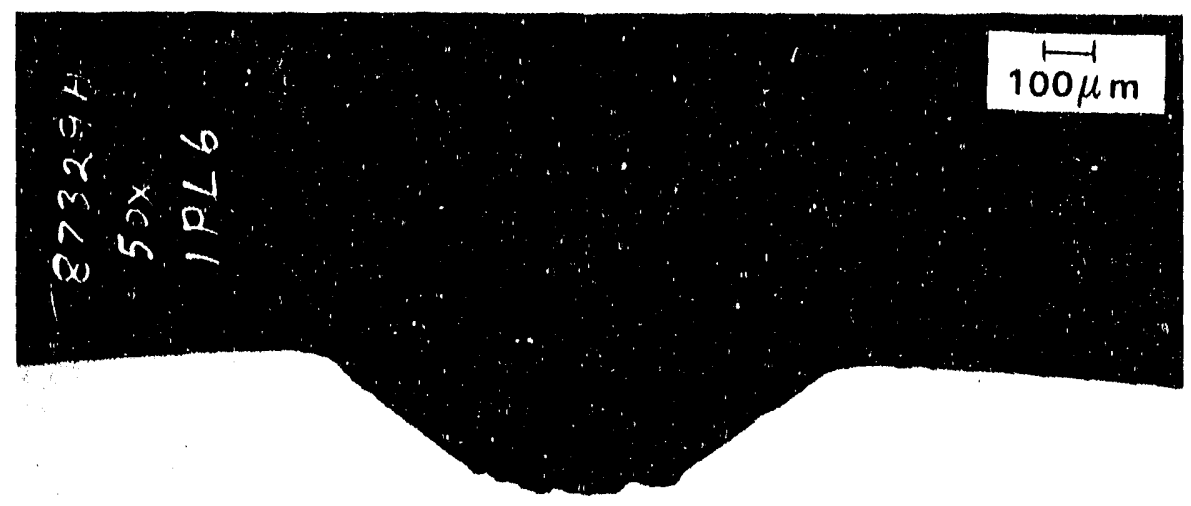

FIGURE 17. Surface Corroston of Electrochemically Prepitted CDA 715 Tear Drop Specimen After 6-Mo Exposure at 95 "C the Gas Phase (50X). Photo No. 87329A. 


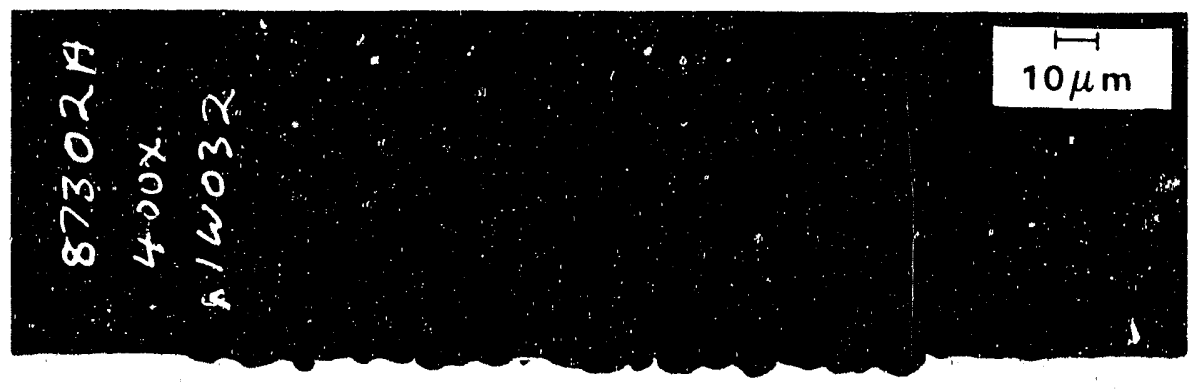

FIGURE 19. Surface Roughening on Specimen 1 W032 Exposed for 9 Mo in the Liquid-Gas Interface at $95^{\circ} \mathrm{C}$. Photo No. $87302 \mathrm{~A}$.

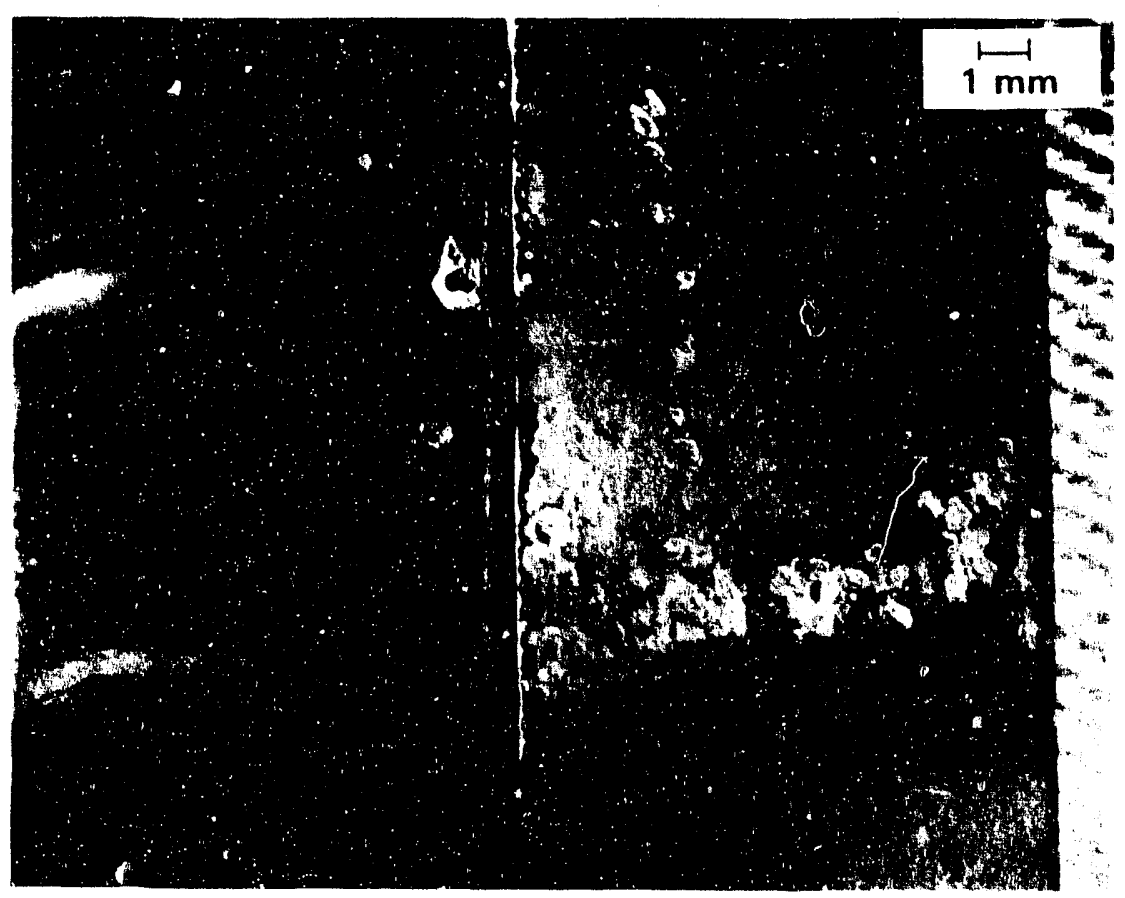

FIGURE 20. The Front Surface of CDA 715 Specimen 3 WOOB at the Liquid-Gas Interface Position (5X). (The gas phase is at the top. The oxide film was removed from the piece on the right side.) 


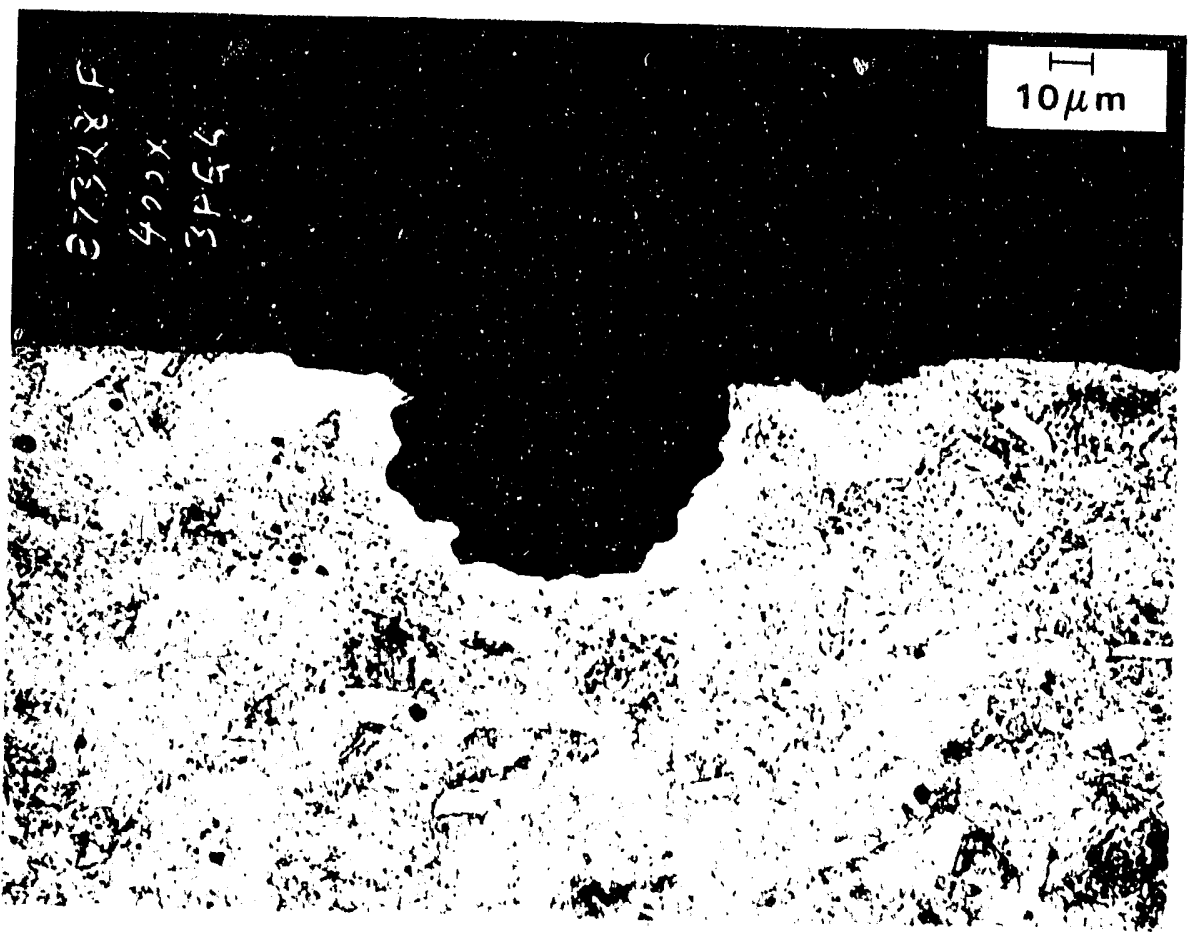

FIGURE 18. Surface Pitting of Electrochemically Prepitted CDA 715 Tear Drop Specimen After 6-Mo Exposure at $95^{\circ} \mathrm{C}$ in the Gas Phase (400X).
Photo No. $87328 \mathrm{~F}$.

oxide layer. There was extensive local corrosion of the interface region of the CDA 715 specimens that received 9-mo exposures. Figure 20 (page 127) shows an extensive crater formation. Figure 21 (87312E) shows the cross section of one crater and the grain structure of the underlying metal. The vertical dimension of the crater is about $25 \mu \mathrm{m}$. These corrosion features are comparable to those seen elsewhere on this alloy, reported below.

In summary, there is no enhanced local corrosion (e.g., metal thinning) at the interface of the gas and bulk water phases (i.e., beyond that observed on specimens totally immersed in either of the phases). Apparently the bulk water is efficient for buffering any acid picked up from the adjacent air phase as far as promoting extra corrosion is concerned. 
WHC-EP-0188

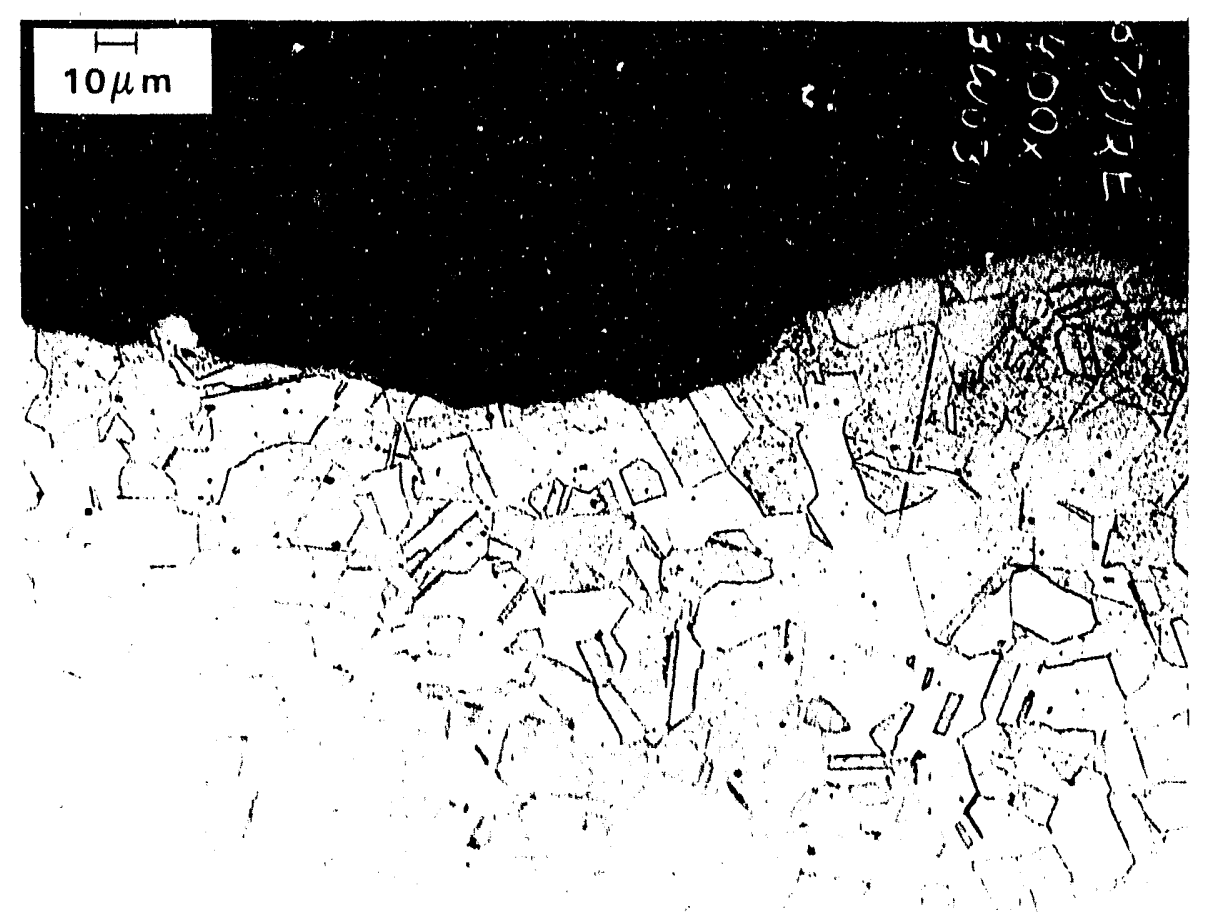

FIGURE 21. Section of Local Corrosion on Specimen 3w031 After 9-Mo Exposure in the Liquid-Gas Interface at $95{ }^{\circ} \mathrm{C}(400 \mathrm{X})$. Photo No. $87312 E$.

\subsubsection{Metallographic Examinations}

From their metallographic examinations, none of the other specimens (not prepitted or interface) showed evidence of subsurface corrosion or cracking. However, there were differences between the alloys in general surface roughness and in the nature of the pits or the local corrosion features.

On the CDA 101/102 specimens, the 150/G specimens showed areas of general surface roughening to a depth of about $5 \mu \mathrm{m}$ (Figure 22) (87301B). On the $95 / G$ specimens, both narrow pits (Figure 23) (87303A) and broad pits ( $80 \mu \mathrm{m}$ wide by $12 \mu \mathrm{m}$ deep) were seen. These showed adherent corrosion products over the pits. Specimens from the $95 / \mathrm{L}$ environment showed surface roughening of about $5 \mu \mathrm{m}$ in depth.

For the CDA $613 / 614$ specimens, isolated areas of roughness were seen (depths $<5 \mu \mathrm{m})$ on the $150 / G$ specimens. The $95 / G$ specimens, showed the most severe 


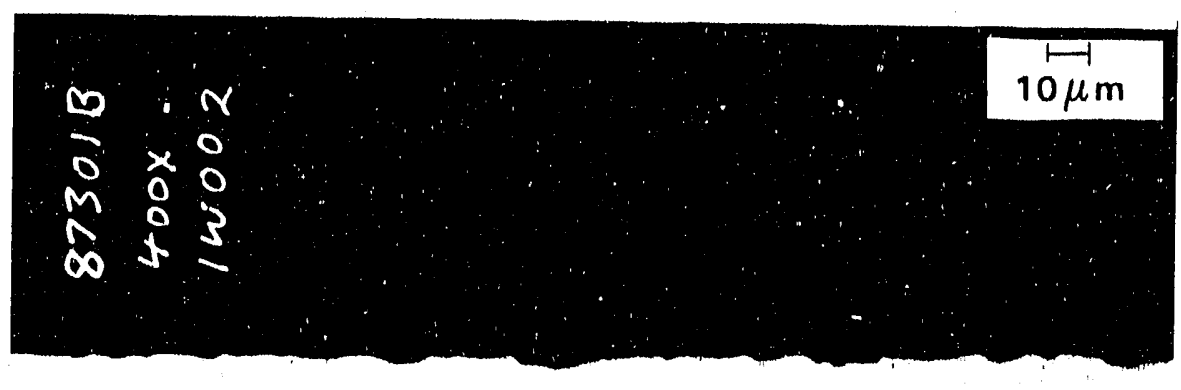

FIGURE 22. General Surface Roughening on Copper Specimen 1 w002 After 14-Mo Exposure in the Gas Phase at $450{ }^{\circ} \mathrm{C}(400 \mathrm{X})$. Photo No. $87301 \mathrm{~B}$.

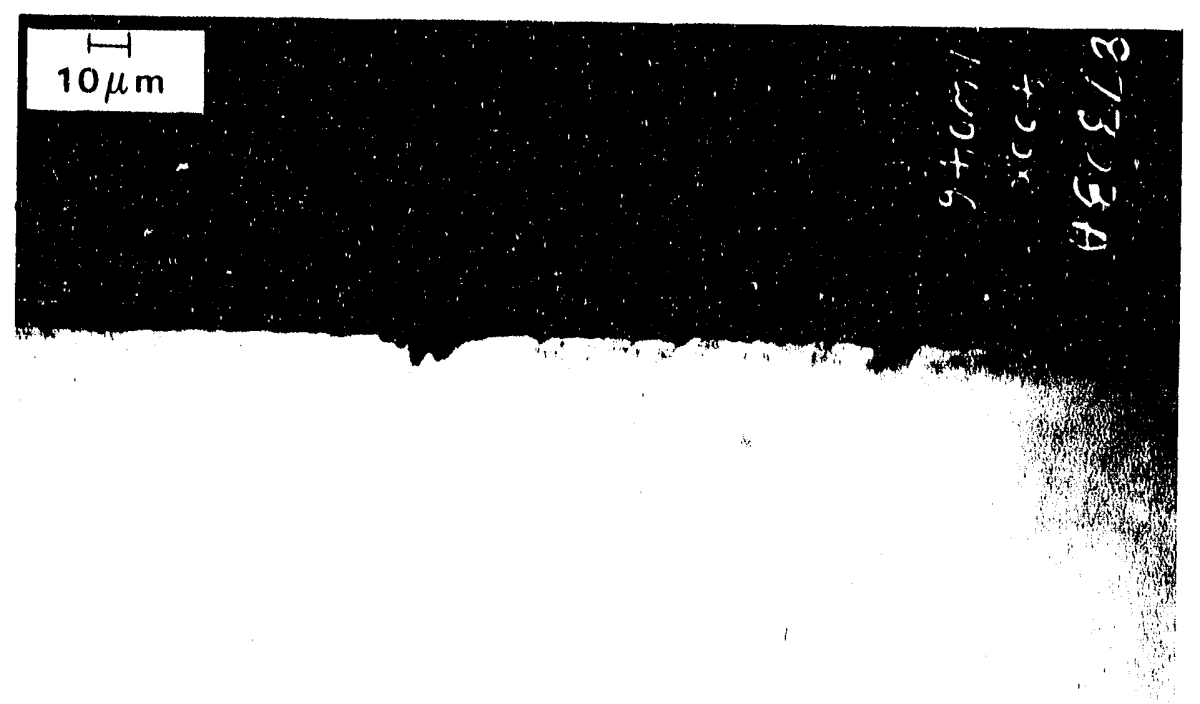

FIGURE 23. Pits in Copper Specimen 1 W046 From 4-Mo Exposure in the Gas Phase at $95{ }^{\circ} \mathrm{C}(100 \mathrm{x})$. Phóto No. $37303 \mathrm{~A}$. 
attack for this alloy. Both roughened surfaces (up to $100 \mu \mathrm{m}$ in depth) (Figure 24) (87306A) and adherent deposits of corrosion product over a roughened surface were seen. The $95 / \mathrm{L}$ exposed specimens had surface roughening of about $10 \mu \mathrm{m}$ and some areas with adherent corrosion products (Figure 25) (87308C) (about $375 \mu \mathrm{m}$ wide and $25 \mu \mathrm{m}$ deep).

On the CDA 715 specimens, the $150 / G$ pieces showed surface roughness of about $13 \mu \mathrm{m}$ and some isolated, broad pits. On the $95 / \mathrm{G}$ specimens, the surface roughness was about $40 \mu \mathrm{m}$ and considerable undercutting of the surface was seen (Figure 26) (873230). From 95/L specimens, roughness of about $15 \mu \mathrm{m}$ was seen and undercutting was also present. Broad pits also were seen (Figure 27) (87314B).

A broad, smooth and symmetrical deformation was observed on most of the specimens (Figure 28) (87301A), including uncorroded archive specimens. The metal grain structure under these features was also compressed and oriented in layers concentric to the curved surface. These apparently resulted from the specimen fabrication process and were not created in these experiments. In some cases, cracks were seen within the area of compressed metal (Figure 29) (87310E). These features would eventually disappear as the metal was corroded to deeper regions that are uniform. However, this suggests that future testing should includie articles that have been prototypically rolled, welded, extruded, or otherwise deformed for a major fraction of the wall thickness. Corrosion behavior in these areas may well be different from that on uniform material specimens.

\subsubsection{Visual Observations}

Results of all of the visual observations are shown in the data base (Appendix A), along with an explanation of the descriptors used. Detailed descriptions of the specimens that were examined early in the program are in the appendix of Reference 3. As an aid for comparing the corrosion behaviors of the three alloys in the three corrosion environments, the data base was sorted for the incidence of the descriptors for visually observed: 1) pits 
WHC-EP- 0188

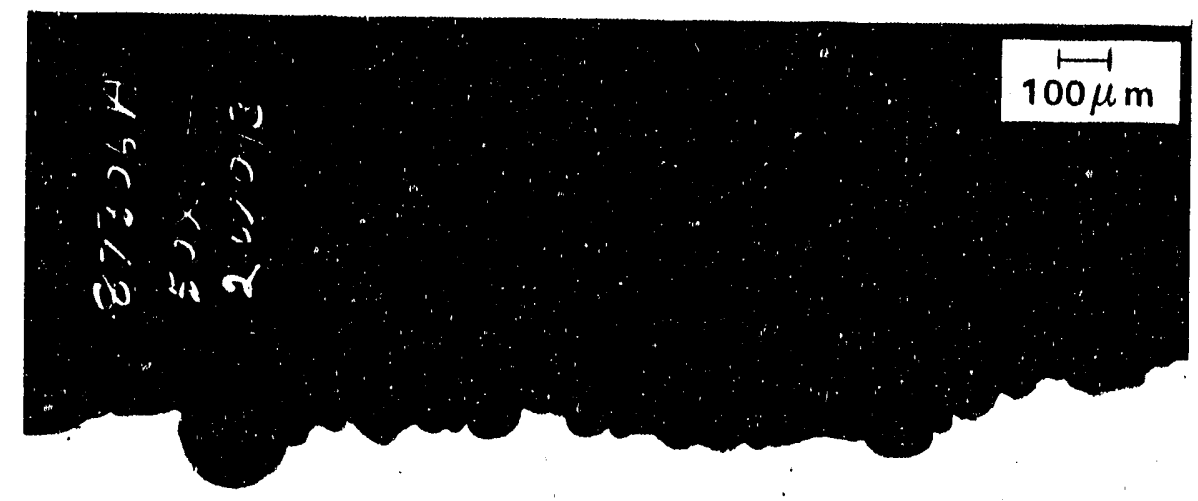

FIGURE 24. Corrosion Surface of CDA 613 Specimen 2W013 From 13-Mo Gas Phase Exposure at $95^{\circ} \mathrm{C}(50 \mathrm{X})$. Photo No. $87306 \mathrm{~A}$.

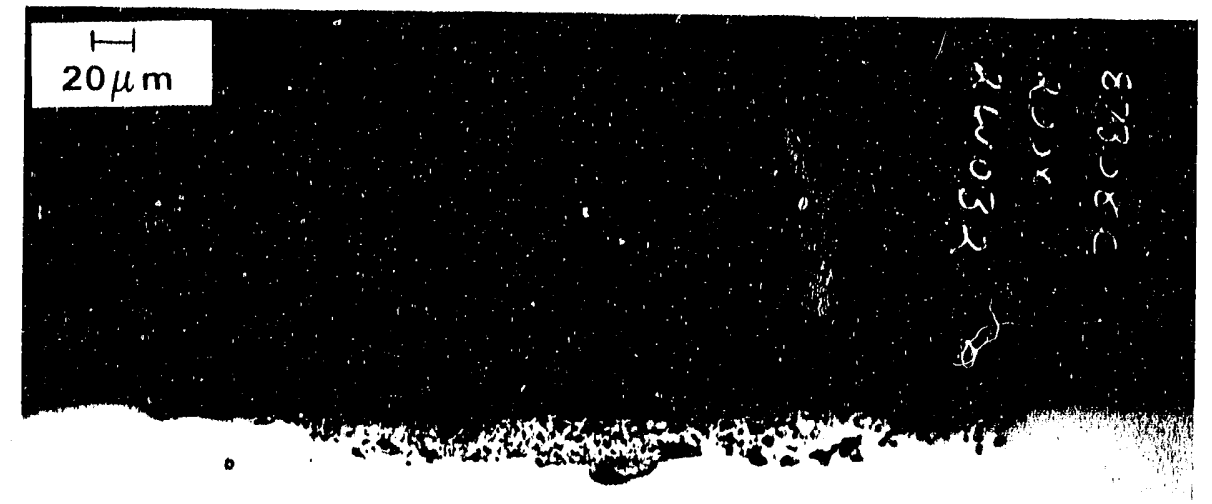

FIGURE 25. Adherent Corrosion Product on CDA 613 Specimen 2W032 After 7-Mo Exposure in Liquid Water at $95^{\circ} \mathrm{C}(200 \mathrm{X})$. Photo No. $87308 \mathrm{C}$. 


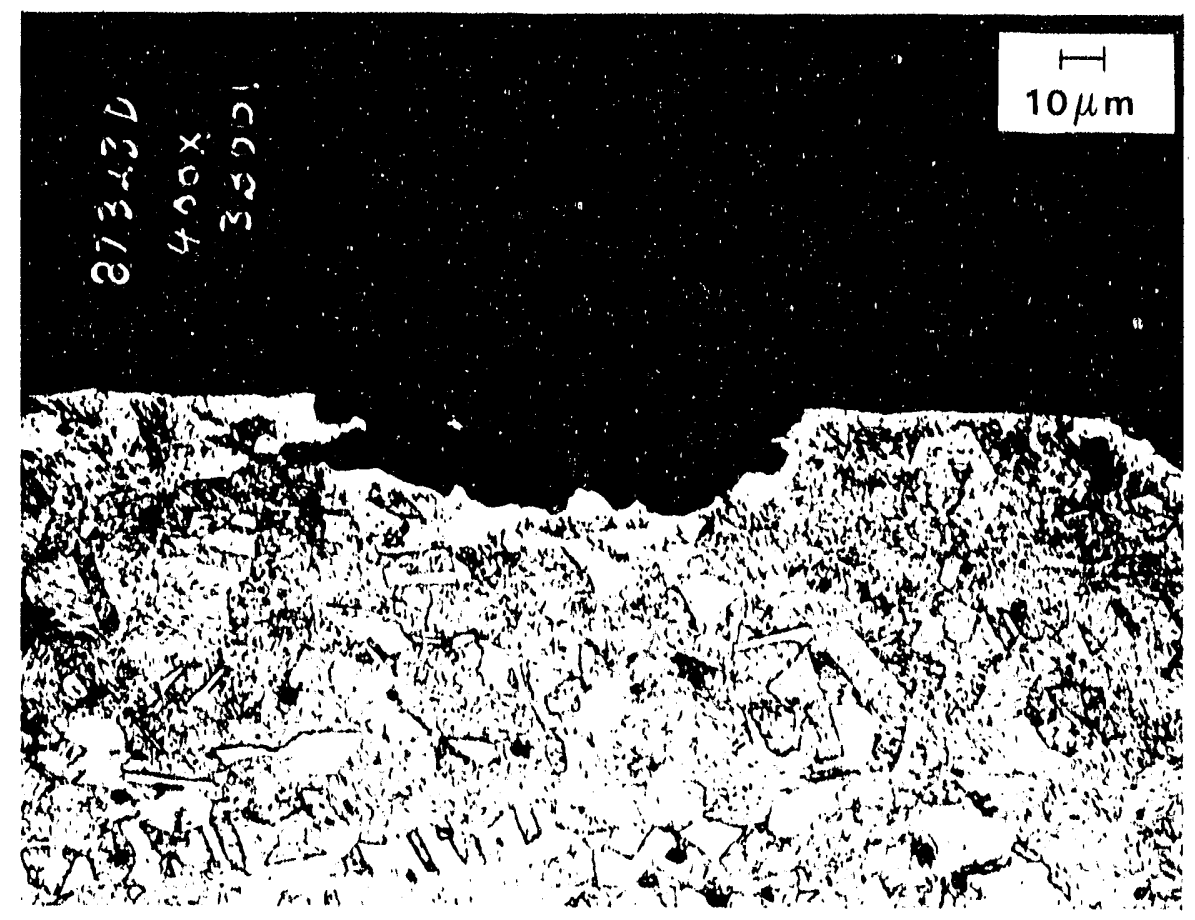

Figure 26. Pit Formed on CDA 715 Specimen 3B001 During 13-Mo Exposure in the Gas Phase at $95{ }^{\circ} \mathrm{C}$. [Note undercut at left side of pit (400X)]. Phot.o No. 87323D.

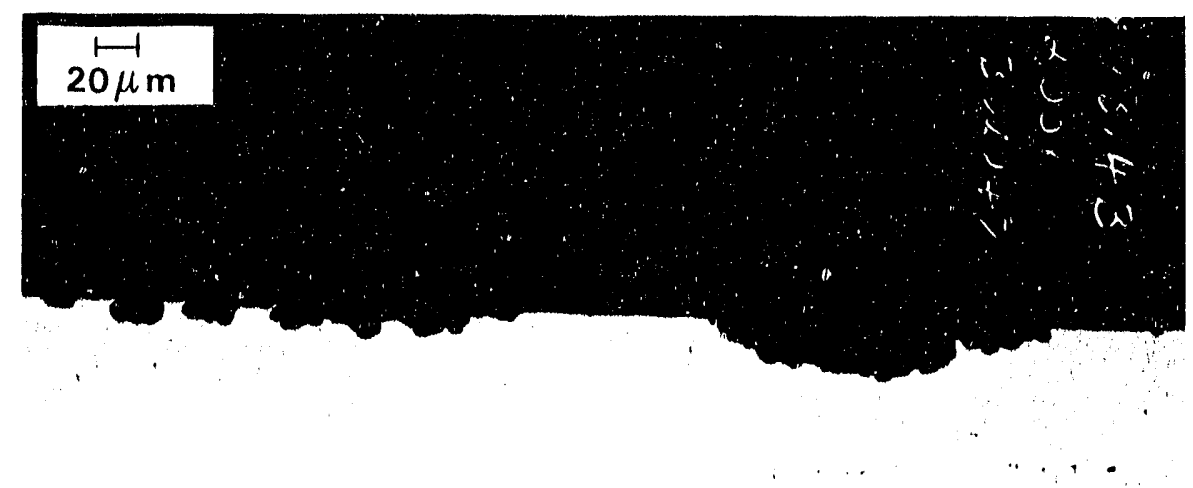

FIGURE 27. Broad Pit and Surface Roughening of Specimen 3W047 After 9-Mo Fxposure in Liquid Water at $95{ }^{\circ} \mathrm{C}(200 \mathrm{X})$. Photo No. $87314 \mathrm{~B}$. 


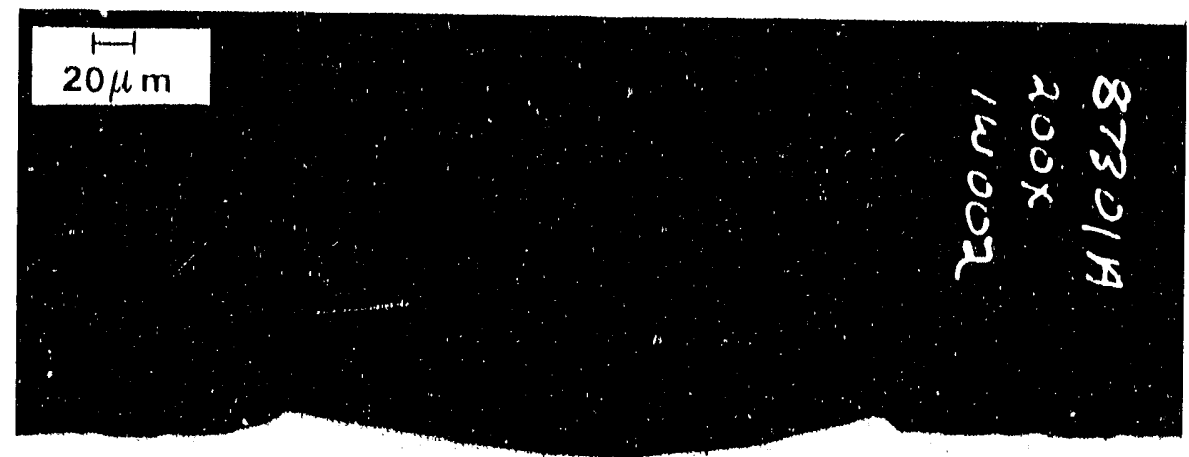

FIGURE 28. Broad Surface Deformations Seen on Most Specimens With and Without Corrosion Exposures (200X). Photo No. 87301A.

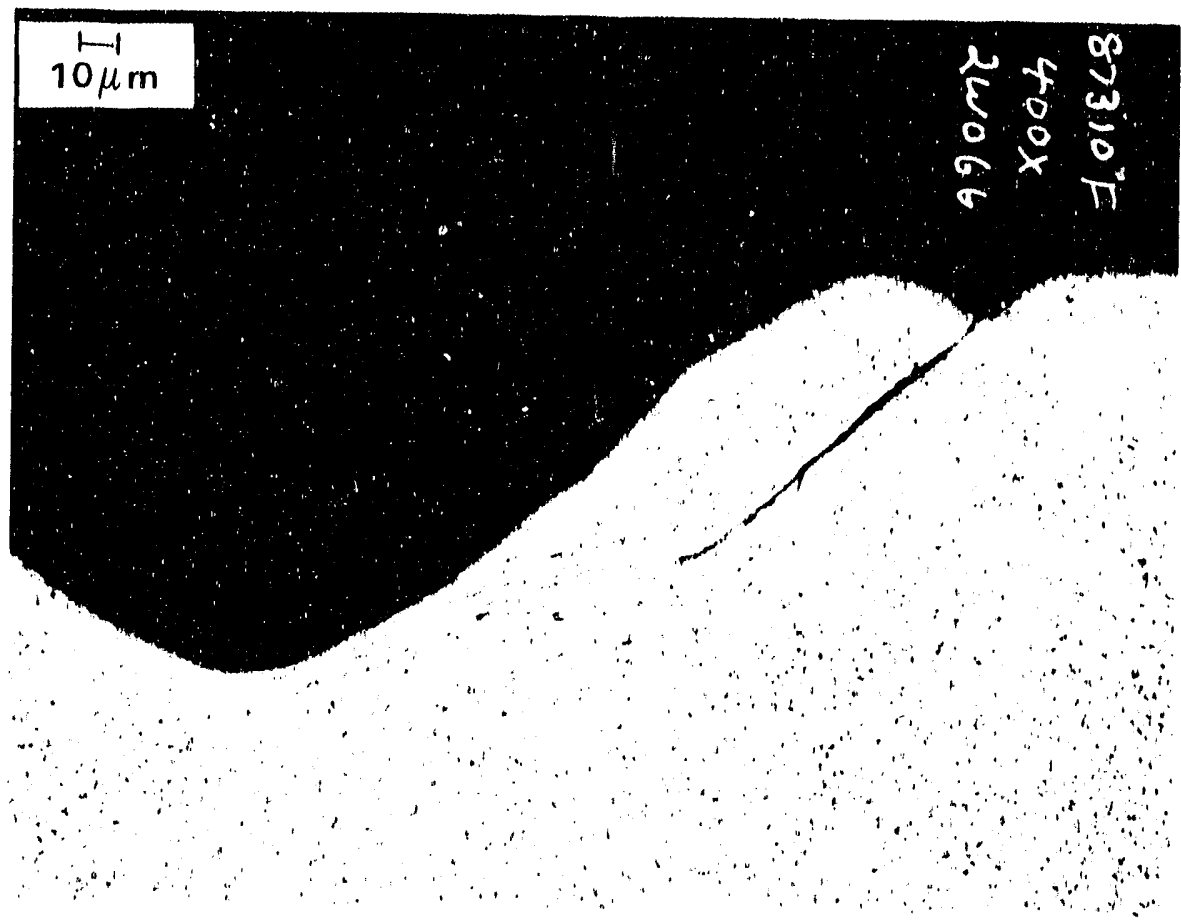

FIGURE 29. Surface Crack Associated with Compression Deformation of Specimen that Occurred Prior to Corrosion Experiments (400X). Photo No. 87310E. 
(PT); 2) local corroston (LC); 3) ffllform-l the features (FL); 4) no features (NF) or clear surface (CL.); and 5) mosatc pattern (MP). Crevice, interface, and prepitted specimens were not included. Full 1 istings of the results are shown in Appendtx B. The numbers of occurrences of each feature are summartzed in Table 12 as the percentages of the number of specimens in each category in each specimen/exposuremenvironment subgroup. The varlous feature types are assumed to occur as independent events. This comparison suggests that the CDA 101/102 matertal may have a more favorable corrosion behavior than the other matertals from the standpotnt of local corroston.

While filiform-like corrosion was seen th the metal surface of the aluminum bronze, only a similar etched pattern was seen on the surface of the nickel alloy. The severe metal surface corrosion, seen on the nickel alloy and designated as MP, mosaic pattern, appears similar to an engraved relief pattern of parallel, but staggered, closely packed dash marks. This occurred mostly on the $95 / G$ spectmens and may be related to the greater spread that was found in the general corrosion rate data, discussed below.

Also, a review was made of the results from the very low-flux, $\left(-3 \times 10^{3} \mathrm{R} / \mathrm{h}\right)$ specimens that had received 3.5 mo of exposure. On the CDA 101/102 specimens, the only corrosion feature seen was crevice corrosion starting around the edges of the $95 / \mathrm{L}$ exposed crevice specimens. There was a significant difference in the metal-oxygen ratio in the oxide layer, however. The metal oxide ratio of the three $95 / G$ specimens averaged 1.34 , white the three $95 / \mathrm{L}$. specimens averaged 0.86 . For the CDA $613 / 614$ specimens, all of the local corrosion features seen at higher flux levels and longer exposure times were seen on these specimens. The metal-oxygen ratios in the corrosion layer were nearly the same, 0.81 for the $95 / \mathrm{L}$ exposed specimens, and 0.98 for those exposed at $95 / \mathrm{G}$. On the CDA 715 specimens, a variety of local corroston features resulted from the $95 /$ G environment. Crevice corrosion was found on the crevice specimens from the $95 /$. environment. Again the metal-oxygen ratios were nearly the sane for the $95 / \mathrm{G}$ exposures $(0.91)$ as for the $95 / \mathrm{L}(0.84)$. 
TABLE 12

PERCENTAGE OF VISUALLY OBSERVED CORROSION FEATURES

\begin{tabular}{|c|c|c|c|c|}
\hline \multirow[t]{2}{*}{ Feature } & \multirow{2}{*}{$\begin{array}{l}\text { Matertal } \\
\text { CDA No. }\end{array}$} & \multicolumn{3}{|c|}{ Envitronment } \\
\hline & & $150 / G$ & $95 / G$ & 95/L \\
\hline $\begin{array}{l}C L \\
\text { or } \\
N F\end{array}$ & $\begin{array}{l}101 / 102 \\
613 / 614 \\
715\end{array}$ & $\begin{array}{l}69 . \\
34 . \\
42 .\end{array}$ & $\begin{array}{r}21 . \\
0 . \\
12 .\end{array}$ & $\begin{array}{r}38 \\
5 \\
14\end{array}$ \\
\hline LC & $\begin{array}{l}101 / 102 \\
613 / 614 \\
715\end{array}$ & $\begin{array}{r}11 . \\
9 \\
3 .\end{array}$ & $\begin{array}{l}24 . \\
53 . \\
79 .\end{array}$ & $\begin{array}{l}10 \\
33 \\
62\end{array}$ \\
\hline $\mathrm{PT}$ & $\begin{array}{l}101 / 102 \\
613 / 614 \\
715\end{array}$ & $\begin{array}{l}23 . \\
46 . \\
25 .\end{array}$ & $\begin{array}{l}55 . \\
59 . \\
42 .\end{array}$ & $\begin{array}{l}29 . \\
86 . \\
19 .\end{array}$ \\
\hline$F L$ & $\begin{array}{l}101 / 102 \\
613 / 614 \\
715\end{array}$ & $\begin{array}{l}0 . \\
0 .\end{array}$ & $\begin{array}{c}\text { none } \\
34 . \\
6 .\end{array}$ & $\begin{array}{l}5 . \\
0 .\end{array}$ \\
\hline MP & $\begin{array}{l}101 / 102 \\
613 / 614 \\
715\end{array}$ & 3. & $\begin{array}{c}\text { none } \\
\text { none } \\
24 .\end{array}$ & 5. \\
\hline
\end{tabular}

\subsubsection{General Corroston (Weight Loss)}

The amount and average rates of metal corrosion and oxide growth were determined from the measured weight changes of the flat, rectangular (weight loss) spectmens. These values are given in the data base (Appendix $A$ ) and are plotted in Figures 30 through 38. The visual examination of these specimens, before the oxtde fflm was removed, showed that the corrosion was not at all uniform over the surface of the specimens. Also, crevice corrosion found around some of the support washers likely biased the results. 


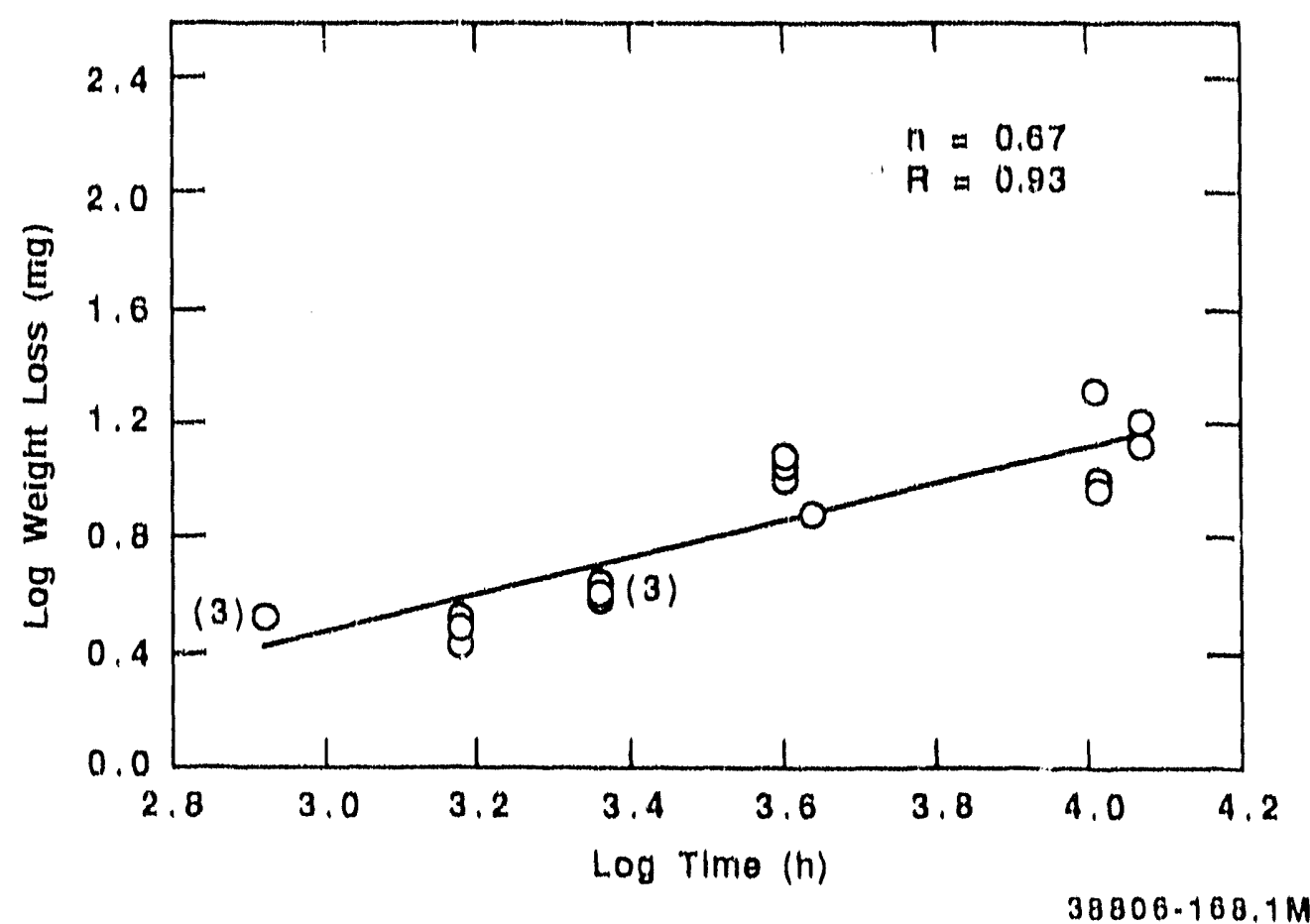

FIGURE 30. CDA $101 / 102$ Corroston at $150^{\circ} \mathrm{C}$ in the Gas Phase.

NOTE: The following information appltes to figures 30 through 38.

$(n)=$ multiple data points for one symbol or closely grouped symbols.

$4.0=$ nominal gamma radiation flux $\times 10^{-5} \mathrm{R} / \mathrm{h}$ in Figures 31,34 and 37.

$n=$ slope of curve - Equation (1) in text.

$R=$ Correlation coeffictent from inear regression.

+ - Data point not used in linear regression in Figures 32, 35 and 38 . 


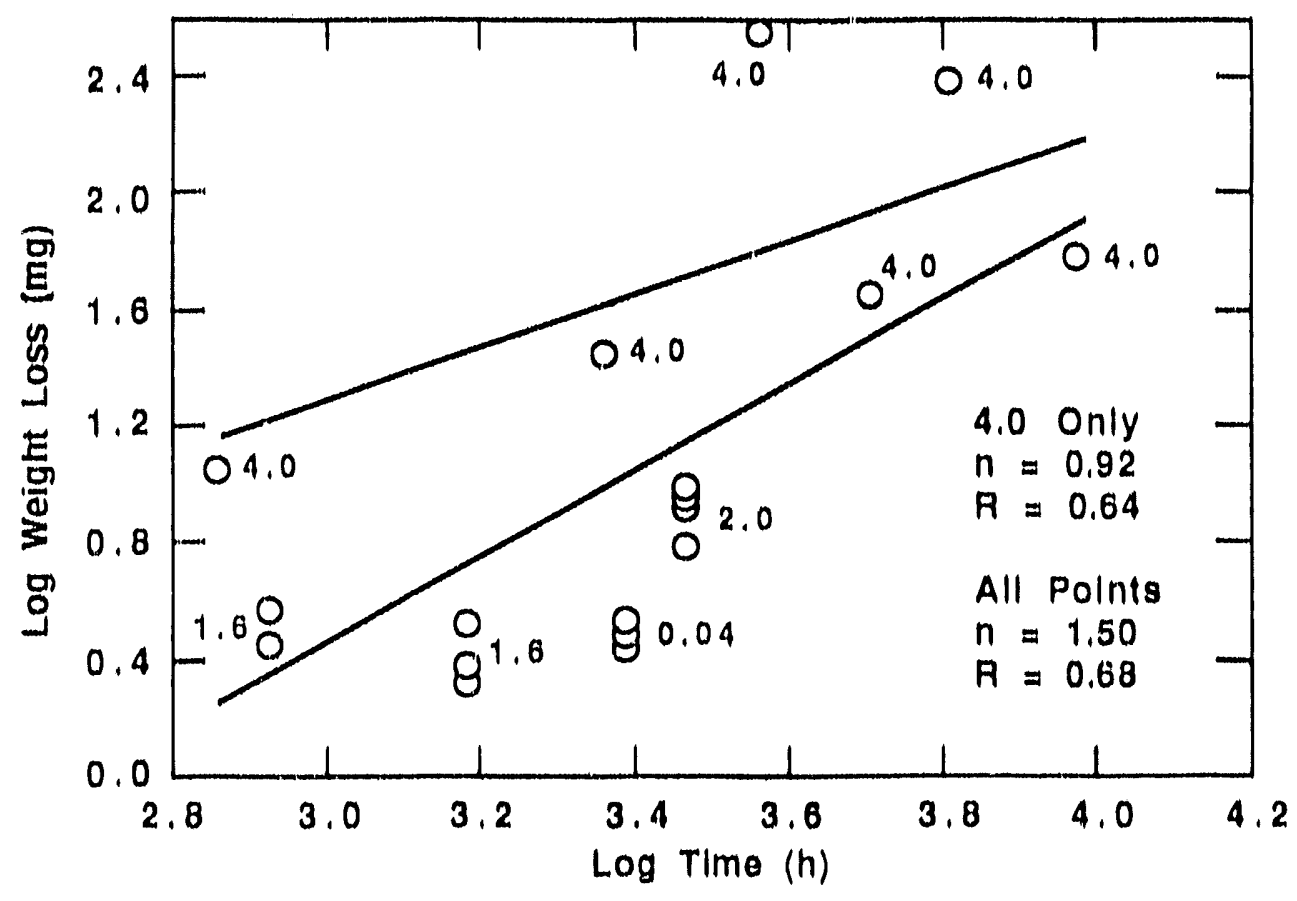

FIGURE 31. CDA 101/102 Corroston at $95{ }^{\circ} \mathrm{C}$ in the Gas Phase. (See Note with Figure 30.)

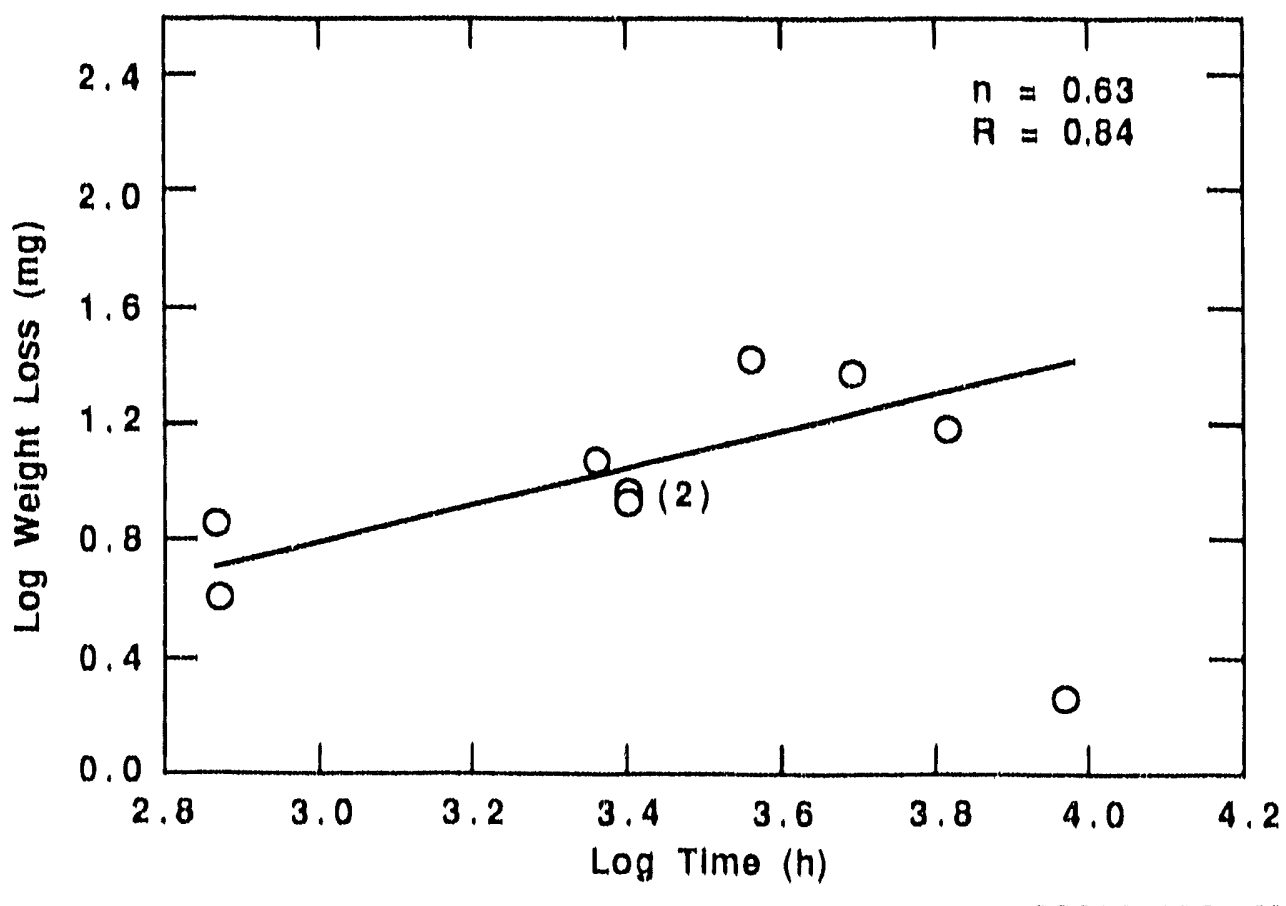

FIGURE 32, CDA $101 / 102$ Corroston at $95{ }^{\circ} \mathrm{C}$ in the liquid Phase. (See Note with Figure 30.) 


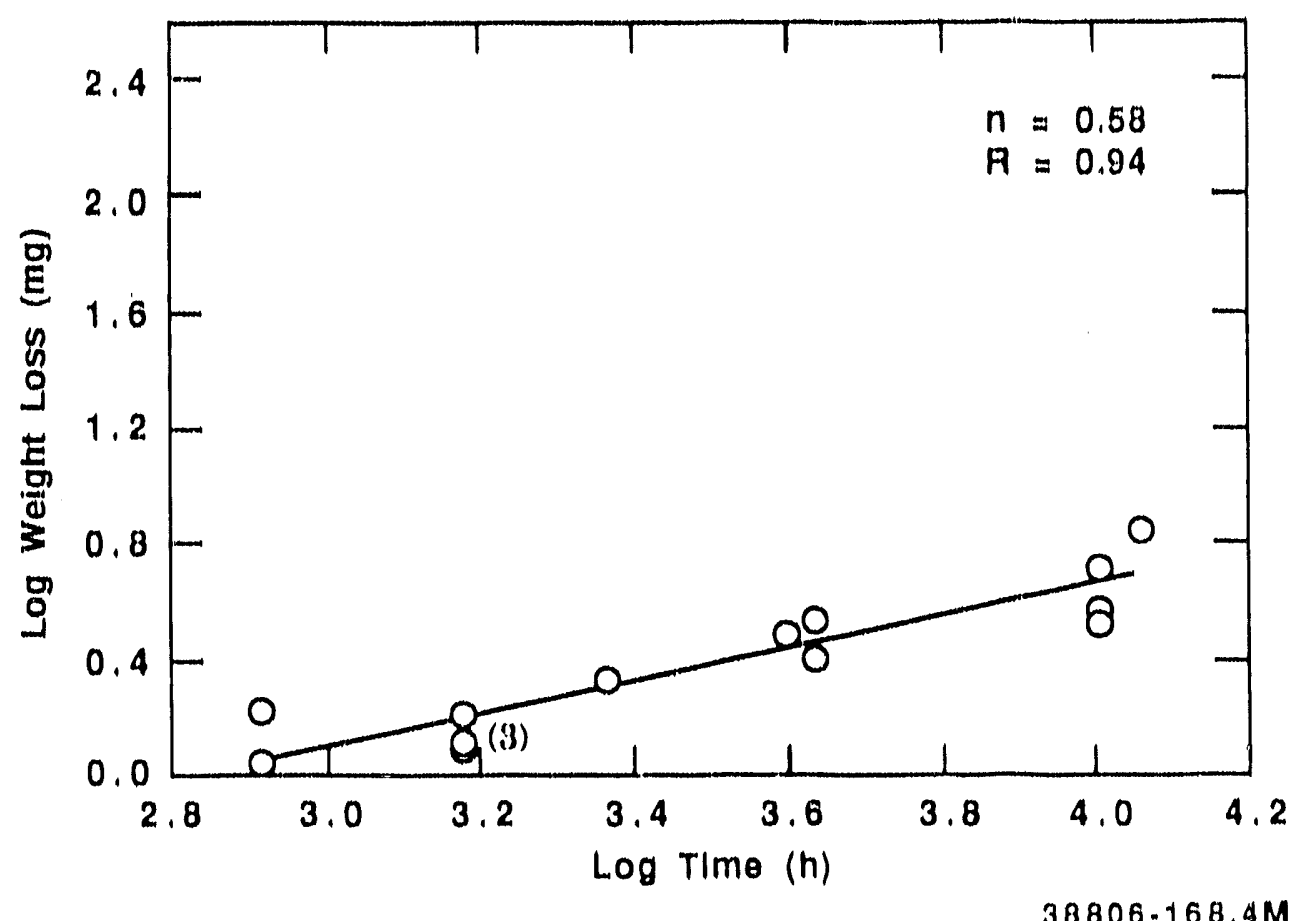

FIGURE 33. CDA 613/614 Corrosion at $150{ }^{\circ} \mathrm{C}$ in the Gas Phaso. (See Note with Figure 30.)

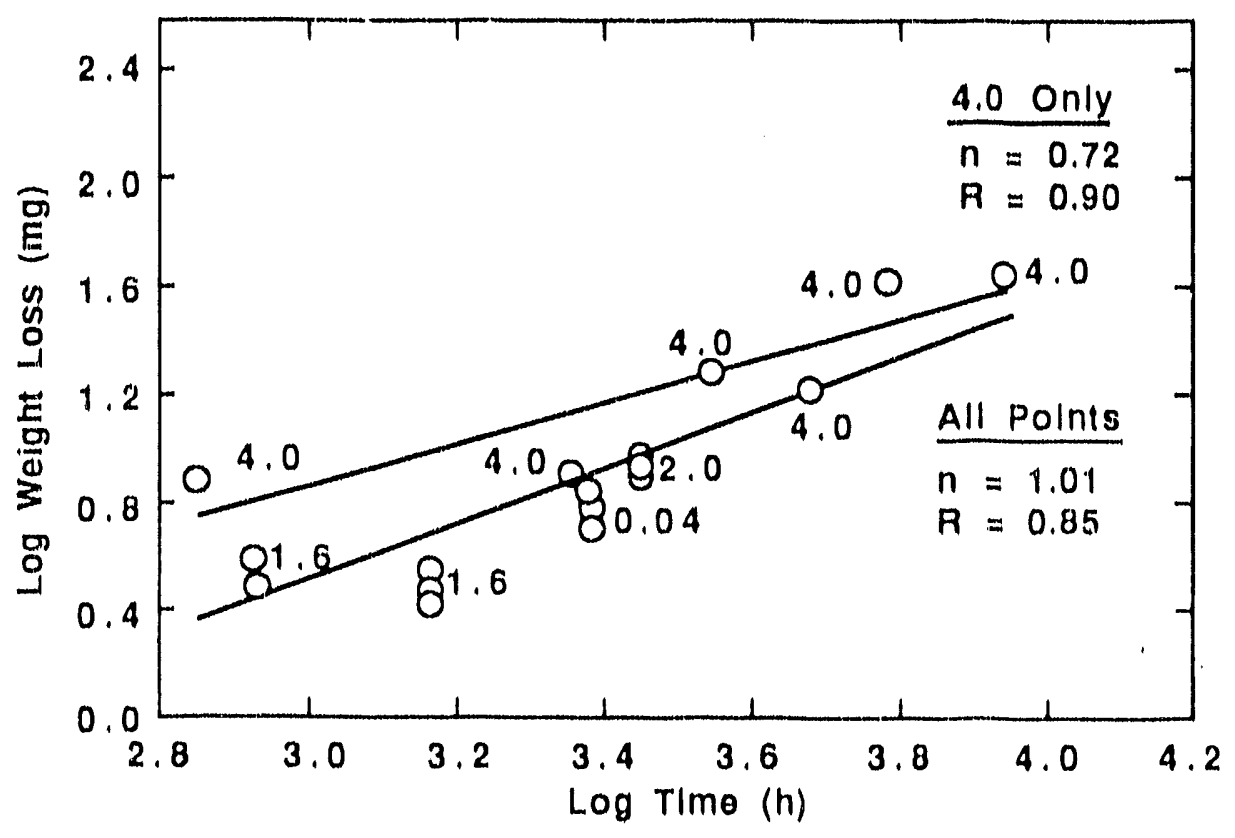

$38806 \cdot 168.5 \mathrm{M}$

Figure 34. CDA 613/614 Corrosion at $95^{\circ} \mathrm{C}$ in the Gas Piase. (See Note with Figure 30.) 


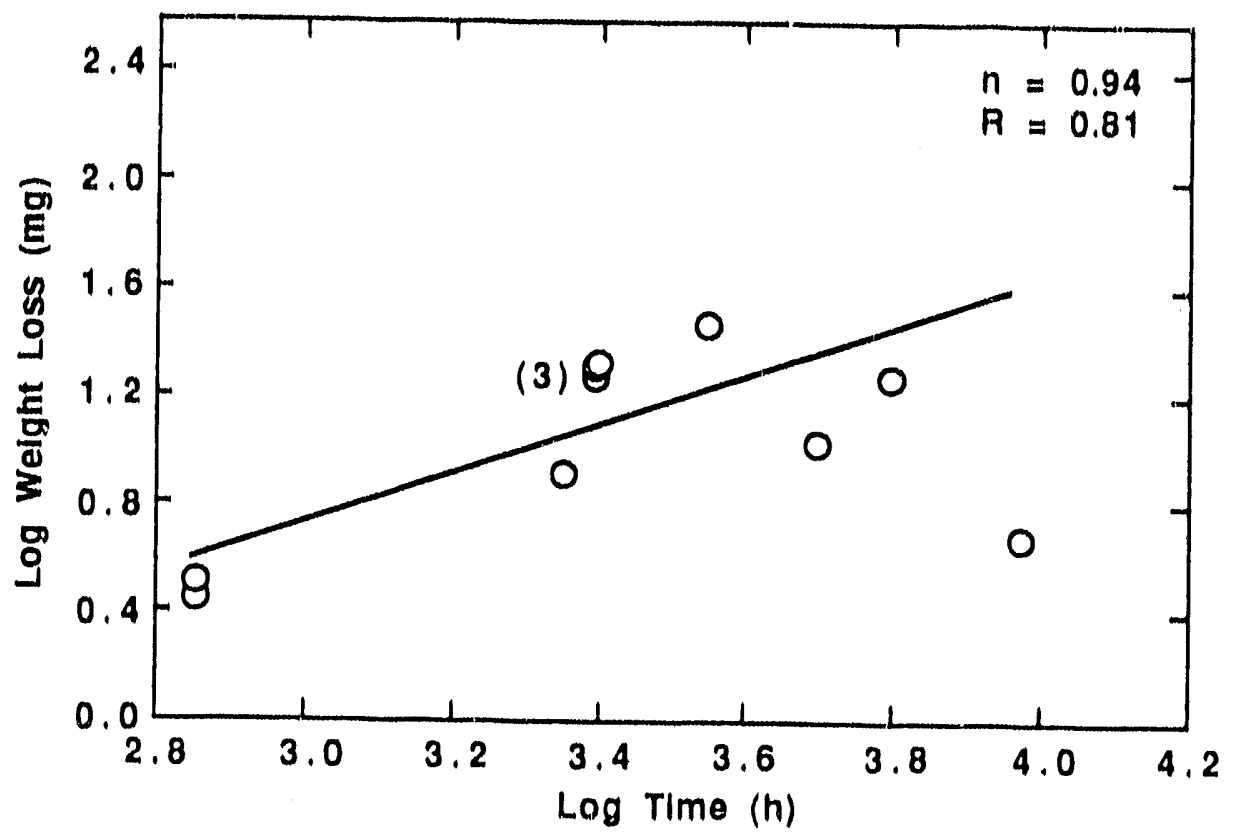

$38806 \cdot 168.6 \mathrm{M}$

FIGURE 35, CDA 613/614 Corrosion at $95{ }^{\circ} \mathrm{C}$ in the Liquid Phase. (See Note with Figure 30. )

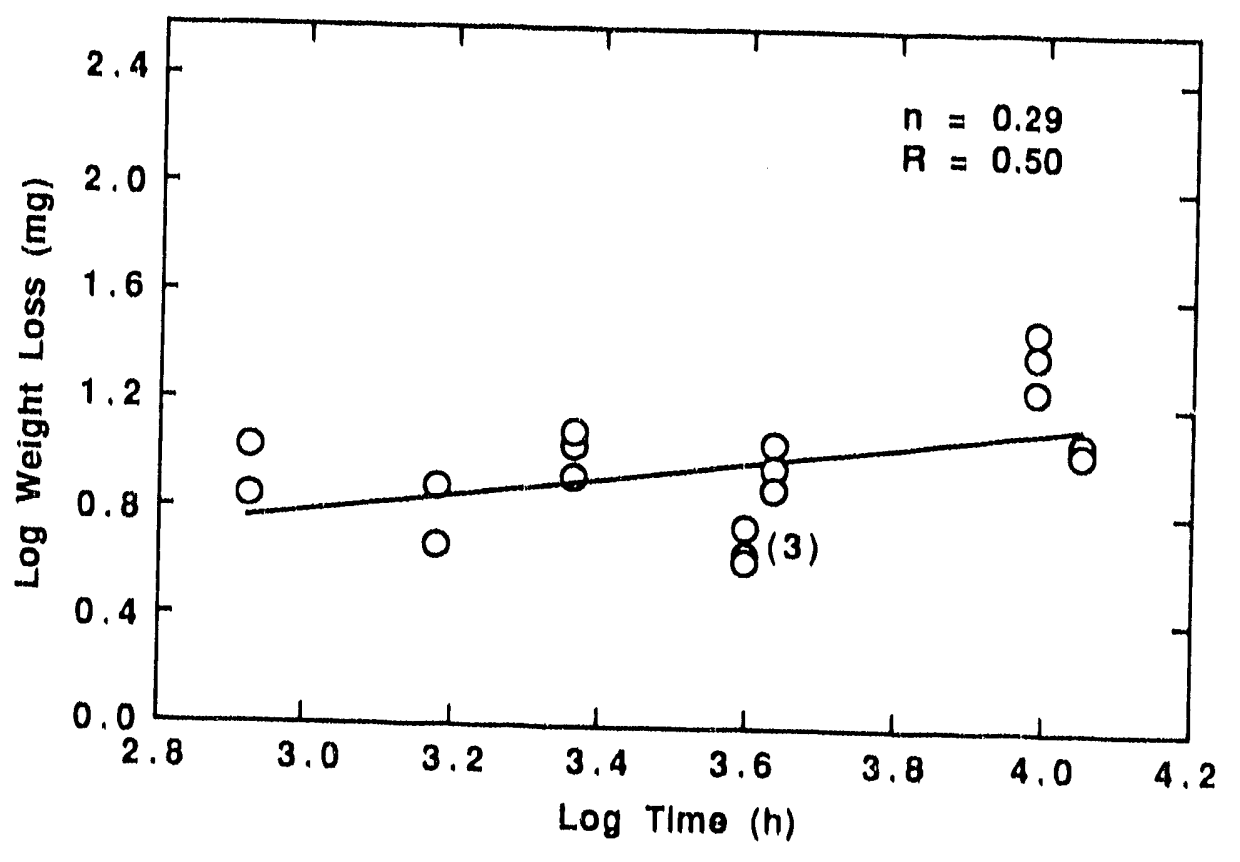

$38806 \cdot 168.7 M$

FIGURE 36. CDA 715 Corrosion at $150{ }^{\circ} \mathrm{C}$ in the Gas Phase. (See Note with Figure 30. ) 


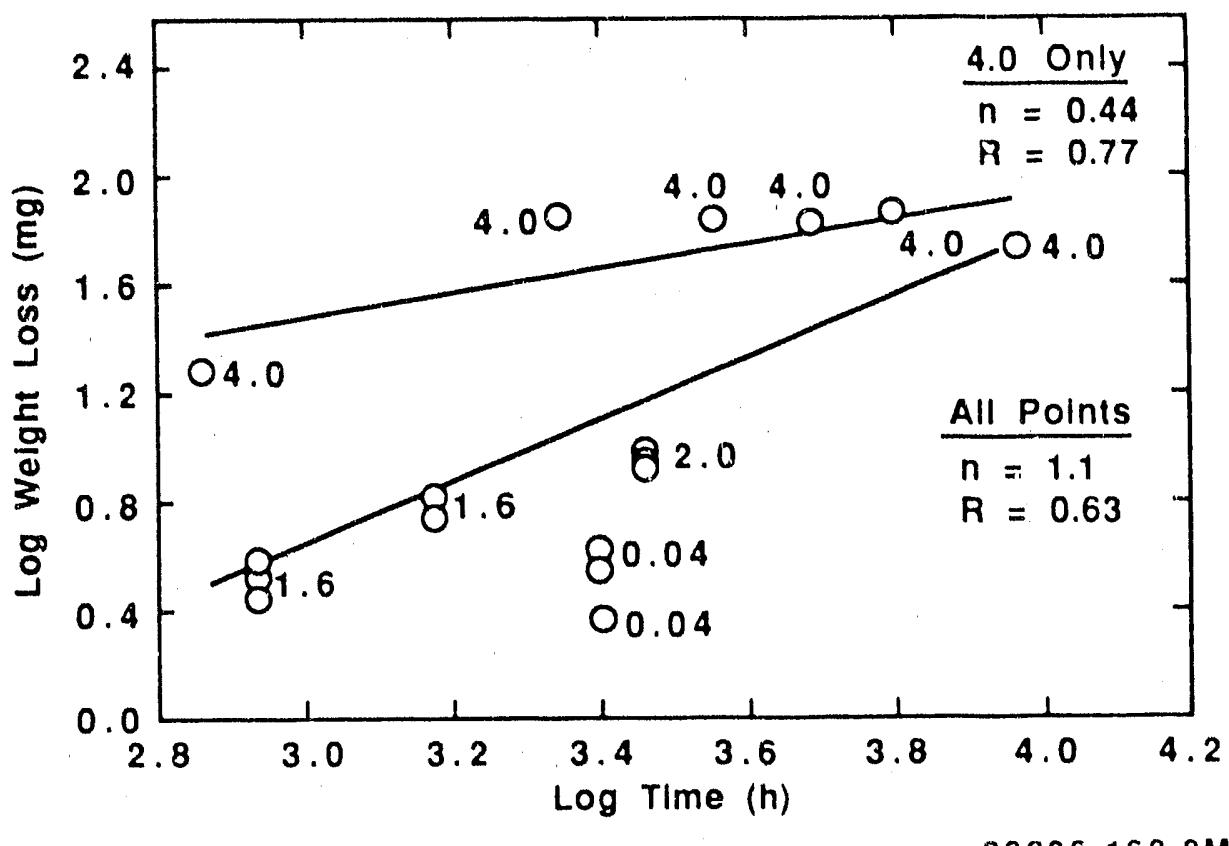

FIGURE 37 . CDA 715 Corrosion at $95{ }^{\circ} \mathrm{C}$ in the Gas Phase.

(See Note with Figure 30.)

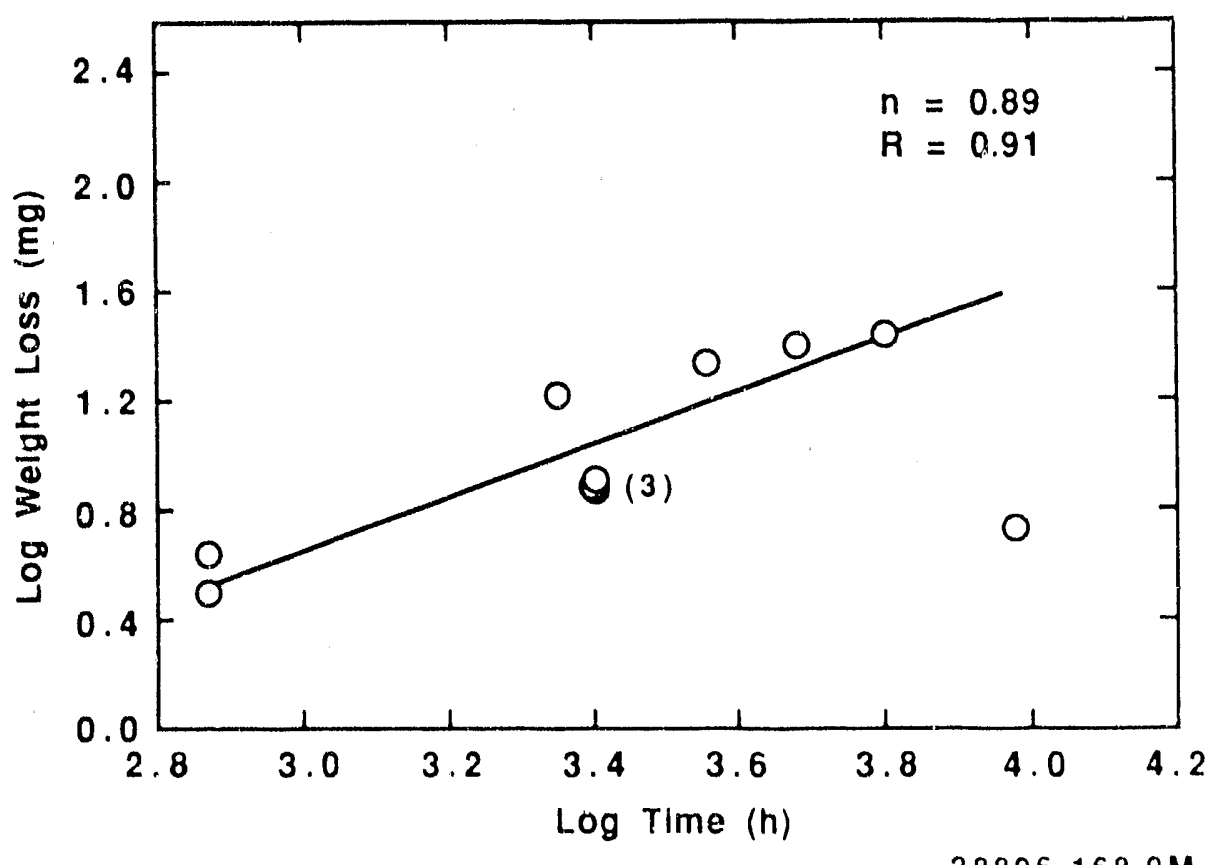

FIGURE 38. CDA 715 Corrosion at $95{ }^{\circ} \mathrm{C}$ in the Liquid Phase. (See Note with Fiqure 30.) 
From the equation:

$$
W=k t^{n}+c
$$

where:

$$
\begin{aligned}
& W=\text { Weight lost by a specimen per unit area } \\
& t=\text { Time } \\
& k \text { and } C \text { are constants, }
\end{aligned}
$$

the order of the time dependency of the corrosion process ( $n$ ) can be examined from a plot of $\log W$ vs. $\log t$. A value of $n=1$ indicates a linear process while $n=1 / 2$ indicates a parabolic process. A linear regression analysis was used to estimate the value of " $n$ " for each of the data subsets. These values and the correlation coefficients " $R$ ". are also shown in the figures. In general, the agreement of replicate values within each subset is considerably better than between adjacent subsets. Thus, the data scatter appears to be related to the corrosion process or subtle environment differences rather than to the methods of measurement.

No effect of radiation level could be seen in the data subsets from the $150 / G$ and $95 / \mathrm{L}$ environments. However, in the data subsets from the $95 / G$ environmeints, a general trend appears of increased corrosion with gamma radiation flux. The general data scatter and lack of data at intermediate exposures preclude assignment of a quantitative value to this effect. For these cases, a second linear regression analysis was made of the maximum flux data only.

\subsection{OXIDE LAYERS}

The third area of examination is the nature and composition of the oxide layers that formed on the various materials and under the different conditions. This information supplements the metal damage results by providing insight into how the corrosion process occurs and what changes might occur in the process with time and changes in the environment. The methods used were visual examination, calculation of the metal-oxygen ratio, Auger electron spectroscupy, and $x$-ray diffraction. 


\subsubsection{Visual}

The oxide layers on the CDA $101 / 102$ and CDA 613/614 specimens were generally tight and adherent. However, on some CDA 101/102 specimens, there were areas where the oxide dissolved much more slowly in the hydrochloric acid solution than was normal, indicating that the oxide structure was not uniform. The layer of oxide on CDA 715 appeared much heavier than on the other materials and had a flat black surface. The oxide on the $95 / G$ exposed specimens was often covered with many small craters. Apparently small pieces of the oxide layer break loose from time to time. This may be related to the unusual mosaic pattern also seen on these specimens, as previously discussed.

\subsubsection{Metal-Oxygen Ratios}

Values of weight-of-metal-lost divided by net-weight-gained and multiplied by the atomic weight ratio give the metal-oxygen ratio (M/O). These were calculated for the general corrosion (weight loss) specimens. Values are given in Appendix $A$ and summarized in Table 13. These values can indicate the internal consistency of the data and differences in compositions of the oxide layers in the different environments.

Since the layers were too thin to quantitatively separate from the base metal, the metal compositions of the CDA $613 / 614$ and CDA 715 oxides were not determined and were assumed to contain only copper and oxygen. The ratios for the pure copper CDA 101/102, however, show the average stoichiometry of the oxide layer and can be compared with those estimated from $X$-ray diffraction and Auger electron spectroscopy results.

The oxide formed on CDA $101 / 102$ exposed at 150/G appears to be $\mathrm{Cu}_{2} 0$ compared with the cuo formed on the ones exposed in the $95 / L$ phase. The oxide on the specimens exposed to $95 / G$ may be mixed phases. The oxides formed on the other materials appear to be about the same, regardless of the reaction phase. 
TABLE 13

SUMMARY OF METAL-OXYGEN RATIOS IN CORROSION LAYERS

\section{Corrosion \\ Conditions}

$150 / G$

$95 / G$

$95 / 1$

Overall

\section{CDA $101 / 10 ?$}

$2.02 \pm 0.31 *$ $2.3 * \star$

$1.63 \pm 0.28$

$0.94 \pm 0.46$

$1.74 \pm 0.71$

Materials

CDA $613 / 614$

$1.06 \pm 0.28$

$0.94 \pm 0.20$

$0.80 \pm 0.13$

$0.74 \pm 0.34$

$1.06 \pm 0.56$

CDA 715

$0.99 \pm 0.18$

$0.99 \pm 0.44$

$0.93 \pm 0.31$

* Standard deviation.

**From Auger electron spectrometry data.

NOTE: In all calculations, copper was assumed to be the only metal present.

\subsubsection{X-ray Diffraction}

$x$-ray diffraction was used for specific identification of the oxide phases in the corrosion layers. Lawrence Livermore National Laboratory examined 22 thin films from 1 -no and 3-mo exposed specimens. (3) Westinghouse Hanford Company examined 18 oxides from specimens that had 5-mo to 16-mo exposures. Most of the Westinghouse Hanford Company work was on powdered samples scraped from the metal specimens in order to eliminate the spectra from the base metal and to remove possible crystal orientation effects. Spectra of the base metals were also made to aid in resolving lines due to the base alloys. Most of the $x$-ray diffraction samples were taken from the outside surfaces of crevice specimens. Results are summarized in Table 14.

Both $\mathrm{Cu}_{2} \mathrm{O}$ and $\mathrm{CuO}$ phases were identified on all samples except the following. Only CuO was found on the CDA 614 specimens exposed in a $95 / L$ environment and on CDA 715 from the $95 / G$ environment. The identification of $\mathrm{Cu}_{2} \mathrm{O}$ on CDA 614 
TABLE 14

SUMMARY OF X-RAY DIFFRACTION RESULTS:

OXIDE PHASES IDENTIFIED

\section{Materials}

Corrosion
Conditions

$150 / G$

$95 / G$

$95 / L$
CDA $101 / 102$

$16: \mathrm{Cu}_{2} \mathrm{O}, \mathrm{CuO}$

$8 \mathrm{P}: \mathrm{Cu}_{2} \mathrm{O}, \mathrm{CuO}$

$5 P: \mathrm{Cu}_{2} \mathrm{O}$

5P:CurO, CuO
CDA 613/614

$16: \mathrm{Cu}_{2} \mathrm{O}(?), \mathrm{CuO}$ 16P: $\mathrm{Cu}_{2} \mathrm{O}, \mathrm{CuO}$

$8: \mathrm{Cu}_{2} \mathrm{O}(?), \mathrm{CuO}$

8P:CUO

5:CuO
CDA 715

$16: \mathrm{Cu}_{2} \mathrm{O}, \mathrm{CuO}$

16P: $\mathrm{Cu}_{2} \mathrm{O}, \mathrm{CuO}$ $\left(\mathrm{Cu}_{0.2} \mathrm{Ni} 0.8\right) \mathrm{O}$

8:C40

$5: \mathrm{Cu}_{2} \mathrm{O}, \mathrm{CuO}$

NOTE: The number starting each entry is the number of months of corrosion for that specimen. The "p" designates that the $x$-ray diffraction sample was on the metal plate. Other samples were powders, scraped from the metal plate.

from the $95 / G$ environment is in question. Of particular interest was the identification of $\left(\mathrm{Cu}_{0.2} \mathrm{Ni} 0.8\right) 0$ phase on the CDA 715 specimen that had received an $150 / G / 16$ exposure.

\subsubsection{Auger Electron Spectroscopy}

All of the Auger electron spectroscopy results have been reported. (3) Some of these are repeated here for emphasis and to update some of the previous interpretations. While the profiles of atomic composition vs, depth in the oxide layers differed between specimens, the most interesting results are shown in Figures 39 and 40 . The very thin corrosion films show a layered oxide structure that has different compositions. The profile in a thin film on an exposed CDA 613 specimen (Figure 39) shows an aluminum-rich layer positionea between the copper oxide and the base metal. The profiles of an oxide film on exposed CDA 715 (Figure 40) show a layer high in nickel content over a layer relatively high in copper content. How these layers are 


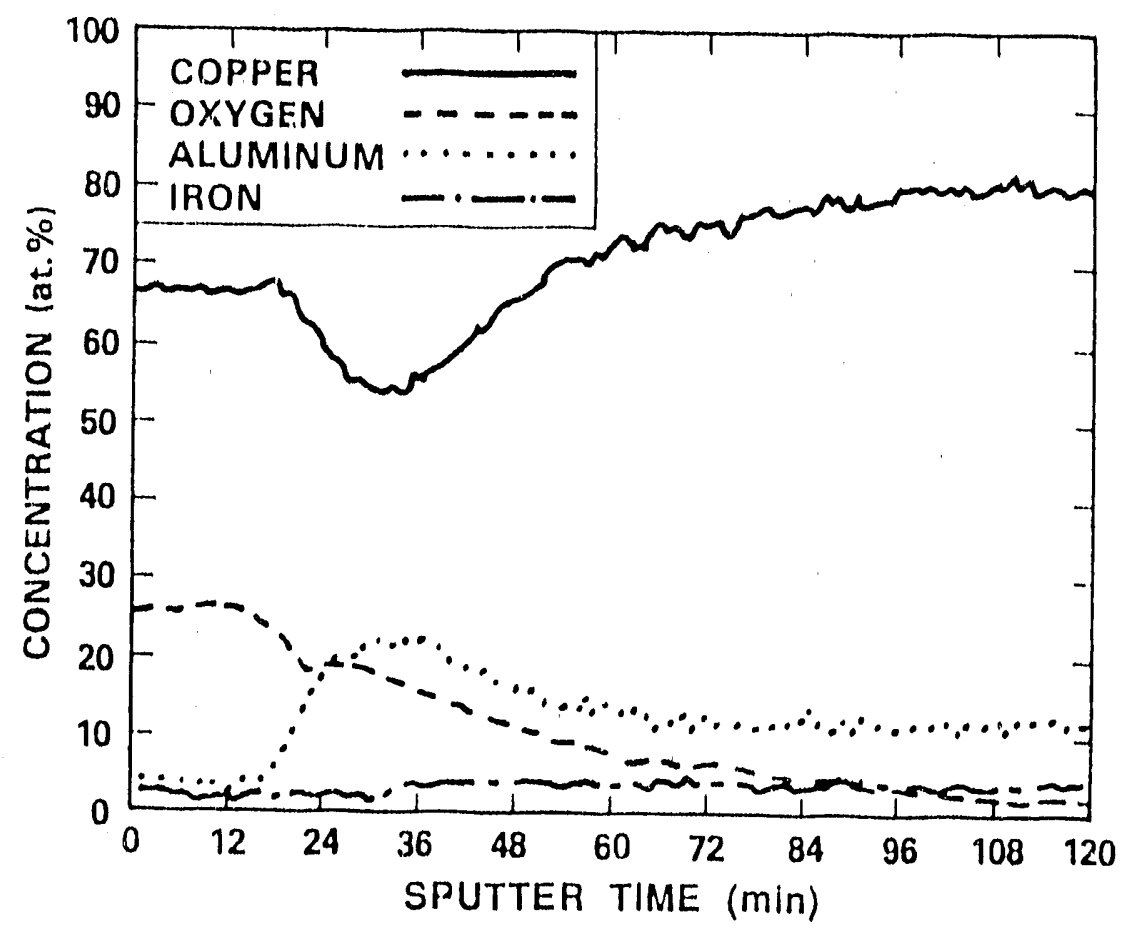

HLOL 8606 176.11

FIGURE 39. Concentration (atom percent) Profile of the Oxide Layer on a CDA 613 Specimen After $1 \mathrm{Mo}$ in the Gas Phase at $150^{\circ} \mathrm{C}$. Sputtering rate is the order of $10 \mathrm{~nm} / \mathrm{min}$.

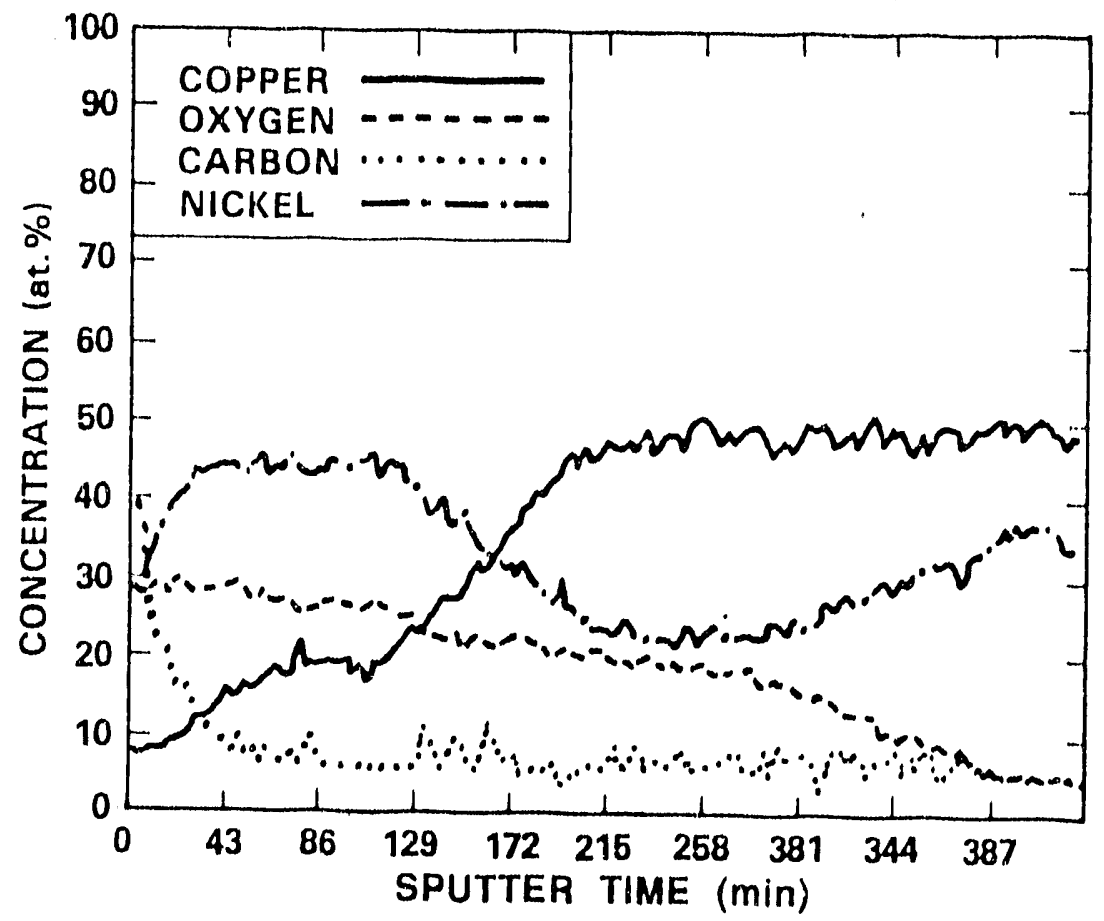

IIEDL. 8000176.8

FIGURE 40. Concentration (atom percent) Profile of the 0xide layer on a COAA 715 Specimen After $1 \mathrm{Mo}$ in the Gas Phase at $95^{\circ} \mathrm{C}$. Sputtering rate is the order of $10 \mathrm{~nm} / \mathrm{min}$. 
distributed as the oxide layers grow was not determfned. Since the Auger electron spectroscopy was tuned to the signal from each of the elements of interest as they occurred on the cleaned oxide surface, the data represent the elements in their chemically combined state. The nickel-copper oxide structure was seen by $X$-ray diffraction on a different specimen. However, no sign of aluminum oxide was seen in the $X$-ray diffraction data. The decline of the metal-oxygen ratio on the CDA $101 / 102$ specimens was continuous and showed no bands or layers. 


\section{0}

\section{DISCUSSION}

This program was bastcally a survey of the effects of gamma radiation on the corrosion behavtors of three copper-base matertals. Since the data are to be used in a preliminary material selection process for nuclear waste barriers, the corrosion exposure conditions were selected to approximate the bastc stages for a cantster environment in tuff. These conditions were 1) atr with a low relattve humidity, 2) air at a lower temperature, near the water dew point and water bolling point, and 3) bulk water at its boiling point. The levels of radiation were selected to be much higher than expected in a repository, in order to emphasize possible radiation effects. In the relatively short time available for these studies, emphasis was given to observing as many behaviors as possible and to identifying the conditions that might be severe. These relatively brief exposure times may not have been sufficient for the formation of oxide layers that are characteristic of long-term steady state conditions. Nor was there time to sequence specimens through the succession of the three environments or to run parallel experiments without the presence of gamma radiation.

There is considerable literature on the oxidation of copper, especially at elevated temperatures $\left(>200^{\circ} \mathrm{C}\right)$. However, there is less known about the process at lower temperatures. The oxidation process becomes even more complex for alloys and in the presence of ionizing radiation. At higher temperatures, the normal oxidation of pure copper follows a parabolic time dependency $[n=1 / 2$ in Equation (1)]. Copper ions migrate through the cationdeficient oxide lattice to react with oxygen near the surface of the oxide film. The oxide phase $\mathrm{Cu}_{2} \mathrm{O}$ is thermodynamically stable under normal, atmospheric conditions. At lower temperatures, however, migration of the cations is controlled by the gradient of the electric field within the oxide lattice. The theory for this is reviewed in detail by smeltzer and Young. (10) The oxidation is a logarithmically time-dependent process up to about $150{ }^{\circ} \mathrm{C}$, has a cubic time dependence at increased temperatures, and follows a parabolic time dependence at $200{ }^{\circ} \mathrm{C}$ and above. (11) 
In these experiments, it is posstble that some of the lonized spectes produced in the motst atr environment by the gamma radiation may migrate into the oxide lattice, whereas oxygen does not. Also, other alloy metals in. the oxide layer will alter tts electronic structure. Since the other metals in the copper alloys will not migrate through the copper oxide lattice at the same rate as copper, it is reasonable that some enrichments of component metals will occur in and under the oxtde film. Hence, the oxidatioil properties expected in these expertments cannot be assumed to be the same as for normal air oxtdation of pure copper.

By necessity, much of the fundamental data on the low-temperature oxidation that is likely to occur were taken on relatively thin films. While this information is important, it is the corrosion behaviors on matertals with the thick flims that are of greatest interest, since the majority of a waste container's service life is spent with a thick corrosion film. If it is assumed, conservatively, that the heavy fllm wlll break and allow the environmental constituents to penetrate to the underlying layers, then the process of healing such flaws is also of interest.

The three types of data recorded during these experiments are 1) corrosion environment, 2) metal degradation, and 3) oxide fllm composition. of the three corrosion environments, $150 / G, 95 / G$, and $95 / \mathrm{L}$, the $95 / \mathrm{G}$ was the most difficult to control in terms of surface conditions on the specimens. This is primarily an experimental problem in temperature and humidity control in a large volume and under remote conditions. Accurate predictions of the sequence of atmospheric compositions in the proposed repository are essential for planning experiments that provide a close simulation.

A summary of observed corrosion behaviors is shown in Table 15. The corrosion rates are values at $10,000 \mathrm{~h}$; the "P" and "L" refer to parabolic and linear time dependence of the corrosion processes (Equation 1), and the numbers are the observed stotchiometries of the oxides formed. In general, the overall corrosion rates are low. At $10,000 \mathrm{~h}, 0.15 \mathrm{mil} / \mathrm{yr}$ is the highest value. It is recognized that for log-log plots of the general corrosion data, 
TABLE 15

SUMMARY OF CORROSION BEHAVIORS

Corrosion

Condtitions

$150 / G$

$95 / G$

$95 / \mathrm{L}$

\section{Matertals}

CDA $101 / 102$

$0.02 \mathrm{~m} 11 / \mathrm{yr}$

$n=0.67(P)$

$M / O=2.0 \pm 0.31$

$0.15 \mathrm{mil} / \mathrm{yr}$

$n=1.5(\mathrm{~L})$

$M / 0=1.6 \pm 0.28$

CDA 613/614

$0.01 \mathrm{mt1/yr}$

$n=0.58(P)$

$M / 0=1.1 \pm 0.28$

$0.07 \mathrm{~m} 11 / \mathrm{yr}$

$n=1.0(\mathrm{~L})$

$M / O=0.94 \pm 0.12$

$0.08 \mathrm{mt} / \mathrm{yr}$

$n=0.93(L)$

$M / 0=0.7 \AA \pm 0.34$
CDA 715

$0.02 \mathrm{mtl} / \mathrm{yr}$

$n=0.29(P ?)$

$M / O=1.0 \pm 0.18$

$0.10 \mathrm{mil} / \mathrm{yr}$

$n=1.1(\mathrm{~L}$ ? $)$

$M / 0=0.80 \pm 0.13$

$0.07 \mathrm{mil} / \mathrm{yr}$

$n=0.91(L)$

$M / O=0.91 \pm 0.38$

NOTE: Copper is assumed to be the only metal present in the oxide layer.

some of the data subsets have considerable scatter (low values of $R$ ). Future studies may indeed alter some of these findings. From the present results, however, the following observations are made.

\subsection{GENERAL OBSERVATIONS}

From these expertments, the most severe corrosion appears to be related to the presence of smal1 amounts of 1 iquid water on the metal surface, either in films or drops. Such small quantities can become concentrated with the corrosive species that are produced by the gamma radiation at the air/water interface and exceed any buffering capacity of the small amount of 1 iquid water. This accelerated corrosion is in keeping with the modeling predictions presented by Van Konynenburg. (2) In contrast, dissolution of these same species in a bulk-water phase will produce a much more dilute solution that is uniformly distributed over an entire specimen. The bicarbonate ion in the Well J-13 water also buffers the pH. 
Except for the pure copper specimens (CDA 101/102) at $150{ }^{\circ} \mathrm{C}$ (low humidity), the predominant oxtde phase appears to be $\mathrm{CuO}$, not the $\mathrm{C}_{2} \mathrm{O}$ that is predlcted by thermodynamics. While $\mathrm{CH}_{2} \mathrm{O}$ appears tn most of the X-ray diffraction spectra, it is apparentiy not present in suffictent quantitios to change the overall metal/ oxide ratios, It is also assumed that the other metals are not present in suffictent quantity in the oxide layers to signiftcantly alter the M/O values.

There was no evidence of stress-assisted cracking of the tear drop specimens etther from the dye penetrant examinations or from the metallographic examinations. Likewise, there was no additional corrosion of specimens at the interface between the gas and bulk liquid phases. What corroston was seen in the interface regton was comparable to that seen on other spectmens mounted completely within the bulk phases. On those spectmens that were electrochemically prepltted by LLNL prior to thetr gamma field corrosion, it appeared that the pits disappeared through the general corrosion processes rather than continuing to propagate. However, there was spontaneous pit formation on all three materials on the specimens that were not prepitted. Some of these pits were captured in the metallographic cross sections. However, thorough examinations and measurements of the pitting were not atteinpted. Seldom did pits cover an entire specimen with a uniform pattern. They often occurred only in certain regions of a specimen. The pits were normally quite broad, at least as wide as they were deep. In the visual examinations, the distinction of pits versus spots was sometimes difficult. Borderline cases were listed as pits, so as not to allow posstble occurrences to go unrecorded.

While crevice corrosion occurred around the edges of the closely spaced pairs of plates, local corrosion also occurred in the mated surfaces well inside of the edges for CDA 613/614 and CDA 715. The metallographic examinations showed uneven corrosion in the region of nonuniform grain structure (e.g., where some surface compressions had occurred during specimen manufacturer). There was evidence of metal component enrichment in the fusion welds of the CDA 613. Although weld study was not part of the scope, no particular corrosion problems were seen in the metallographic examination of the sectioned 
wolds, It is conciluded, however, that any future corrosion studtos should include test thems that contain the welds, deformation, deep crevices, etc., of a proposed applications destgn, along with spectmens for general corrosion.

\section{$5.2 \quad \operatorname{CDA} 101 / 102$}

Corroston of pure copper is quite simtlar under the 150/G and 95/l. environments, although the oxide layer appears to be mostly cuo in the latter case. Under $95 / G$ conditions, the corrosion is different. It appears to be a linear process, rather than a paraboltc one, and appears to have about five times the rate at $10,000 \mathrm{~h}$. It may be dependent on the levol of the gamma flux under these conditions. The makeup of the oxide is intermedtate to that produced under the other condtions. In the crevice specimens, local corroston occurred only near the spectmen edges and not in the inner regtons of the space between the two plates. The surfaces of the prepitted specimens remained relatively smooth. There was some tendency for this material to ptt, but it was not repe table. The pits were broad. If these pits were due to some undatected impurity in the corrosion environment, then the impurity can be assumed to be at a very low concentration. Control of a signiffcant (pit. causing), trace impurity in the operating environment of a reposttory could be difficult. A few large, tsolated ptts were found to be from particles of foreign materials imbedded into the surfaces during manufacture of the specimens and not removed by the cleaning processes.

In the visual inspection of the low flux spectmens, crevice corrosion was the only type of local corrosion found. Relative to the other matertals, then, CDA 101/102 showed much less local corrosion at the low flux.

\section{3}

\section{CDA $613 / 614$}

This aluminum bronze appears to oxidtze regularly and relatively slowly in the $150 / G$ phase. The cuo is the preduminant product. The parabolic process in the $150 / G$ environment becomes a linear process in the $95 / G$ and $95 / \mathrm{L}$ environ. ments. The apparent ganma flux dependency is also not lceable in the $95 / G$ phase. 
Constderable underftlim and other types of local corrosion were observed. As with the CDA 715 alloy, the oxide layer is apparently not homogoneous. Hence, it will be more difficult to charactertze it under all posstble reposttory conditions and sequences of geologtcal events.

\section{$5.4 \quad$ CDA 715}

While the data from the $95 / \mathrm{L}$ environment show a well-behaved, 1 inear rate of corrosion with the formation of $\mathrm{CuO}$, the corrosion behavlors in the $150 / \mathrm{G}$ and 95/G envtronments are more ambiguous. The wide scatter in the data from the 95/G enviroment may be due partly to the gamma radiation dependence and also to a process whereby the sillill pleces of oxide that break off allow accel. erated corrosion in that area. Overall, this may lead to the mosatc pattern found in the metal surface. The scatter in the group of data from the $150 / \mathrm{G}$ environment suggests that there is a yet-to-be-determined vartable affecting those corrosion results. This may well be a consequence of the structure or properties of the oxide layer. These results suggest that the corrosion behavior of this matertal is complex under the conditions of those experiments. 


\subsection{BEEERENCES}

1. W. E. Glassley, "Reference Waste Package Enviromment. Report, " UCRL-53726, Lawrence Livermore Nat lonal Laboratory, Livernore, CA, 1986. HSQ.880517.2445

2. R. A. Van Konynenburg, "Radlation Chemfcal Effects in Experiments to Study the Reaction of Giass in an Environment of Ciamma-Irradiated Air, Groundwater, and Tuff," UCRL-53719, Lawrence Lifvermore National

Laboratory, Livermore, CA, 1986. NNA.891026.0012

3. W.H. Yunker, Corrosion of Copper-Based Matertals In Gamma Radiation, HEDL-7612, Hanford Engtneering Development Laboratory, Richland, WA, 1986. NNA. 900125.0076

4. W. H. Yunker and R. S. GIass, "Long-Term Corrosion Behavior of CopperBase Matertals in a Camma-Irradiated Environment, "Proc. of the Matertals Research Socjety, vol. 84, pp. 579-590, 1987. NNA.870420.0058

5. ASTM G30-79, "Recommended Practice for Making and Issing U-Bend Corrosion Test. Specimens," Annual Book of ASTM Standards, para 7.2, American Socitety for Testing and Materials, Philadelphia, PA, 1979. NNA.891128.0589

6. U.S. Department of Commerce, Directory of Federal Laboratory and Iechnology Resources, U.S. Department of Commerce, Washington, D.C., 1986.

7. ASTM G1-81, "Recommended Practice for Preparing, cleaning, and Evaluating Corroston Test Spectmens, "Annual Book of ASTM Standards, American Soctety for Testing and Materials, Philadelphia, PA, 1981. NNA.891120.0022

8. ASME Boiler and Pressure Vessel Code, "Nondestructive Examination," Section V, Article 6, American Soctety of Mechanical Engineers, New York, NY. NNA.870730.0031

9. D. G. Farwick, Quality Assurance Program Plan for Westinghouse Hanford Co. Support of LINL Waste Package Task, NNWSI Prolect, EDT No. GR-0039, Westinghouse Hanford Company, Richland, WA, Aprtl 1986.

10. W. W. Smeltzer and D. J. Young, "Oxidation Properties of Transttion Metals," Progress in Solid-state Chemistry, Vol. 10, Part 1, pp. 17-54, 1975. NNA.890919.0249

11. 0. Kubaschewski and B. E. Hopkins, oxidation of Metals and Alloys, 2nd ed., Butterworth and Co. Itd., Iondon, UK, 1962. 
WHC-EP-0188

A P P N D I X A

DATA BASE

$A-1 / A-2$ 


\section{APPENDIX A}

\section{DATP. BASE}

The following tables contain the primary information on the identification, corrosion environment and experimental results for the specimens used in these experiments. Excluded are the specimens that were electrochemically prepitted by LLNL. (see text). The information was entered into a symphony* data base. It was then verified, examined, and extracted for presentation. A column-by-column explanation of the tables follows. The entries are grouped by material and listed alphanumerically by specimen serial numbers.

* Symphony, $\mathrm{V} i . i$ is a irademark of Lotus Deveiopment Corpuration. 
TABLE A1

EXPLANATION OF DATA BASE TABLES

Column

\section{Contents}

Alloy code: $\operatorname{CDA} 101 / 102=1 ; \operatorname{CDA} 613 / 614=2 ; \operatorname{CDA} 715=3$. Specimen form code: $W=$ weight loss; $B=$ tear drop; $C=$ crevice. Serial number within each subset of alloy and form.

Note: Columns 1, 2 and 3 combine to make the unique specimen identification numbers.

CDA alloy identification number, from the chemical compositions.

ID number of vessel in which specimens were exposed (T-1, T-2, etc.) Identification of the cage(s) in which specimens were mounted.

Exposure periods (sequential) for specimens (1 through 5).

Exposure phase: $L=1$ iquid; $G=$ gas; $I$ = interface.

Nominal temperature of exposure in ${ }^{\circ} \mathrm{C}$.

Total exposure time (hours).

Total exposure time (months).

Nomina? garma exposure dose rates $\times 10^{-5} \mathrm{R} / \mathrm{hr}$.

Measured weight loss (mg) - 'W' specimens only.

Measured corrosion film weight (mg) - ' $W$ ' specimen only. Calculated corrosion rate mil/year - ' $W$ ' specimen only. Metal-oxygen weight ratio - ' $W$ ' specimen only.

7 Analytical procedures used: $A=$ Auger electron spectroscopy; $X=X$-ray diffraction; $D=$ dye penetrant examination; $M=$ metallographic examination; $P=\operatorname{photograph}(s)$. All specimens received a $10 x$ visual examination.

Results of visual examination (see Table A-2 for the description codes.) 
TABLE A-2

\section{DESCRIPTOR CODES USED TO CHARACTERIZE THE SPECIMIN SURFACES FROM VISUAL EXAMINATIONS}

The codes are pairs of letters as defined below. Adjacent codes describe one type of feature. "/"s separate the descriptions of different features. These are qualitative descriptors; there is overlap in some of the meanings. The descriptors are somewhat suggestive of their meaning; they should be strung together to make phrases. For example, "FWDKSPPT" reads a few dark spots and pits.",

\section{Abbreviation}

$A R$

BK

$\mathrm{CL}$

$\mathrm{CO}$

CU

DD

DK

FL

FM

FW

GE

IS

LC

$L G$

LT

$M D$

MP

NF

PT

RO

RS

RU

SM

SO

SP

VS

WD

$X \mathrm{~L}$

$n M$
Meaning

Limited area of coverage

Black appearance

Clear, clean surface

Coloration/stain, not opaque

Copper colored

Dense

Dark appearance

Filiform-1ike (underfilm corrosion $n$ )

Film - not opaque, full coverage

A few, more than 5

General coverage, most of specimen

Isolated occurrence - fewer than 6

Local corrosion, not FL, PT, etc.

Large - greater than $10 \mathrm{mil}$

Light/white in appearance

Medium - range of 6 to $10 \mathrm{mil}$

Mosaic pattern of corrosion

No corrosion features

Pit corrosion

Rows of corrosion features

Residue

Roughened surface

Small - range of 1 to $5 \mathrm{mil}$

Smooth surface

Spots

Very small - less than $1 \mathrm{mil}$

On weld

Extra large - greater than $100 \mathrm{mil}$

Located in band ' $n$ ' mm wide around

the edge of a crevice specimen. 


\section{INDEX}

Abbreviation

Color:

BK
CU
DK
LT

Coverage:

DD

IS

FW

AR

GE

RO

WD

nM

Size:

VS
$S M$
$M D$
$L G$
$X L$

Surface:

$C L$
$N F$
$C O$
$F M$
SO
RU

Features:

$\mathrm{FL}$

LC

MP

PT

SP

RS
Meaning

Black appearance

Copper colored

Dark appearance

Light/white in appearance

Dense

Isolated occurrence - fewer than 6 A few, more than 5

Limited area of coverage

General coverage, most of specimen

Rows of corrosion features

On weld

Located in band ' $n$ ' $\mathrm{mm}$ wide around the edge of a crevice specimen.

Very small - less than $1 \mathrm{mil}$

Smal1 - range of 1 to $5 \mathrm{mil}$

Medium - range of 6 to $10 \mathrm{mil}$

Large - greater than $10 \mathrm{mil}$

Extra large - greater than $100 \mathrm{mil}$

Clear, clean surface

No corrosion features

Coloration/stain, not opaque

Film - not opaque, full coverage

Smooth surface

Roughened surface

Filiform-like (underfilm corrosion $n$ ) Local corrosion, not FL, PT, etc.

Mosaic pattern of corrosion

Pit corrosion

Spots

Residue 


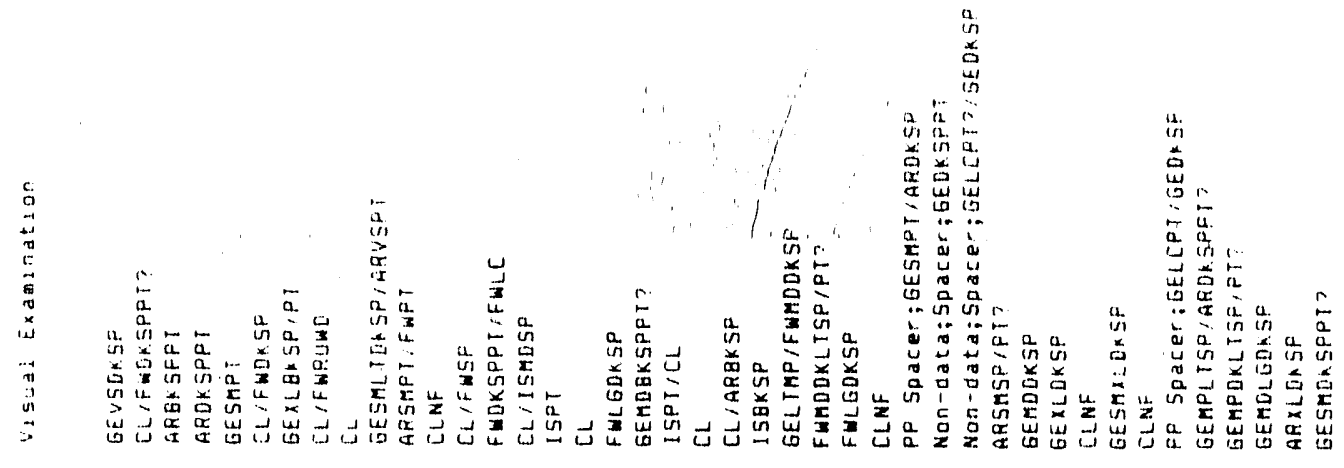

a a a a

a a a d a

a

$\stackrel{1}{\boldsymbol{x}}$

$\ddot{x}$

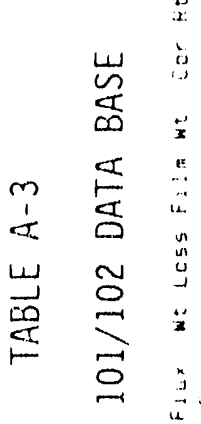

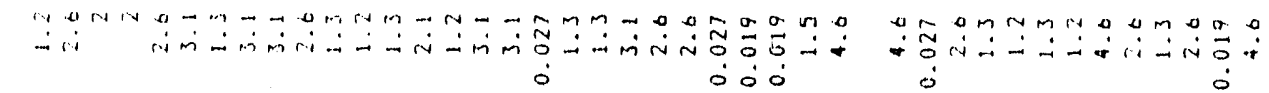
S

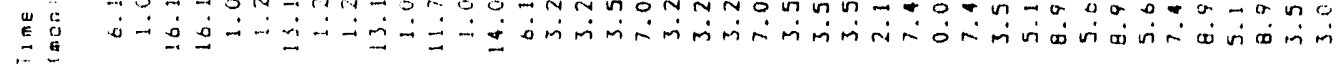

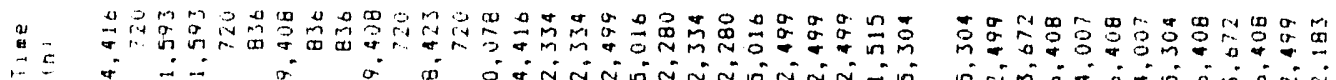

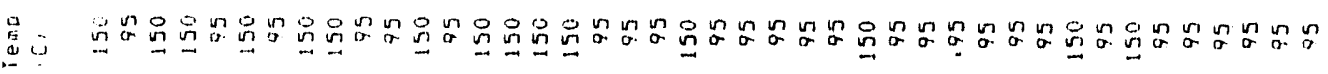
ט

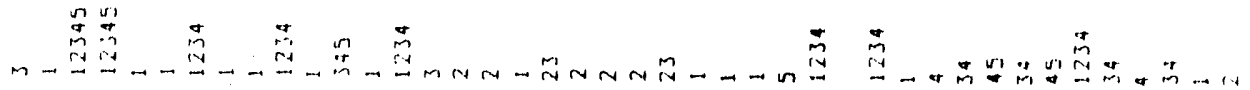

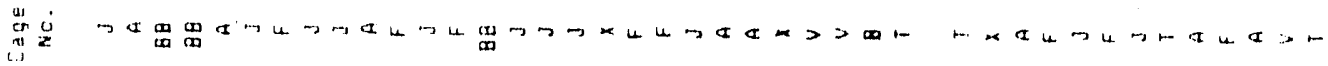

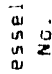

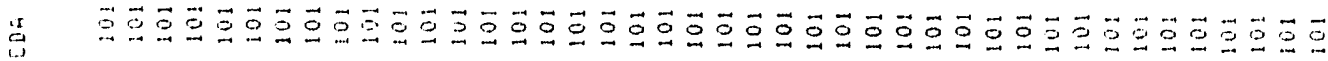

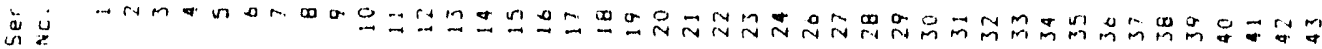
$\stackrel{2}{2}$ का $\underline{-}$ 


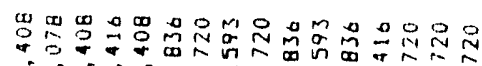
吕

c

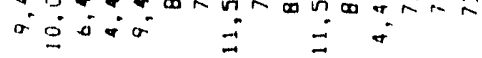

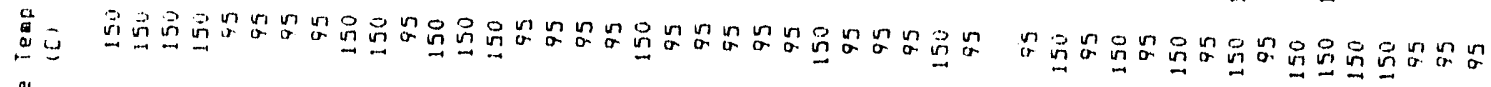

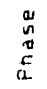
لـ + $\stackrel{n}{5}$

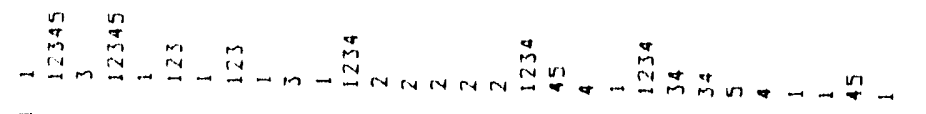

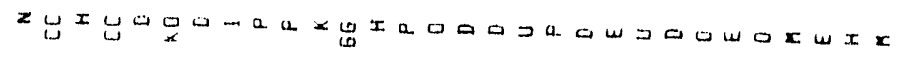

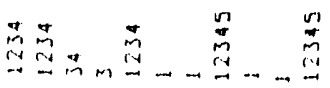

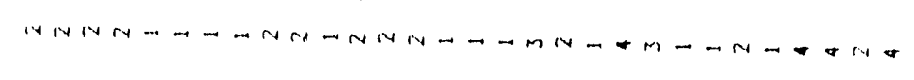

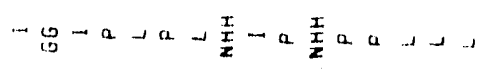
$\stackrel{a}{g}$

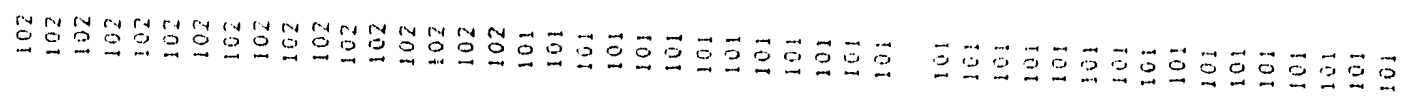

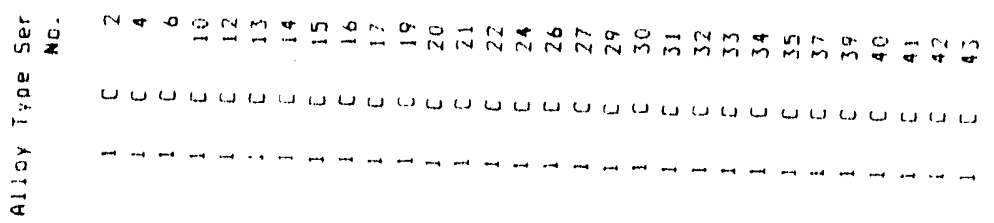




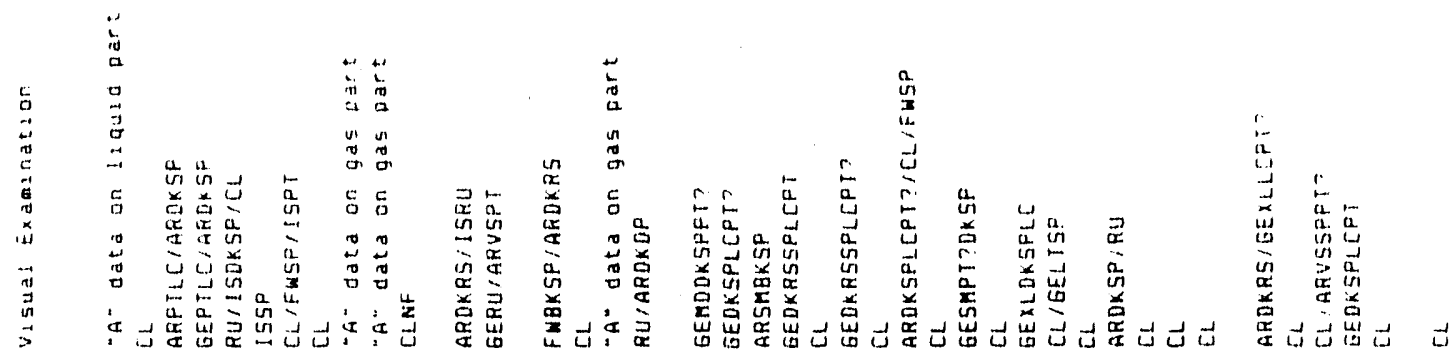

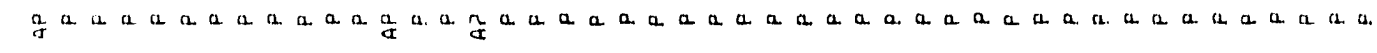

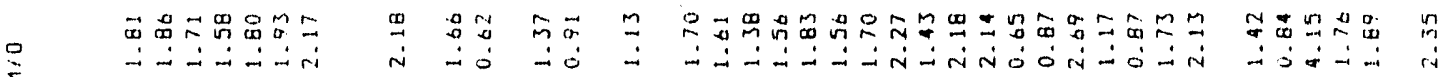

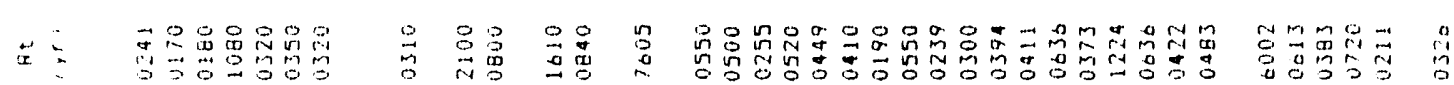

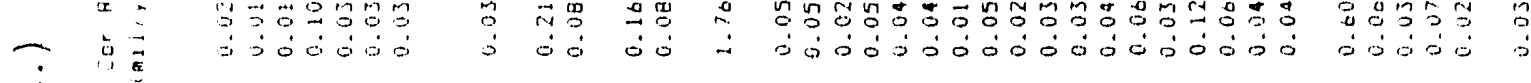

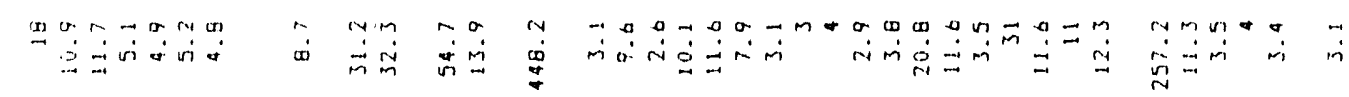

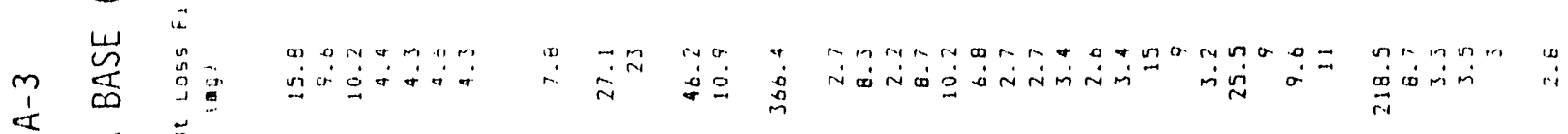
山 I

r w 0
0
0
0

घ

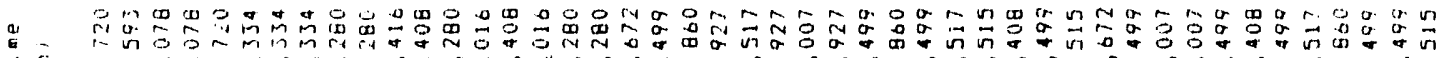
I E E E

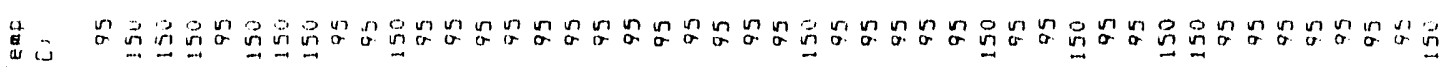

...

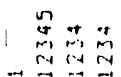

Her

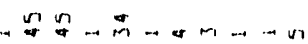

总范

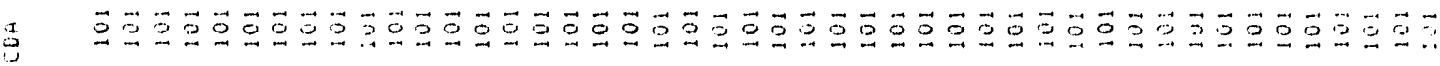

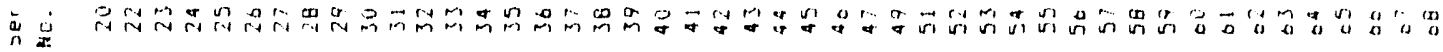

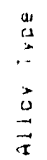




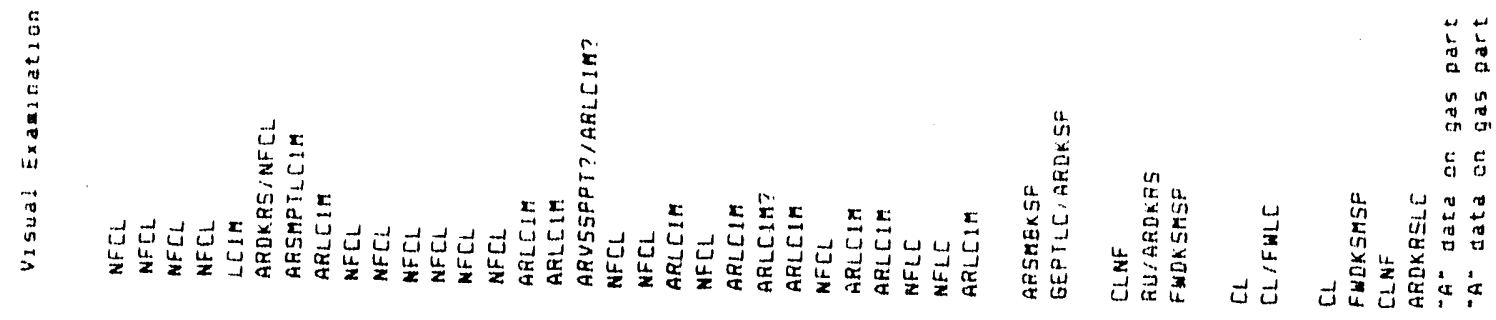

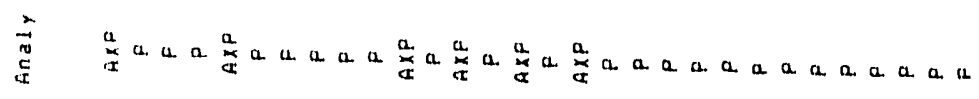

a. a. 11 a is a. a a. ca. a a. a. a. a. a. a

岁

$\stackrel{0}{\mathbf{x}}$

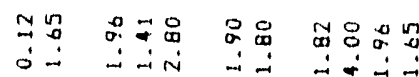

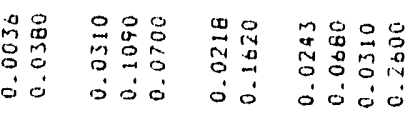

जi

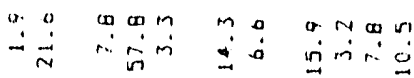

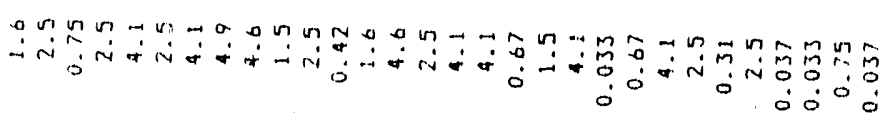

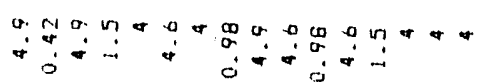

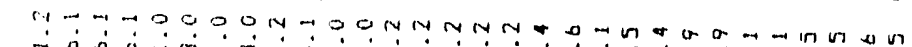

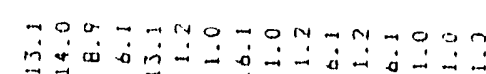

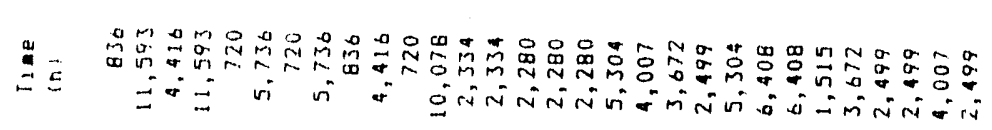

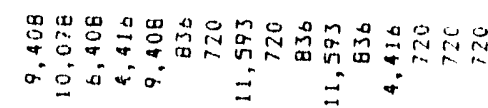

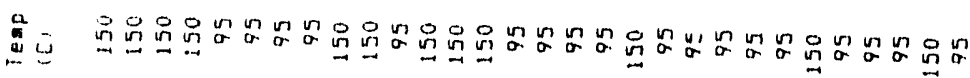

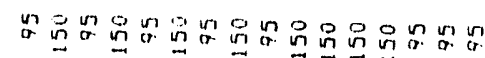

岾

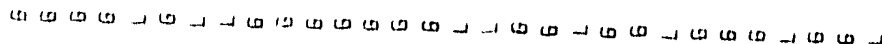

-

$\stackrel{4}{5}$

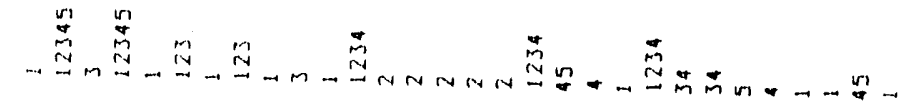

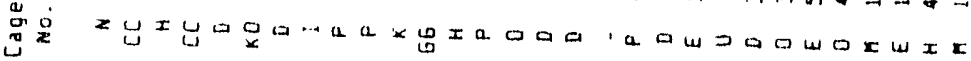

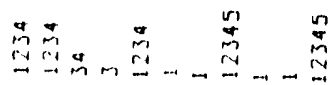

雚

它

要

nin

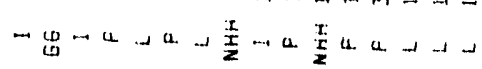

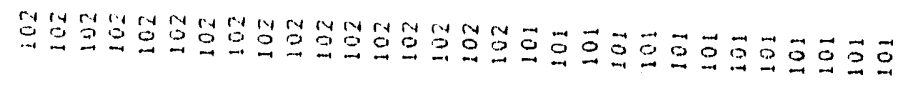

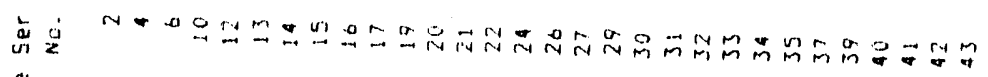

$\stackrel{a}{a}$

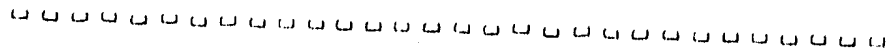

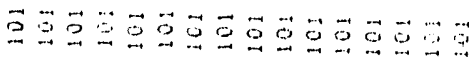

a 
WHC-EP-0188

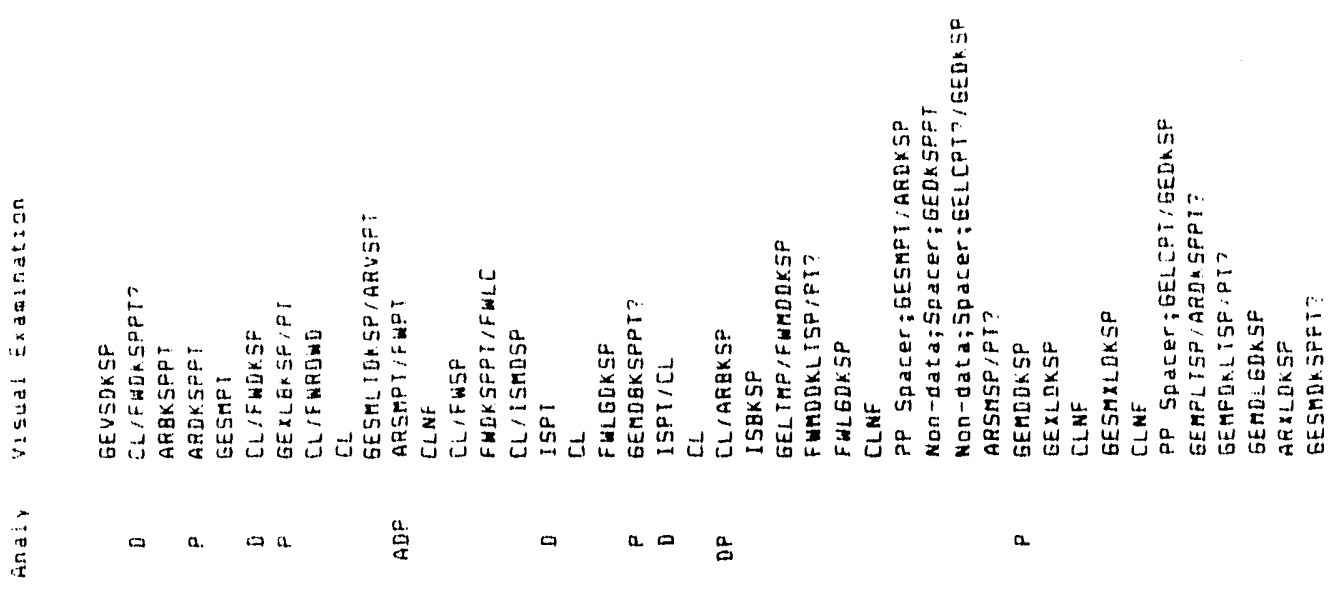

$\vec{x}$

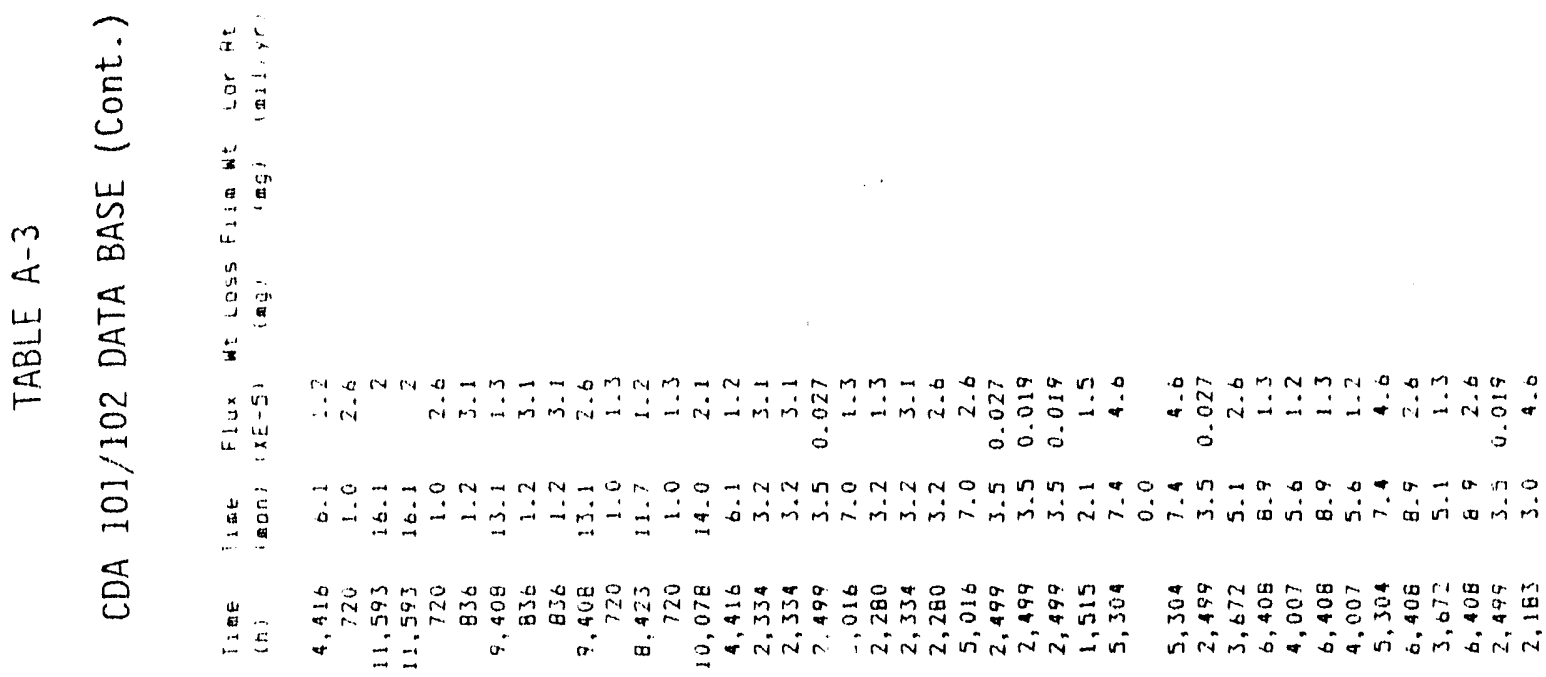

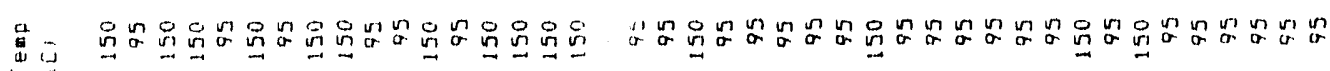

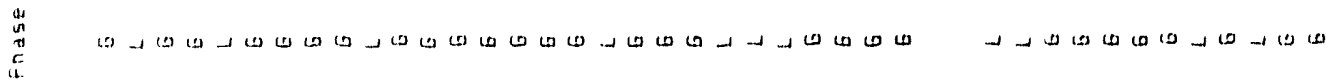

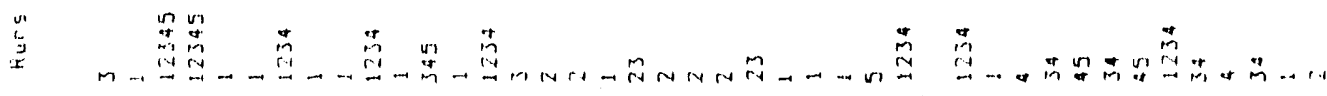

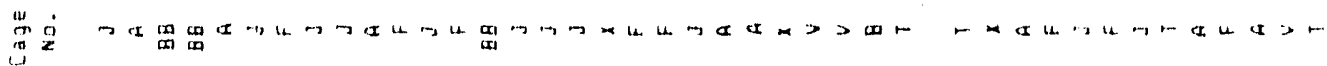

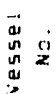

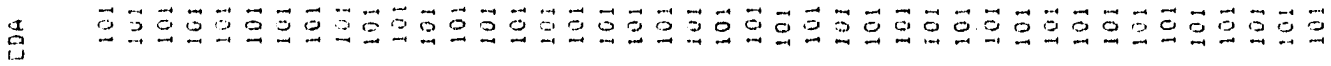

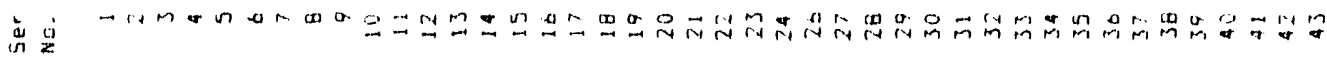

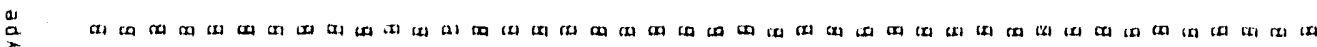

$\vec{a}$ 


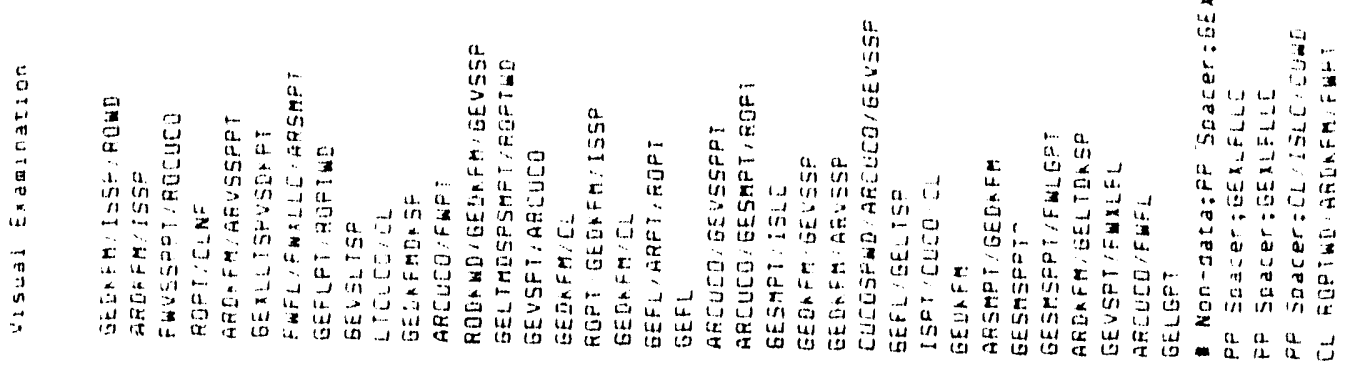

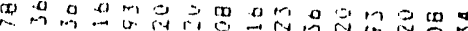

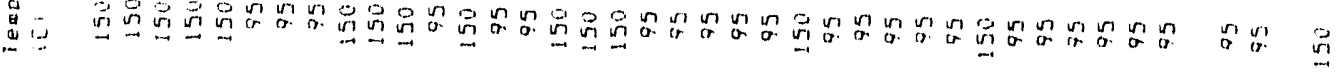

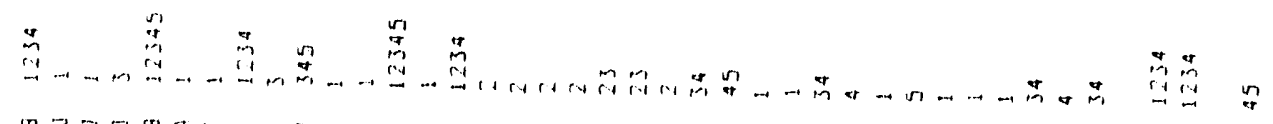

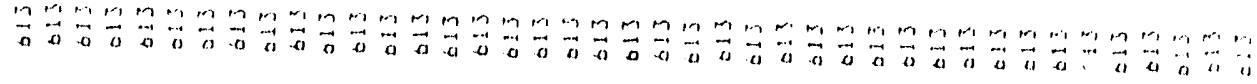

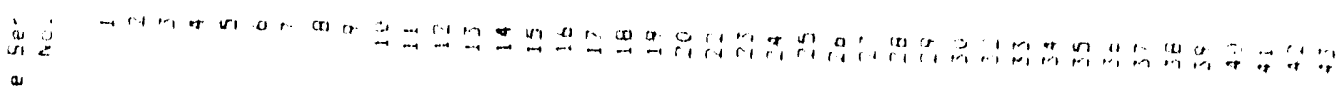


WHC-EP. 0188

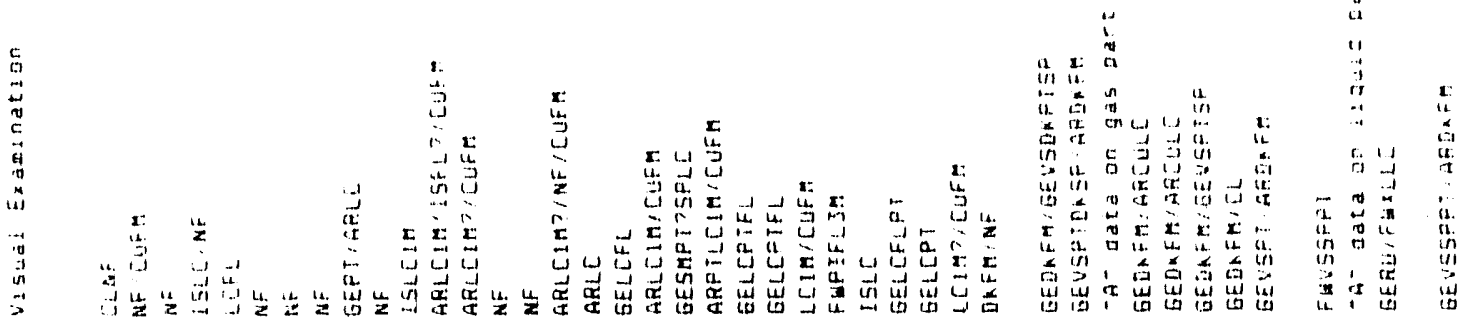

究 4 a c a

a. a a. a a a. a. a. a. a. a. a. a. a.

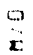

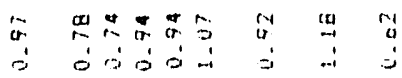

$x$

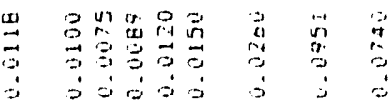

cor rians

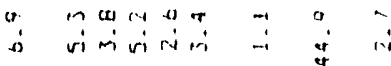

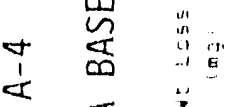

崖 㚗

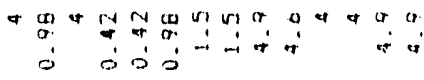

弟

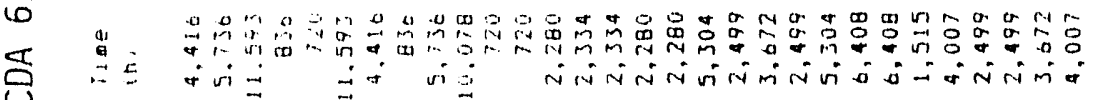

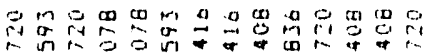

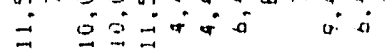

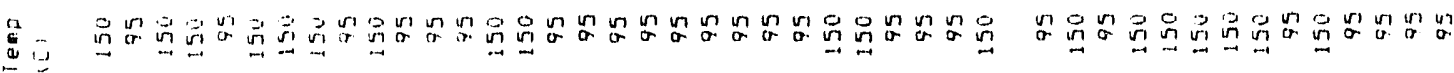

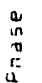
. 3 A

is

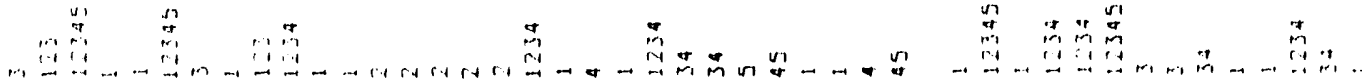

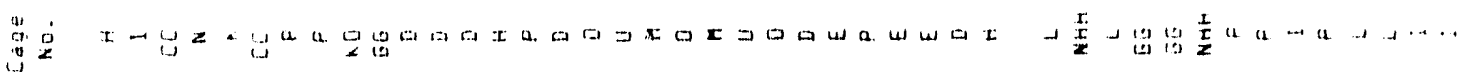

$a$
in
in
an
in

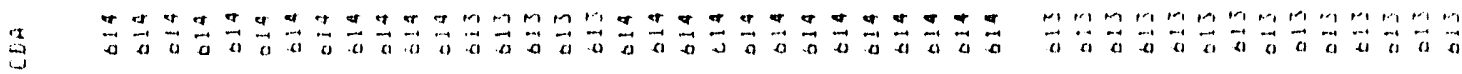

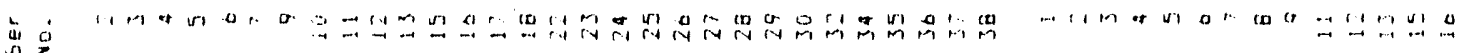

:

1. H W

$3 \times$ 

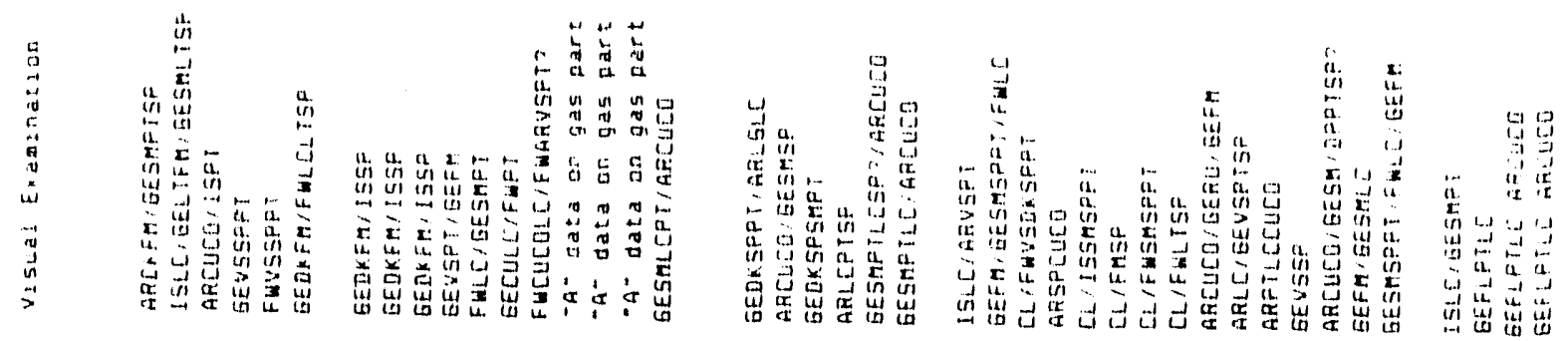

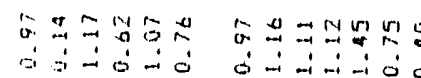
a. a.

$\min \cos x+\cos 20$

का $\quad$ का

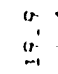

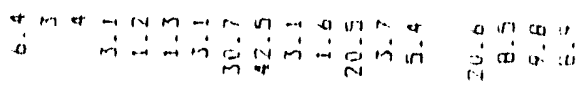
$\ddot{x}$

व $\stackrel{4}{6}$

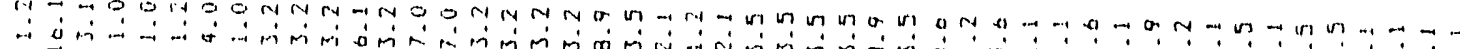
6

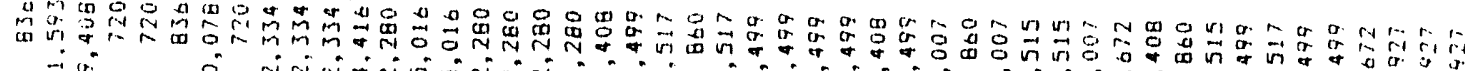

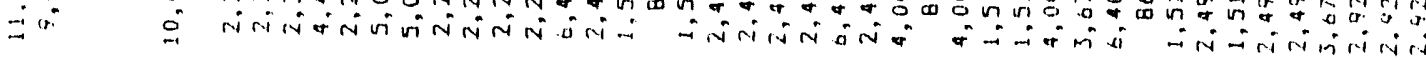

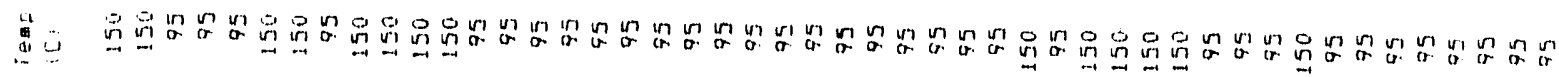

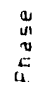
(1) 5 (5)

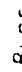
$\underbrace{n+4}_{i=1}$

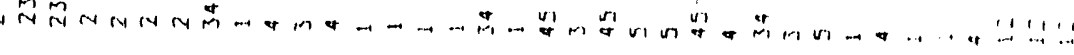

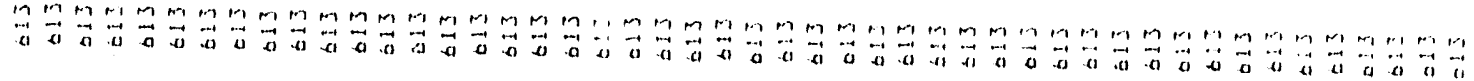

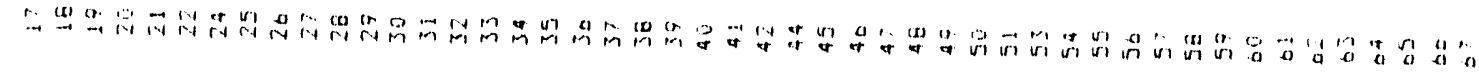


WHC-EP-0188

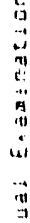

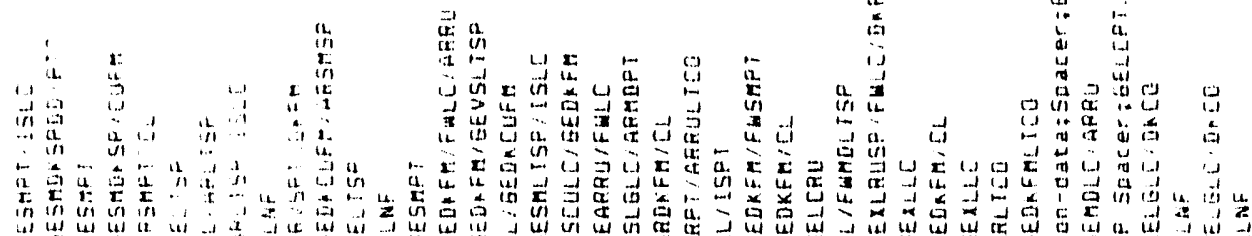

窟:

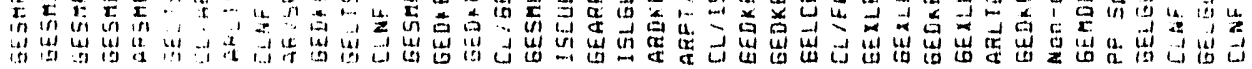

11. 4. $\Leftrightarrow$ a

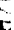

a.

$\vec{\theta} \vec{\theta}$

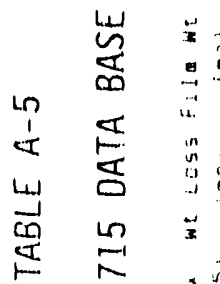

吉

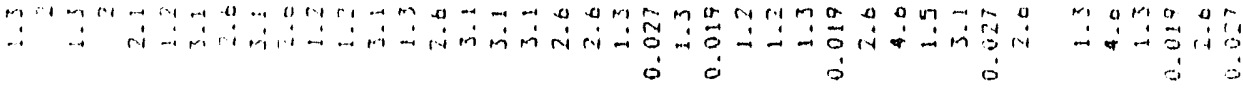

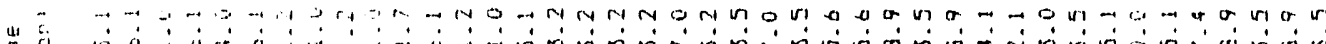

$\therefore$ a

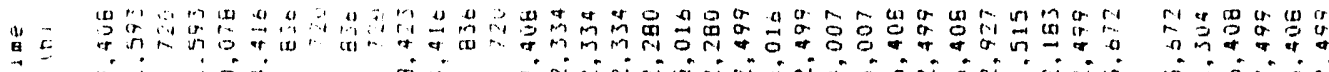

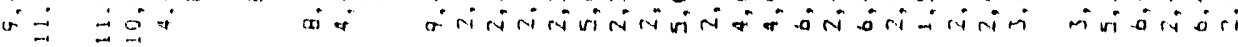

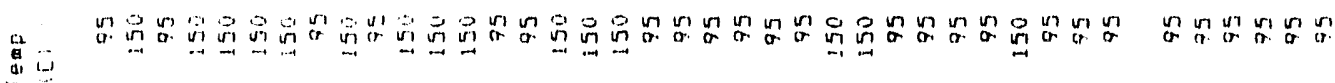

由

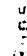

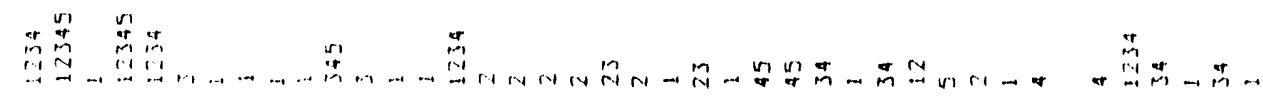

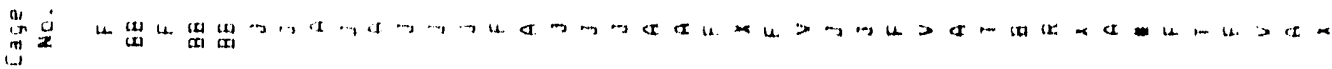

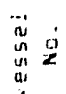

$\stackrel{\text { s. }}{\overrightarrow{3}}$

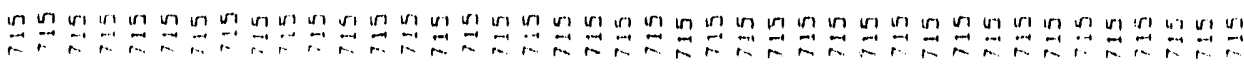

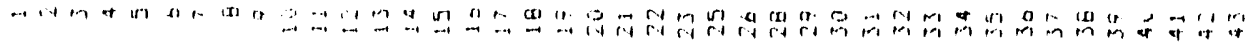

$\stackrel{4}{a}$

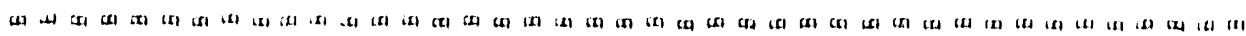

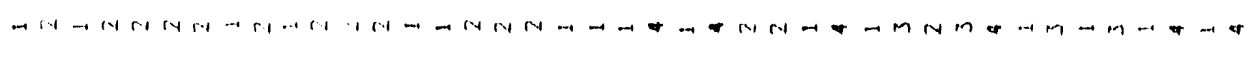




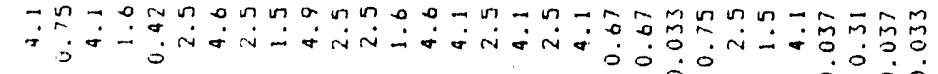

(1)

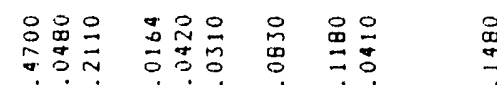
$\dot{0} \dot{0} \dot{0} \dot{0} \dot{0} \dot{0} \dot{0} \dot{0}$

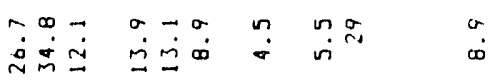

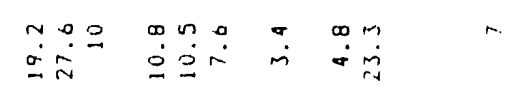

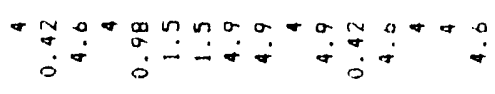
n E

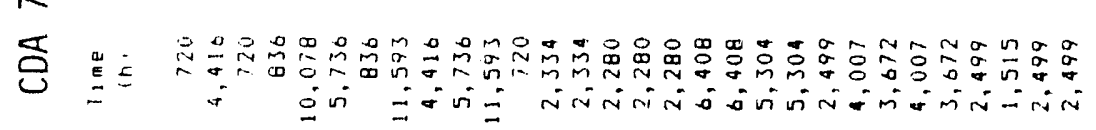

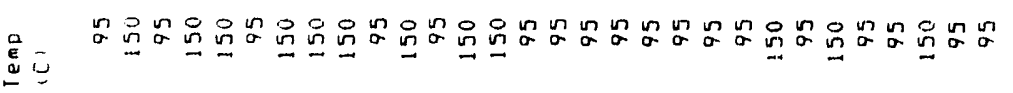

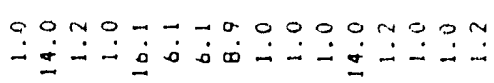

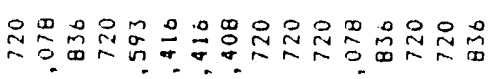
$\therefore$ ¿ंक $0_{0} \ln n=$

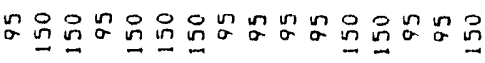
in
s
c
D טג

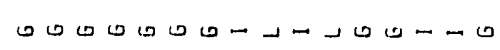
$\stackrel{\substack{n \\ c}}{a}$

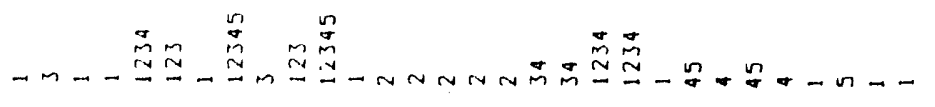

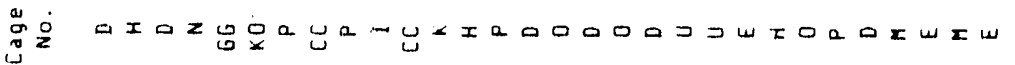

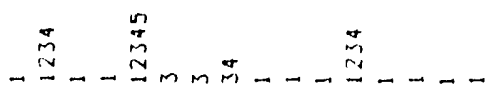
$i_{\substack{n \\ n}}^{\infty}$

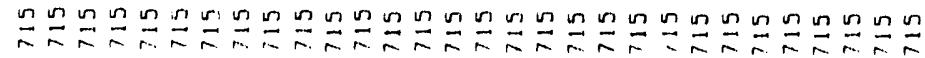

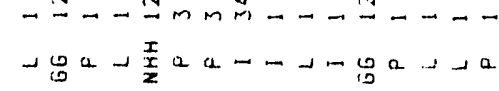

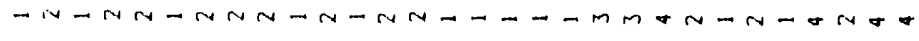

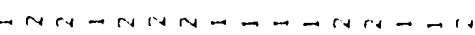

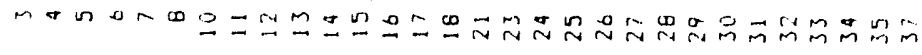

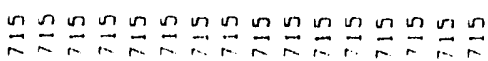
$\stackrel{a}{a}$ נמים

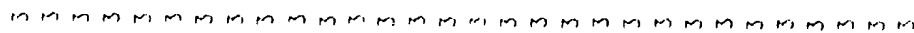

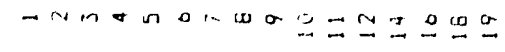
$\frac{a}{a}$ 


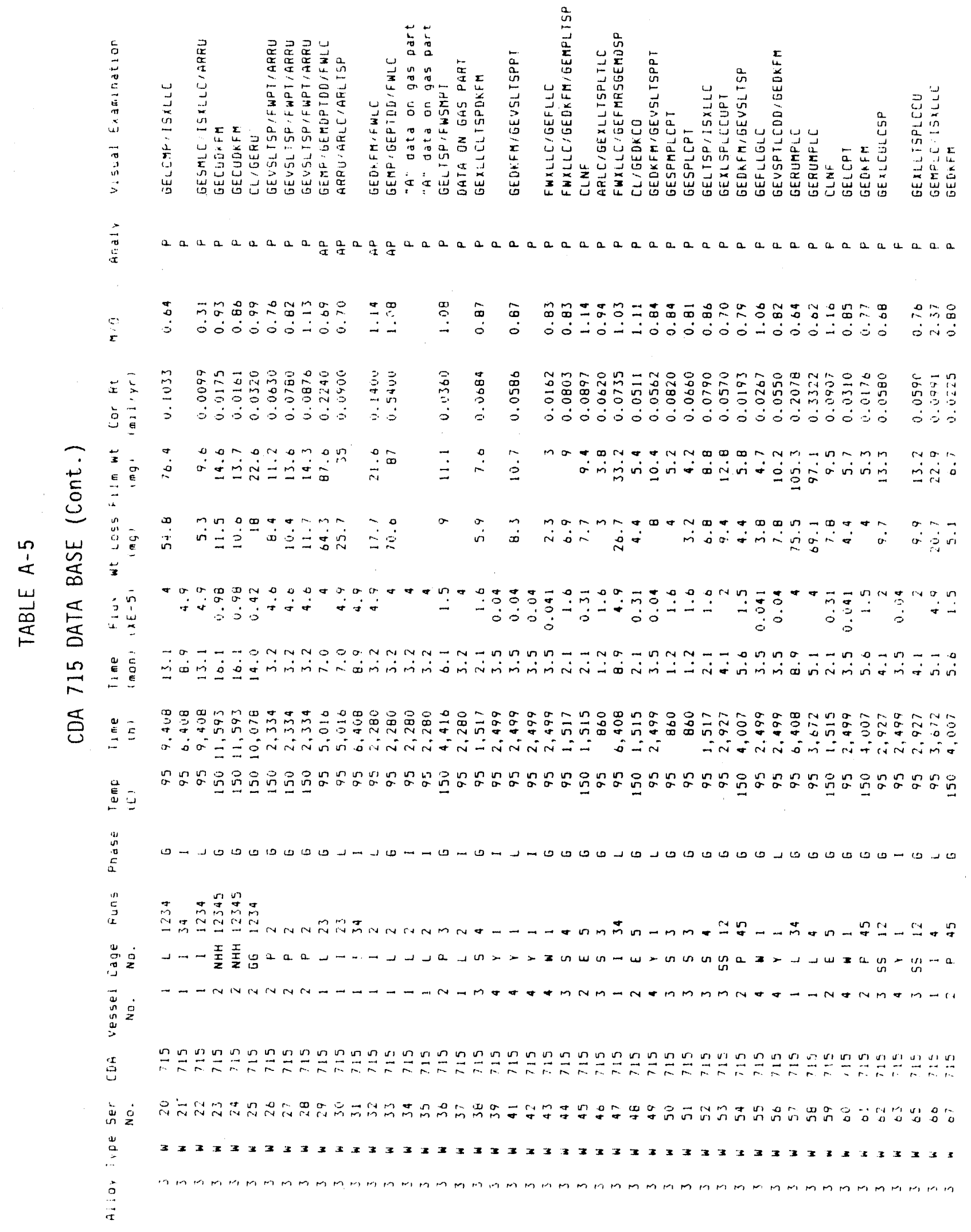

$$
\text { A-17/4.18 }
$$


A P P ENDIX B

SUBGROUPS OF SPECIMENS SORTED BY ALLOY

AND SPECIFIC CORROSION FEATURES/CONDITIONS

Note: [xplanaition of columns and codes are in Tables $A 1$ and $A 2$ of Appendix A.

$$
B-1 / B-2
$$




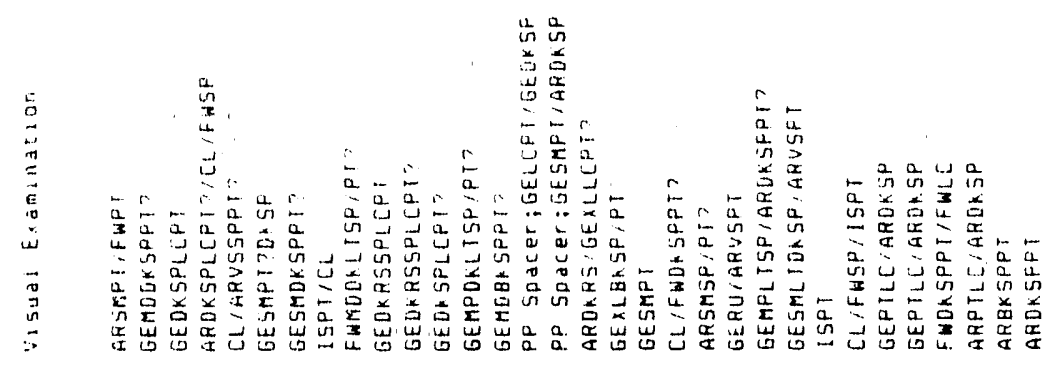

$\underset{c}{i}$ i

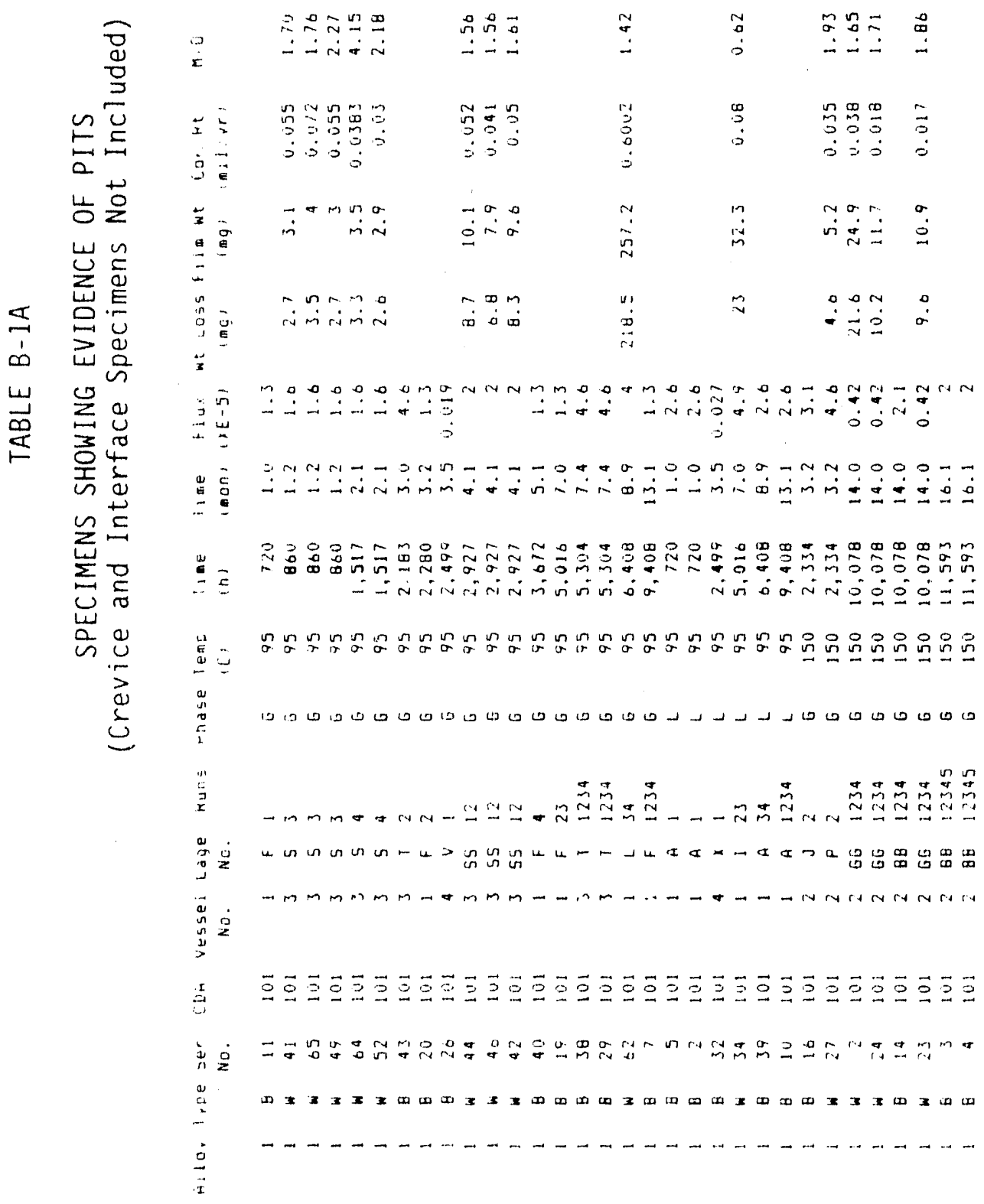






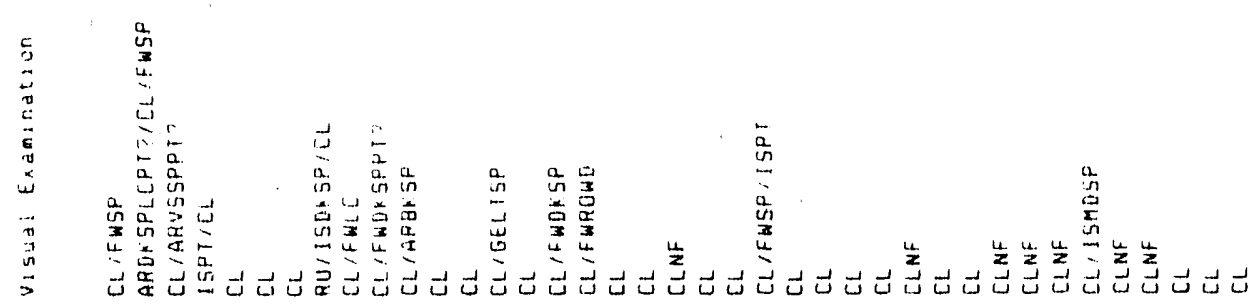

i

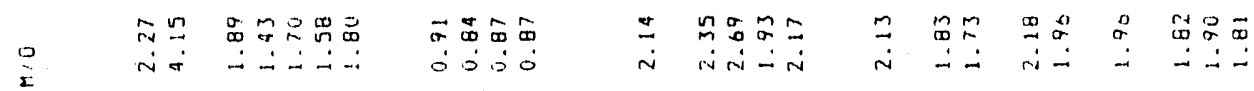

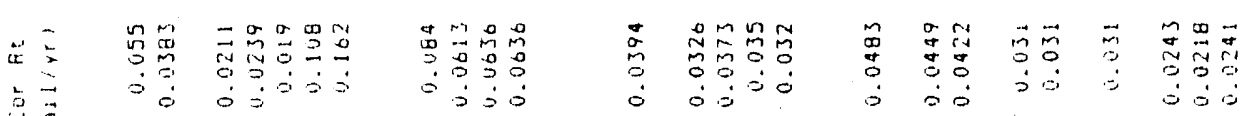

$$
\begin{aligned}
& \text { 荡 向 } \\
& \overrightarrow{2} \\
& \text { 雚首 } \\
& \ddot{3}
\end{aligned}
$$

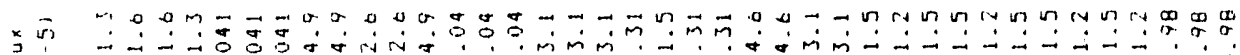

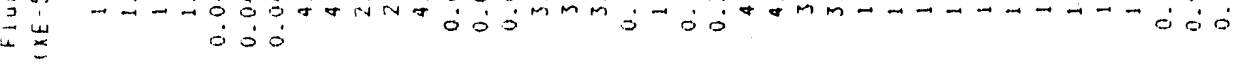$$
\text { U }
$$

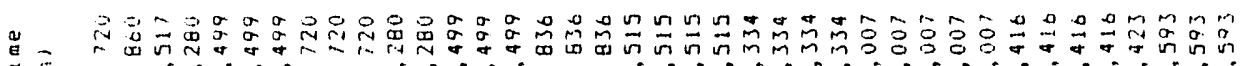

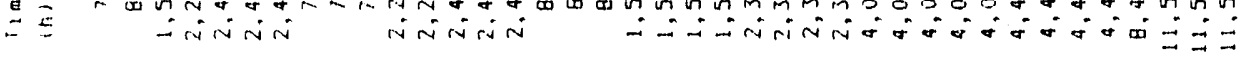

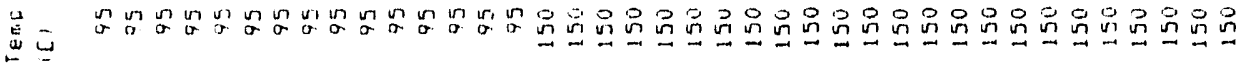

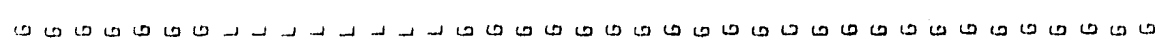
要

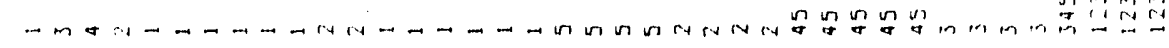

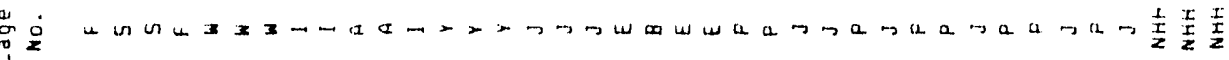

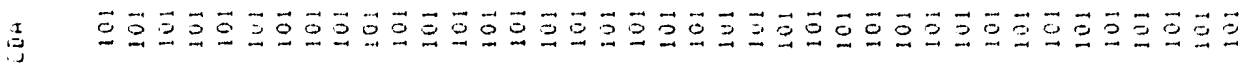

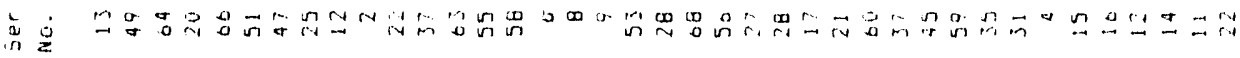


WHC-EP-0188

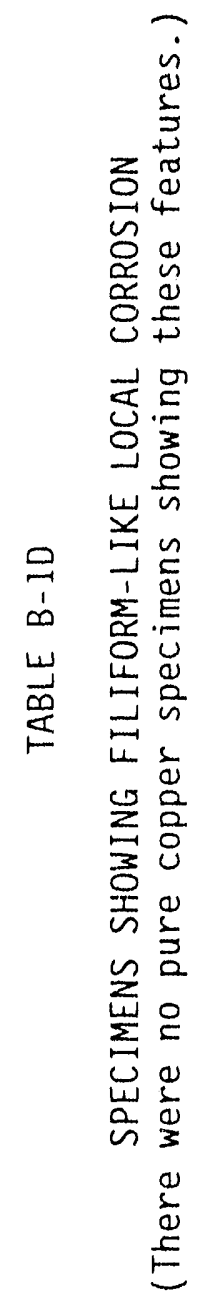

B- 6 


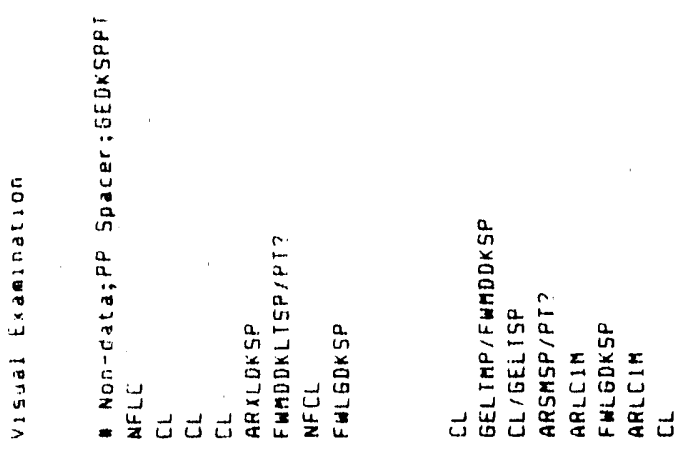

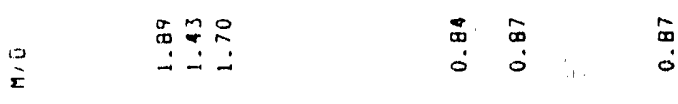

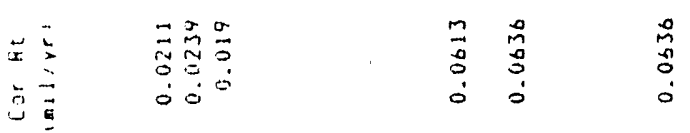

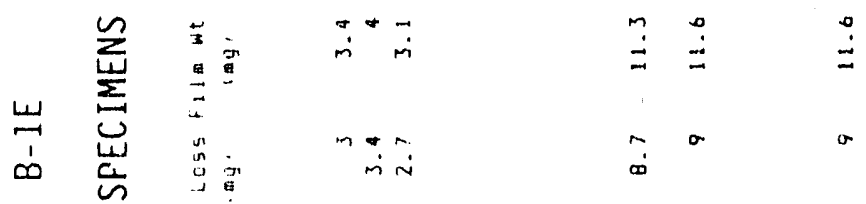

崖 层 J $\quad$ ت

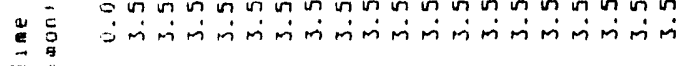

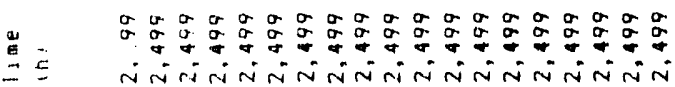

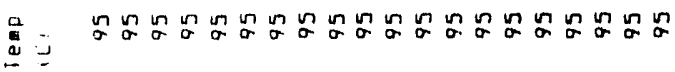

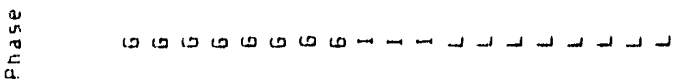

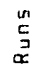

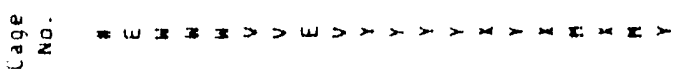

离

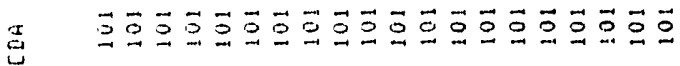

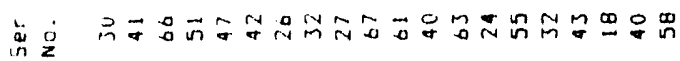

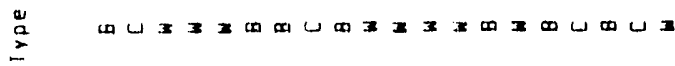

耍 


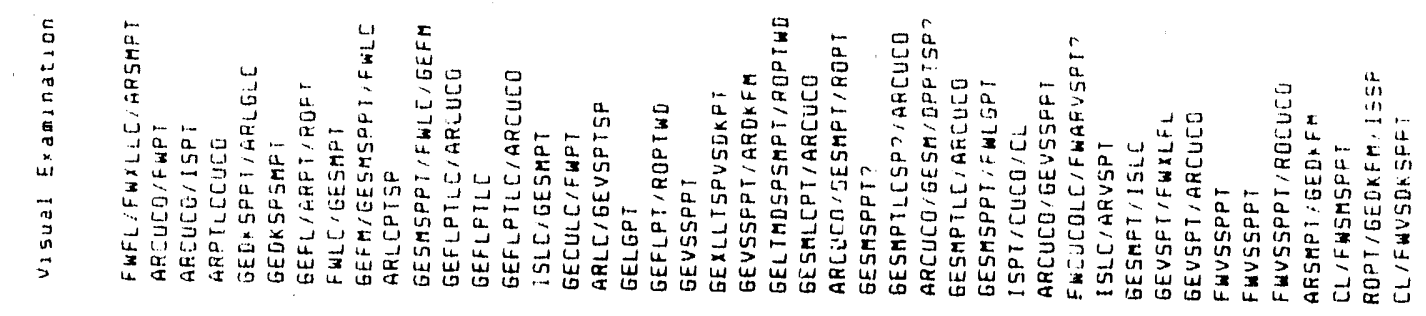

2
0
$c$
$c$

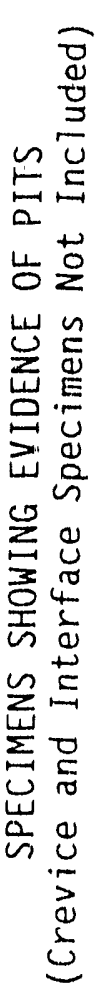

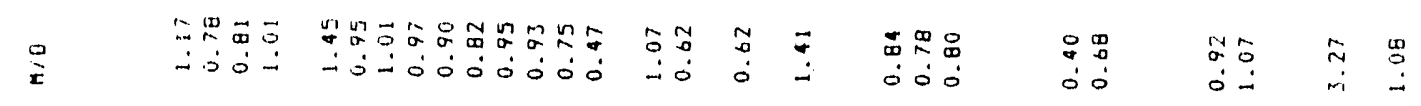

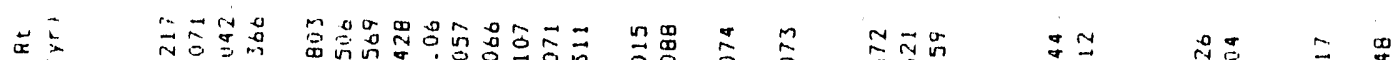
点

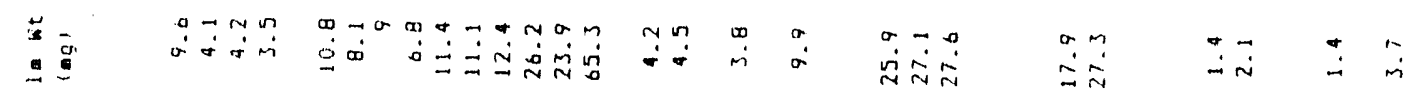

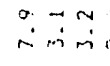

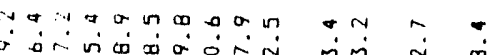

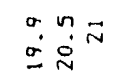
$=\underset{a}{a}$ $\because$ 3

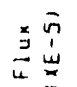

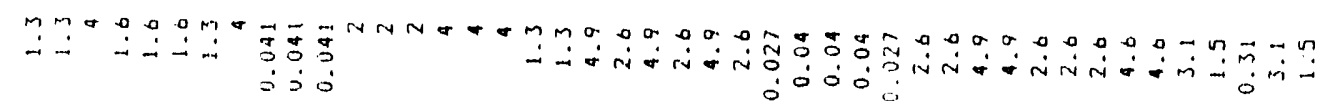

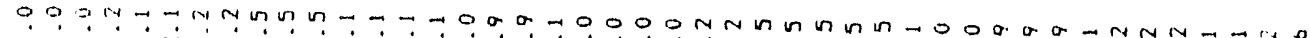
-

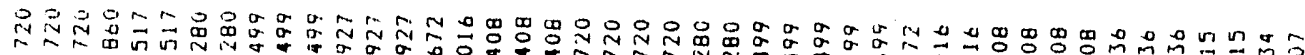

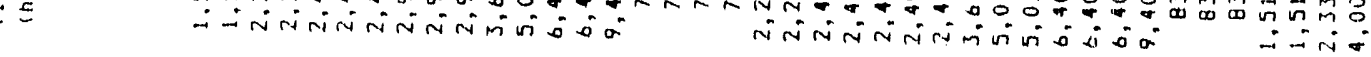

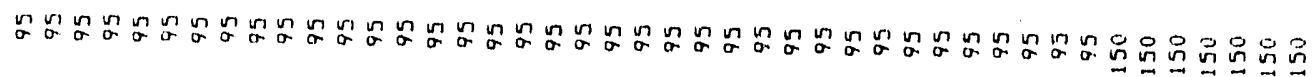

แ)

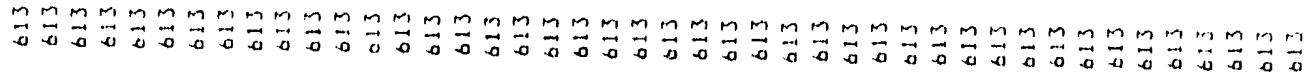
in

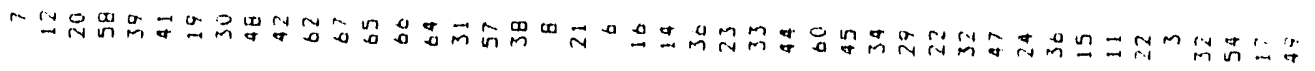
$\stackrel{a}{2}$ 

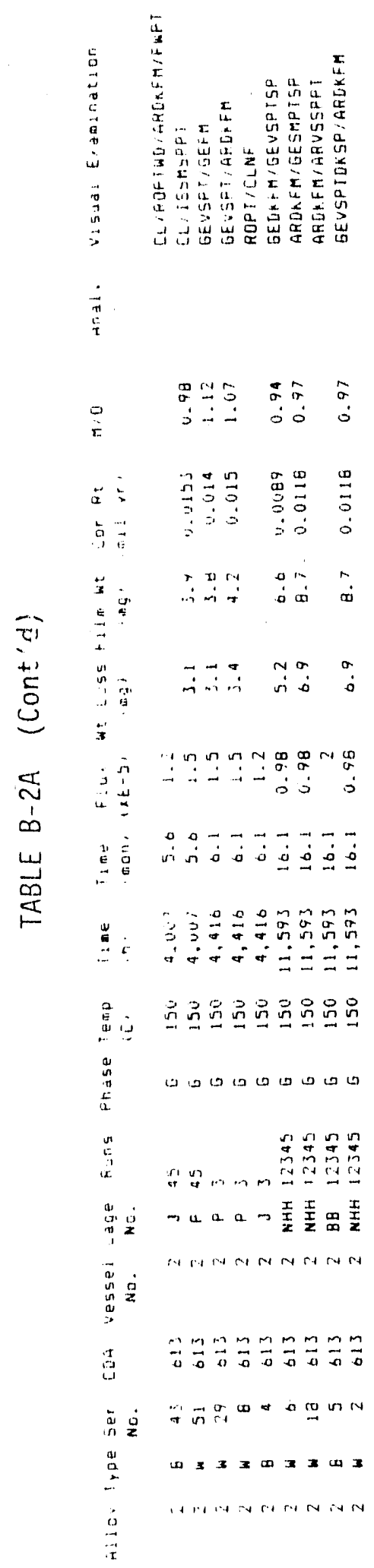

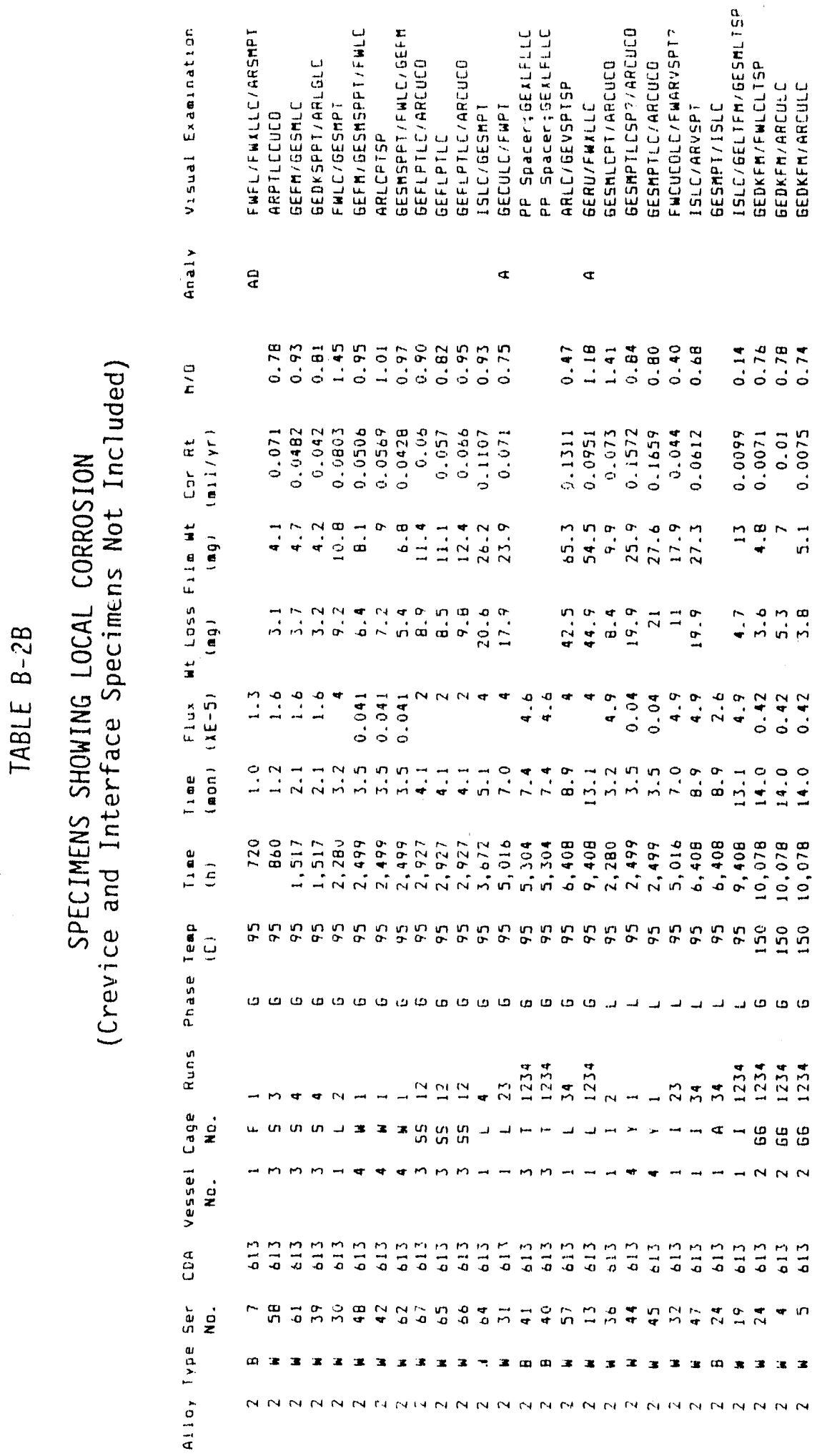

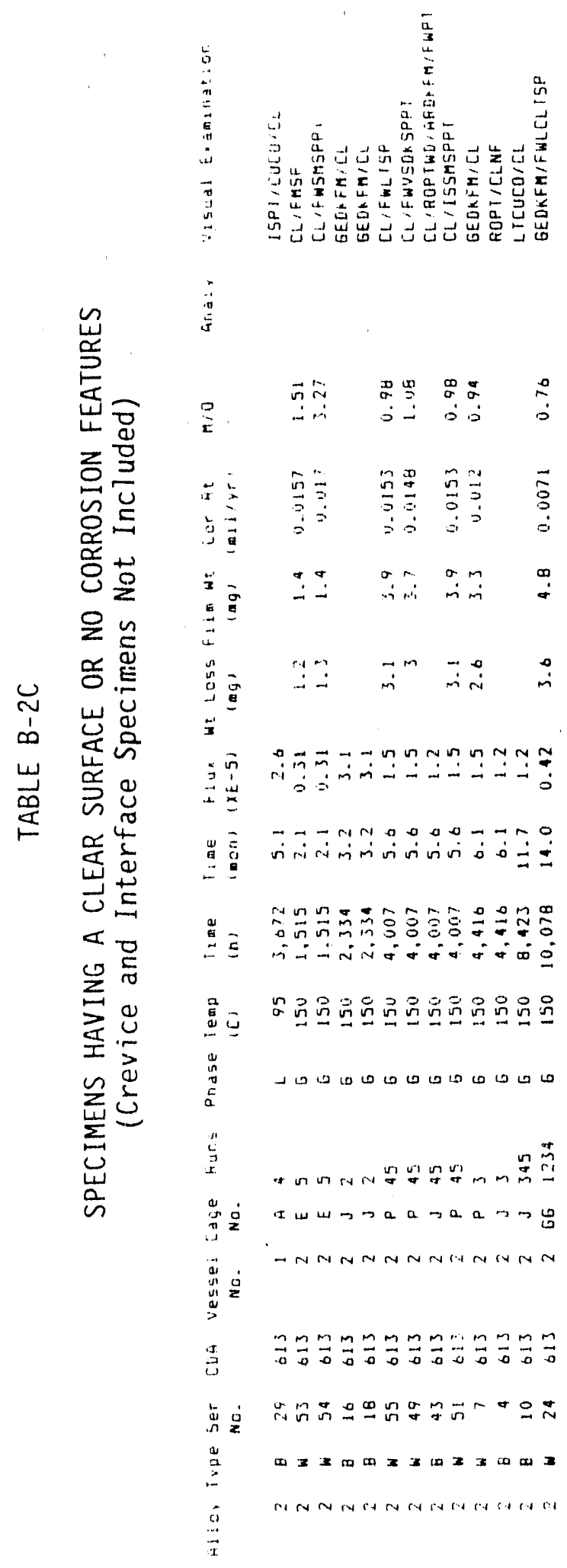


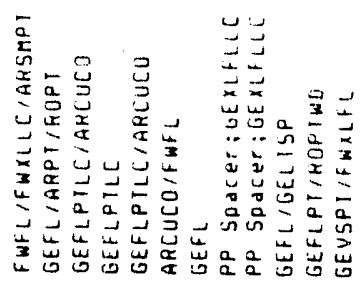

웅

\begin{tabular}{|c|c|c|}
\hline & $\stackrel{\rho}{\underline{x}}$ & 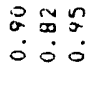 \\
\hline & $\begin{array}{l}x \\
x \\
z\end{array}$ & 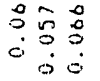 \\
\hline
\end{tabular}

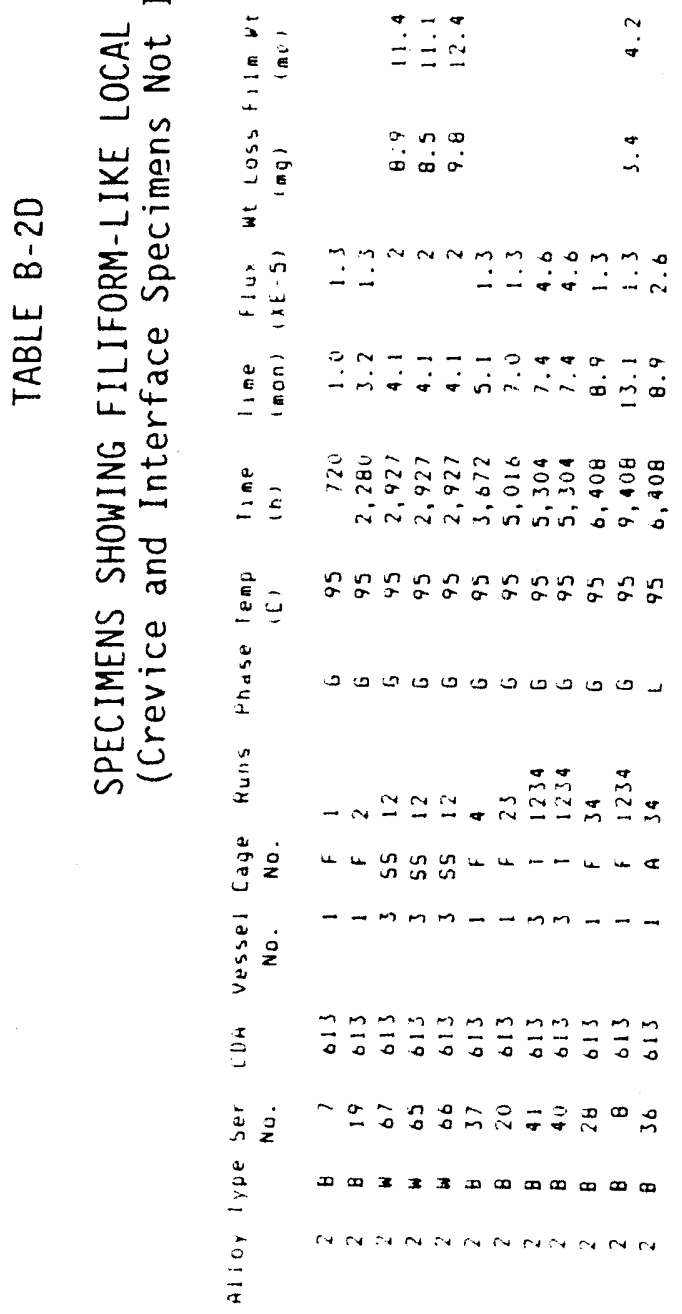




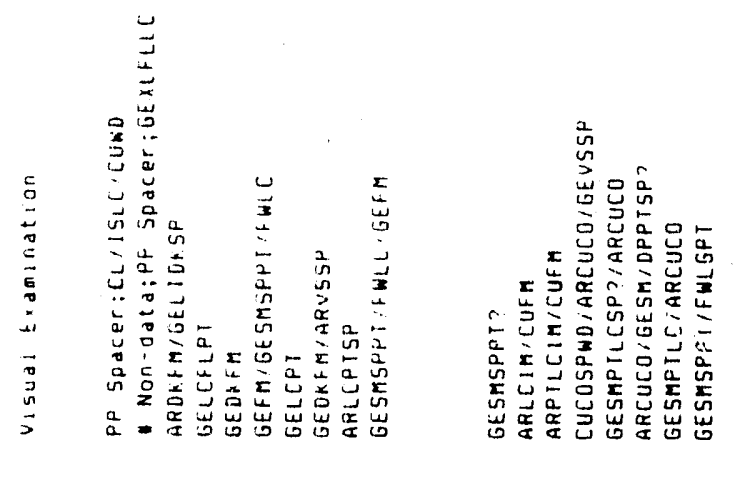

$\frac{2}{2}$

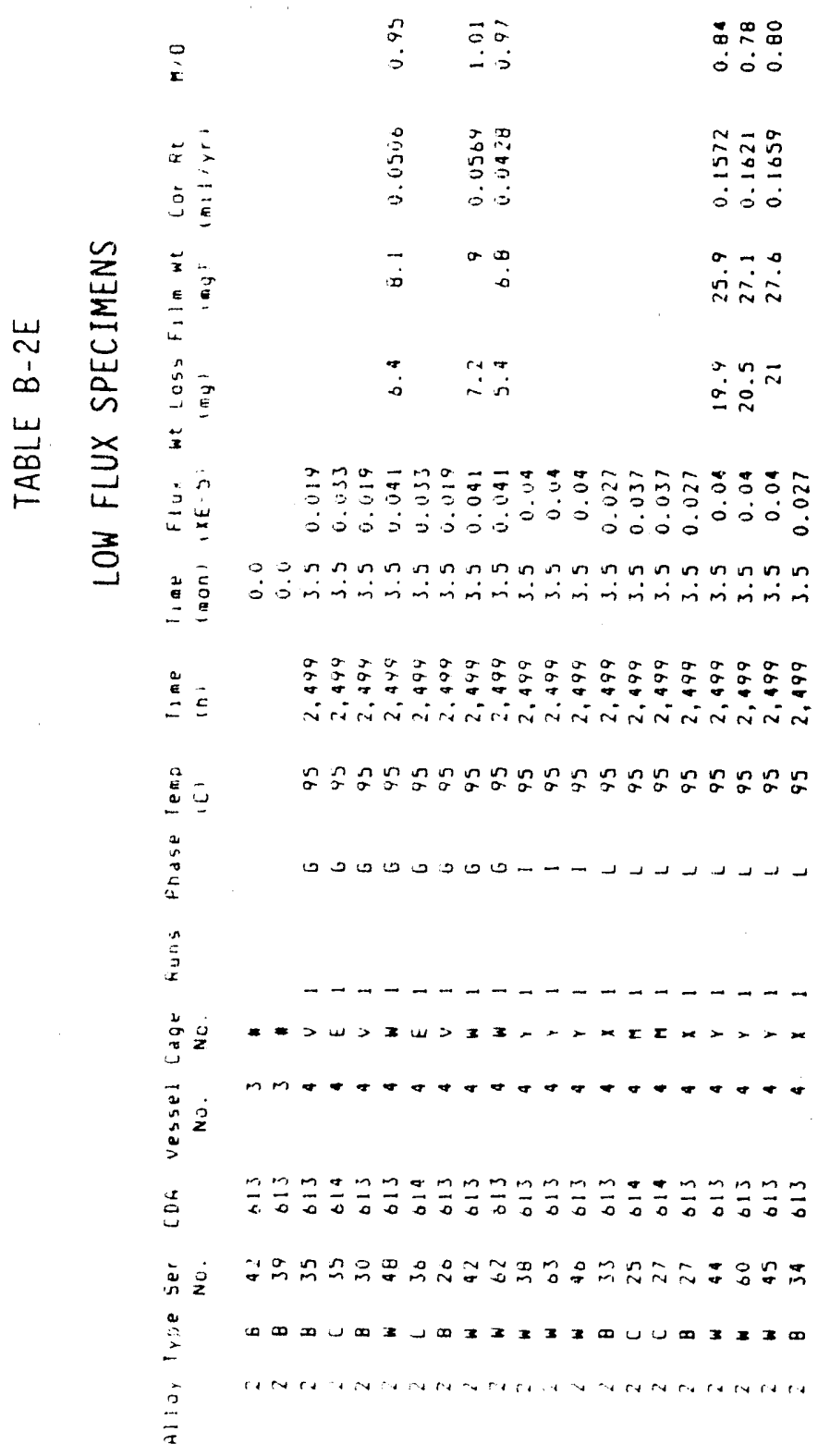


WHC-EP-0188

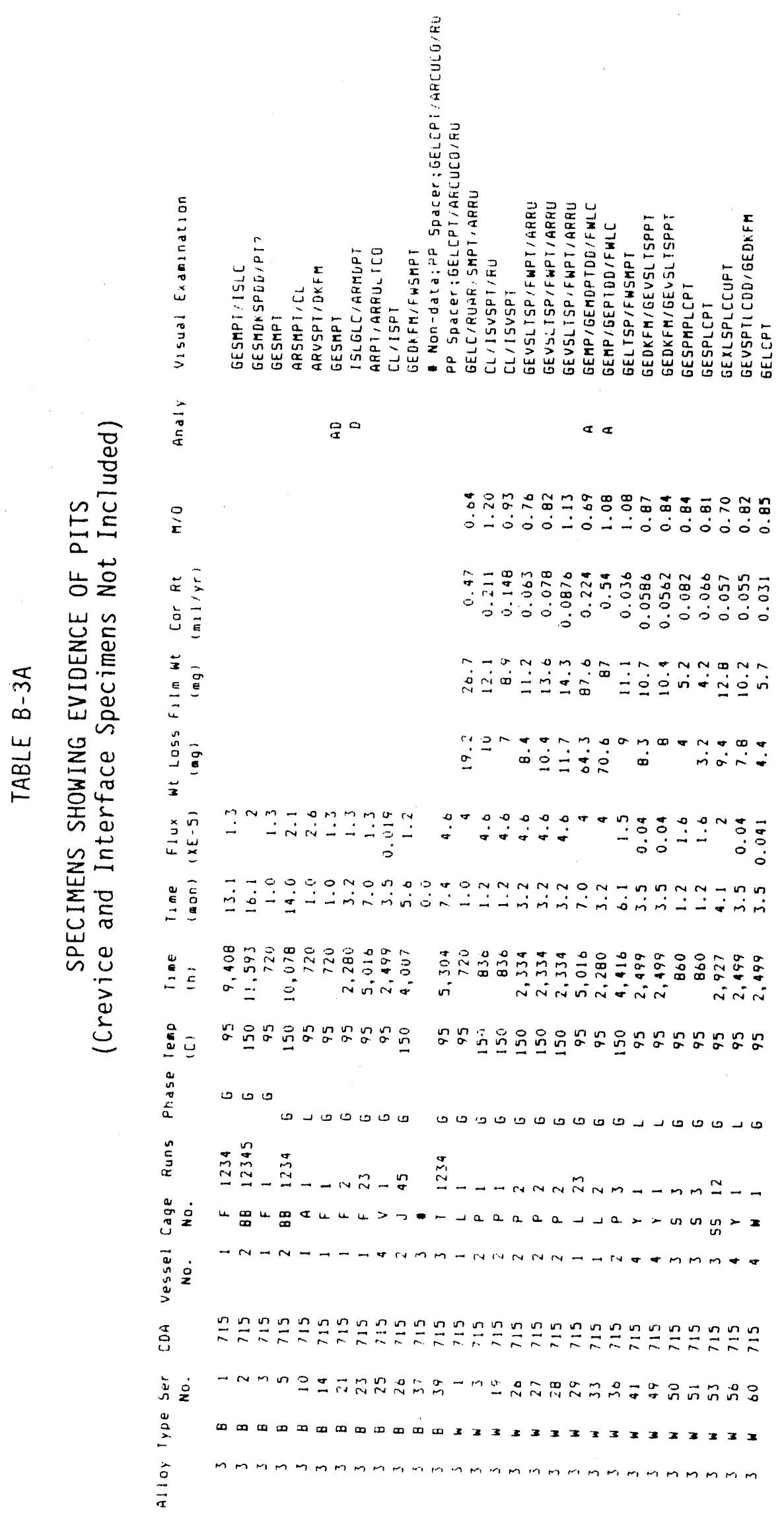




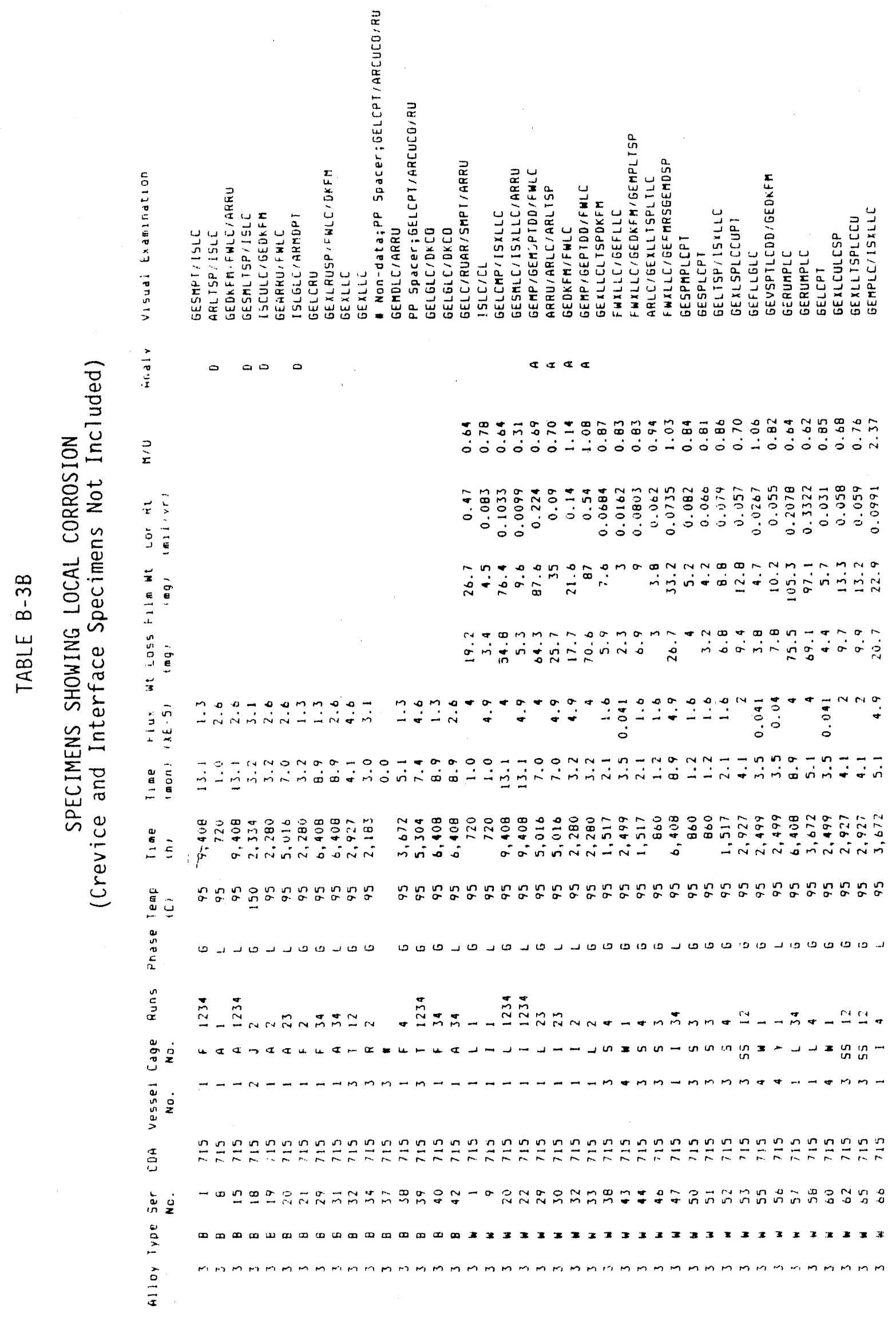




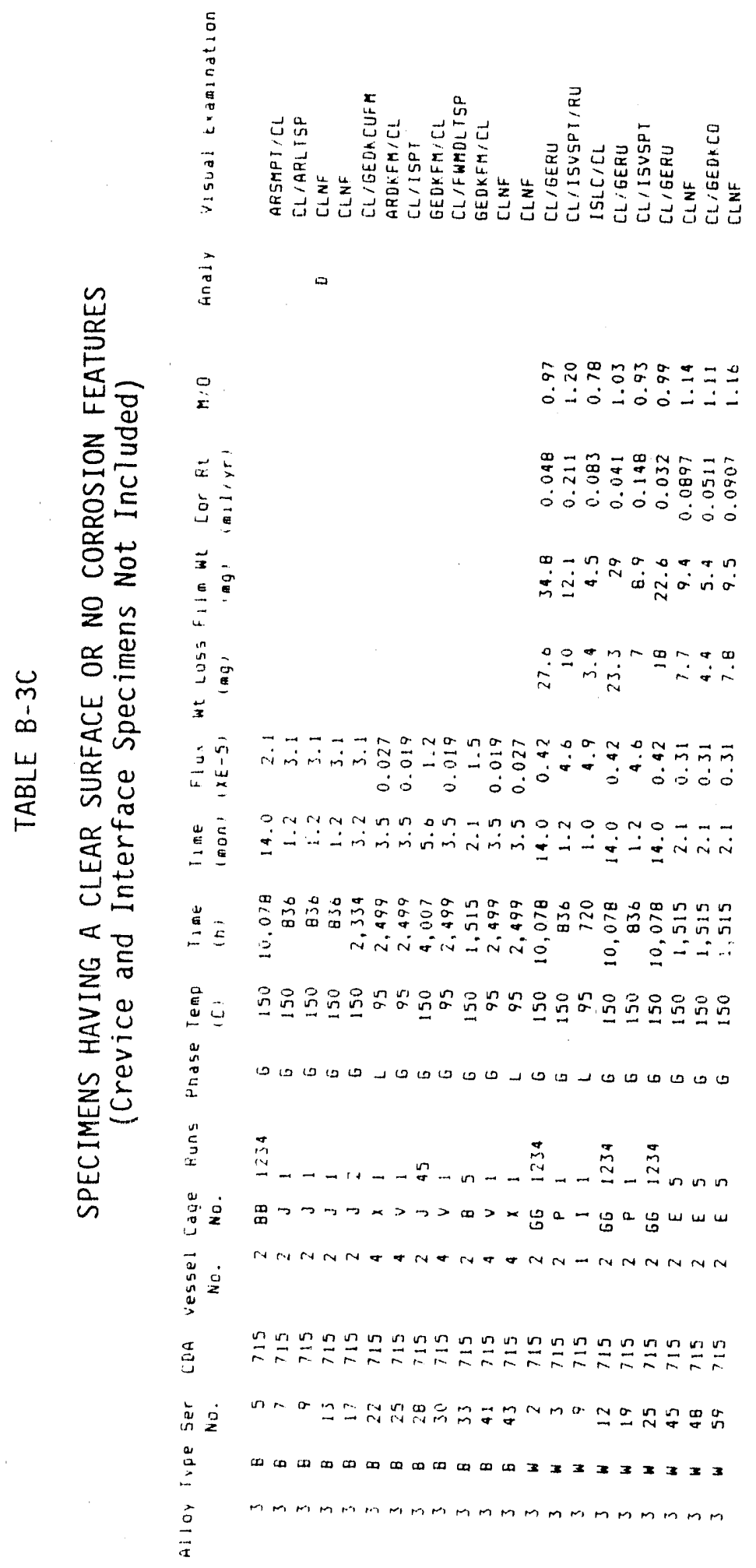


WHC-EP- 0188

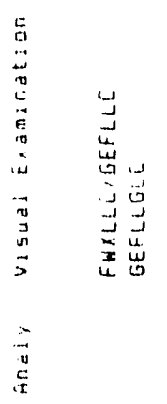

实导

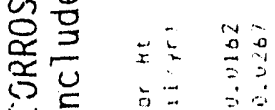

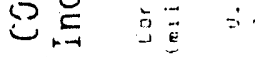

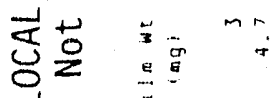

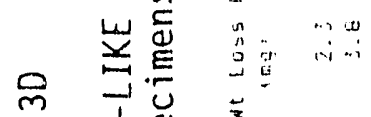

1) $\sum^{1}$

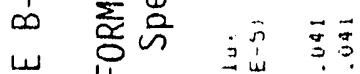

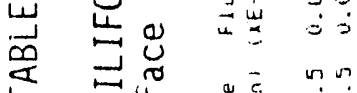

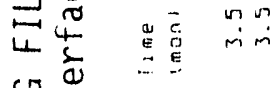

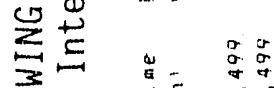

울을 에

$\sum 00$ 量

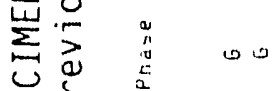

岁

它

$\stackrel{21}{3}$

喿品 $\underset{2}{2} \quad 3$

荘

总 $\stackrel{n}{2} \stackrel{n}{=}$

离紊等

$\stackrel{a}{a} \times 3$

$\stackrel{\circ}{\vec{x}} m m$ 
WHC-EP-0188
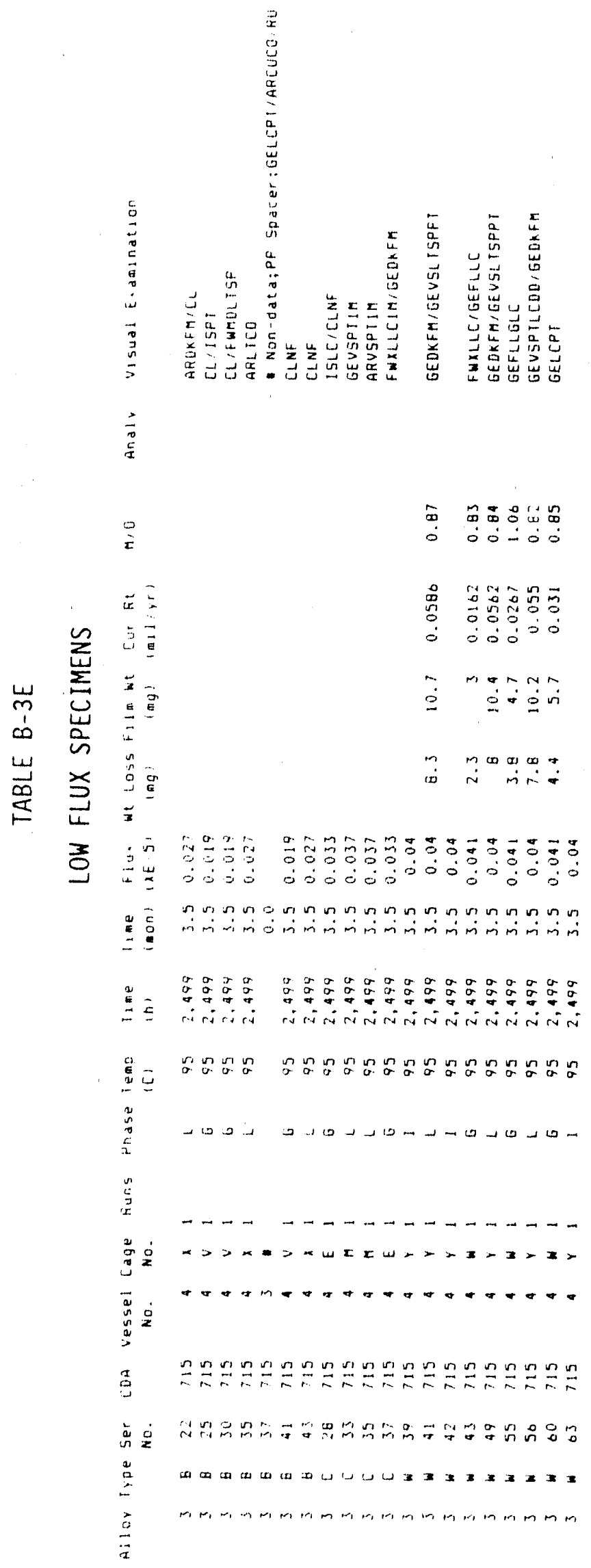

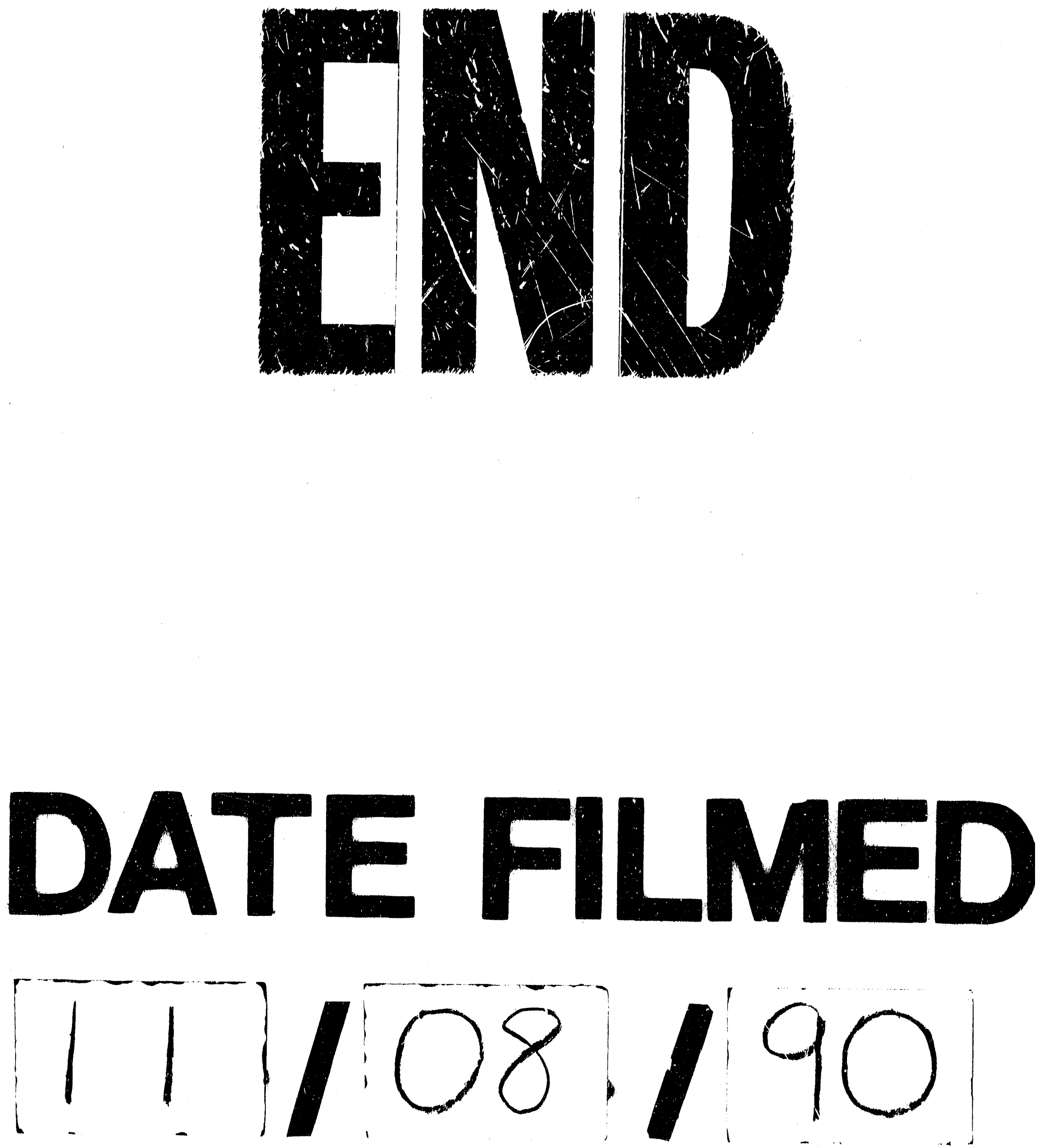
